DOCUMENTOS OCASIONALES

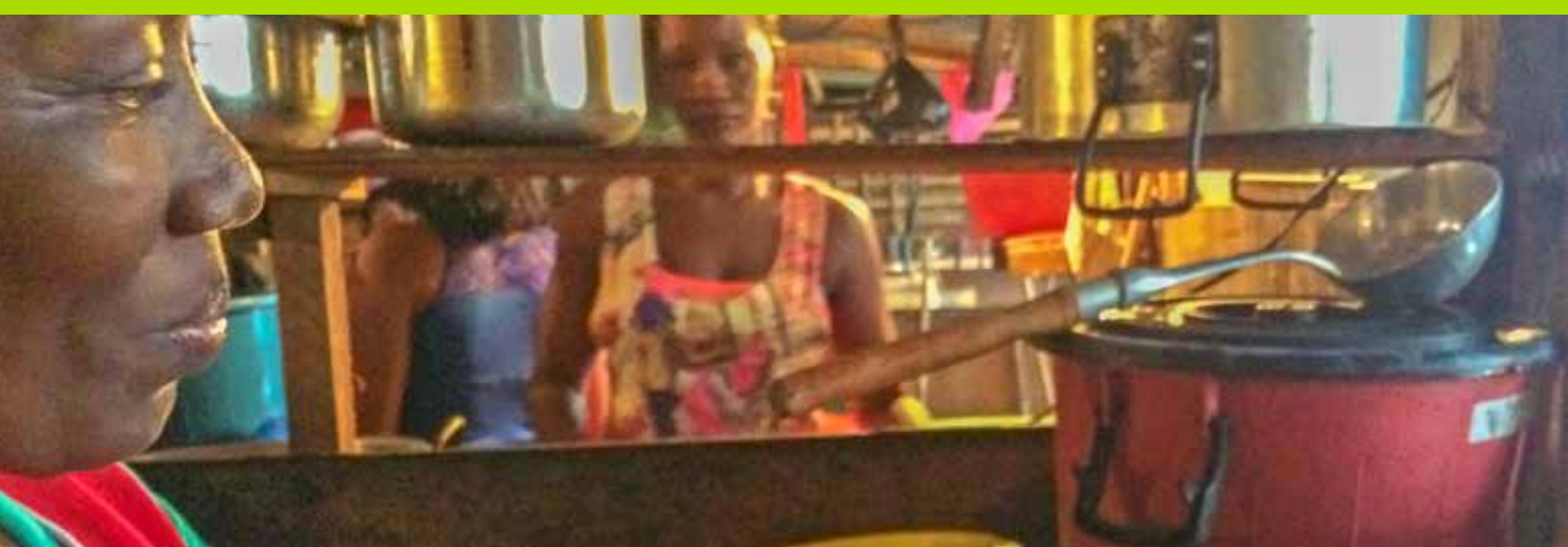

3

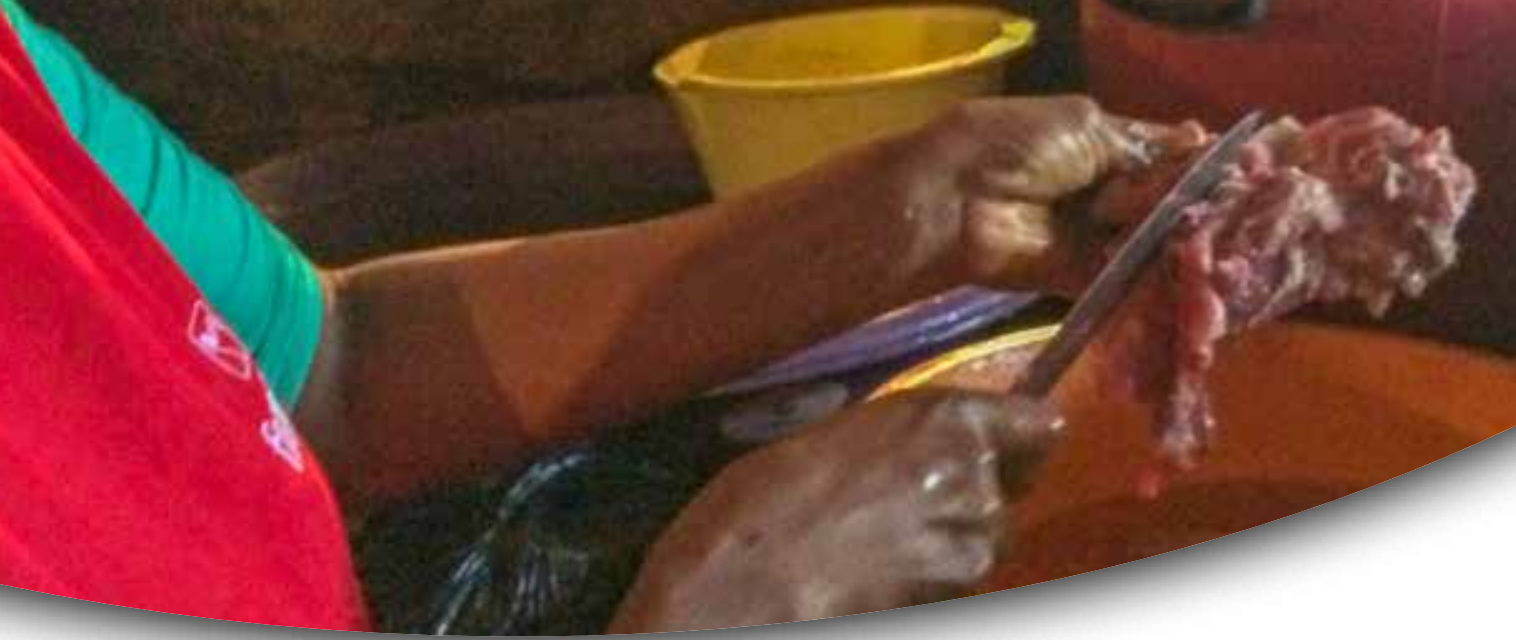

Diagnóstico sobre el comercio de carne de monte en las ciudades de Colombia

María Paula Quiceno-M

Nathalie van Vliet

Jessica Moreno

Daniel Cruz-A 



\title{
Diagnóstico sobre el comercio de carne de monte en las ciudades de Colombia
}

\author{
María Paula Quiceno-M \\ Fundación S. I. - Science International (Colombia) \\ Nathalie van Vliet \\ Centro para la Investigación Forestal Internacional (CIFOR) \\ Jessica Moreno \\ Fundación S. I. - Science International (Colombia) \\ Daniel Cruz-A \\ Fundación S. I. - Science International (Colombia)
}


Documentos Ocasionales 136

(C) 2015 Centro para la Investigación Forestal Internacional (CIFOR)

(1) Los contenidos de esta publicación están bajo licencia Creative Commons Attribution 4.0 International (CC BY 4.0), http://creativecommons.org/licenses/by/4.0/

ISBN 978-602-387-011-0

DOI: $10.17528 /$ cifor/005740

Quiceno-M MP, van Vliet N, Moreno J y Cruz-A D. 2015. Diagnóstico sobre el comercio de carne de monte en las ciudades de Colombia. Documentos Ocasionales 136. Bogor, Indonesia: CIFOR.

Foto por María Paula Quiceno/Fundación S. I.

Vendedora de comida en plaza de mercado. Quibdó, Chocó.

\author{
CIFOR \\ Jl. CIFOR, Situ Gede \\ Bogor Barat 16115 \\ Indonesia \\ $\mathrm{T}+62(251) 8622-622$ \\ $F+62(251) 8622-100$ \\ E cifor@cgiar.org
}

\title{
cifor.org
}

Quisiéramos agradecer a todos los donantes que apoyaron esta investigación a través de sus contribuciones al Fondo de CGIAR. Para ver la lista de donantes del Fondo, visite: https://www.cgiarfund.org/FundDonors

Cualquier opinión vertida en este documento es de los autores. No refleja necesariamente las opiniones de CIFOR, de las instituciones para las que los autores trabajan o de los financiadores. 


\section{Tabla de contenido}

Agradecimientos $\quad$ v

Prólogo vi

1 Introducción 1

2 Descripción de la zona de estudio y metodología 3

2.1 Zona de estudio 3

2.2 Descripción metodológica 5

3 Sitios de venta y distribución de la carne de monte $\quad 7$

$\begin{array}{lll}3.1 & \text { Plazas de mercado } & 7\end{array}$

$\begin{array}{lll}3.2 & \text { Restaurantes y asaderos } & 10\end{array}$

3.3 Puestos de comida, vendedores ambulantes y otras modalidades 12

4 Usuarios de la cadena de comercio de carne de monte $\quad 14$

$\begin{array}{lll}4.1 \text { Cazadores } & 14\end{array}$

4.2 Vendedores en plazas de mercado, ambulantes, restaurantes, asaderos,

$\begin{array}{ll}4.3 \text { Consumidores } & 16\end{array}$

5 Composición de especies en la cadena de mercado de carne de monte 18

$\begin{array}{ll}5.1 \text { Región Amazónica } & 18\end{array}$

5.2 Región Andina 18

5.3 Región Orinoquia 18

$\begin{array}{ll}5.4 \text { Región Caribe } & 19\end{array}$

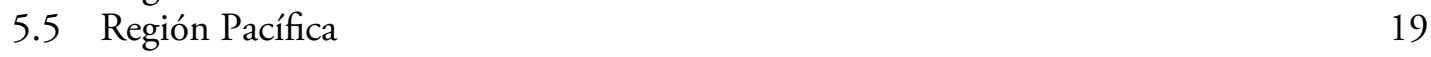

6 Áreas de captación y rutas de comercio $\quad 25$

6.1 Región Amazónica 26

6.2 Región Andina 28

6.3 Región Orinoquia 28

6.4 Región Caribe 29

6.5 Región Pacífica 30

7 Precios de compra y venta de la carne de monte 31

8 Discusión 36

9 Referencias

Anexos $\quad \mathbf{4 1}$

1 Total de sitios visitados por región. 41

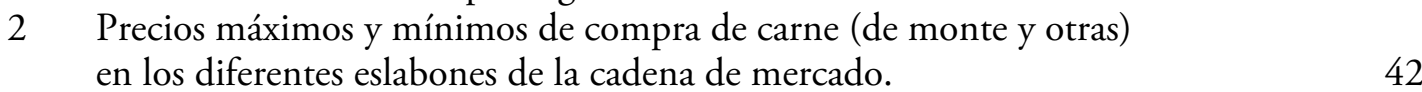

3 Listado de especies con mayor reporte de comercio en las cinco regiones y
su estado de conservación. 


\section{Lista de figuras y tablas}

\section{Figuras}

1 Zona de estudio en Colombia. 3

2 Cadena general de mercado de carne de monte en Colombia. $\quad 17$

3 Especies representativas consumidas por región. 23

4 Mapa de rutas de comercio de carne de monte en Leticia y Puerto Narińo. 25

5 Mapa de rutas de comercio de carne de monte en Inírida, Guainía. 26

6 Mapa de rutas de comercio de carne de monte en los municipios

de Villanueva, Monterrey, Tauramena, Aguazul, Yopal, Pore,

Paz de Ariporo y Hato Corozal (Casanare). 27

7 Mapa de rutas de comercio de carne de monte de los municipios de Santa Marta, Ciénaga, Aracataca y Fundación (Magdalena), y El Copey (Cesar). 28

8 Mapa de rutas de comercio de carne de monte en los corregimientos de Quibdó y Tutunendo, en Quibdó, y en el corregimiento de Yuto, en El Atrato (Chocó). (1) 3 6

\section{Tablas}

1 Biomas, sistemas ambientales territoriales y sitios visitados. 4

2 Sitios con venta de carne de monte en cada lugar visitado. $\quad 8$

3 Plazas de mercado y puestos visitados con venta de carne de monte. 8

4 Puestos de comida y vendedores ambulantes. 13

5 Cazadores identificados y reportados. 14

6 Total de actores identificados en la cadena de mercado de las cinco zonas visitadas. $\quad 15$

7 Listado de fauna silvestre reportada en la cadena de mercado. 21

8 Precios promedio de venta de carne de monte en los diferentes eslabones de la cadena de comercio. 


\section{Agradecimientos}

Agradecemos la activa participación de todos los actores de la cadena de mercado que compartieron con nosotros su conocimiento sobre el uso y comercio de la carne de monte en cada región visitada. Asimismo, a quienes acompañaron los recorridos: Nawin Bun Say, Moisés Alberto Villafañe Izquierdo, Jairo Miguel Guerra, Marelbi Cuesta, Eliceo Matapi, José Luis Silva, Yamile Moreno, Leady Téllez, Delio Suárez, Jimmy Sáenz, Fanny Suárez. Además, a las instituciones educativas Francisco Miranda, Los Libertadores, Custodio García Rovira y Luis Carlos Galán; al Centro de Estudios Amazónicos Parature; al Instituto de
Investigaciones Ambientales del Pacífico (IIAP); a Margarita Escobar, Juanita Gómez y José Fernando Escobar, de la Fundación SI; y a la Fundación Omacha. Finalmente, agradecemos de manera especial a Rocío del Pilar Moreno y a Enrique de la Montaña, por su dedicación en la revisión del manuscrito y sus oportunos comentarios.

Este trabajo fue financiado por USAID, a través del Programa de Investigación del CGIAR sobre Bosques, Árboles y Agroforestería, y por CIFOR, en el marco de la Iniciativa de Investigación sobre Carne de Monte. 


\section{Prólogo}

Por Juan Camilo Cárdenas (profesor titular, Facultad de Economía - CEDE, Universidad de los Andes)

En ocasiones se pregunta uno por qué existe una aprobación social tan alta al consumo de especies silvestres que son capturadas en los ríos y los mares; algo de aprobación —incluso elegancia-al consumo de aves silvestres con plumas coloridas; y, al mismo tiempo, una desaprobación —en relación con las anteriores - si se sirve en la mesa un pedazo de carne de algún animal silvestre que se mueve por la tierra, en especial si es de patas cortas. La incorporación de tabús en el consumo de carne de monte es más común que en los casos de consumo de otras especies que viven en el agua o vuelan. Es muy probable que esa mayor frecuencia de tabús esté asociada a mayores riesgos de que mamíferos y otros animales vertebrados con los que los seres humanos son más cercanos genéticamente sean portadores de enfermedades peligrosas, lo que aumenta las probabilidades de zoonosis y, por tanto, los riesgos para la salud de las personas. El caso más reciente y sonado ha sido el del último brote de ébola en varios países africanos, que muchos atribuyen al consumo humano de carne de murciélago.

La carne de monte ha sido parte de la dieta de la humanidad desde sus orígenes, y continúa siendo hoy parte de las fuentes de proteína de muchas comunidades en el planeta. La pesca en los mares no solo tiene una aprobación generalizada sino que es aprobada legalmente en la inmensa mayoría de costas del mundo. La cacería y consumo de aves silvestres continúa siendo una actividad legal en muchas latitudes: un deporte autorizado e incluso con un cierto estatus social. La cacería, la comercialización y el consumo de carne de monte, mientras tanto, continúan siendo actividades subrepticias pero que, por múltiples razones culturales, mantienen una demanda importante, la cual genera a su vez una actividad económica que emplea y sustenta actividades económicas de poblaciones rurales y urbanas en el mundo entero, donde Colombia no es la excepción.

La carne de monte representa un caso clásico de un recurso de uso común en el que la cacería por parte de un cazador aumenta sus ingresos o bienestar por venta o consumo, pero en el que la suma de las capturas de todos los cazadores afecta a cada uno de ellos al generar presión sobre las poblaciones naturales de la especie en cuestión. Los riesgos de la "tragedia de los comunes" en estos casos se derivan de esa divergencia entre el interés individual y el interés colectivo. Pero, en este caso, hay dos grandes elementos adicionales que hacen de este un problema particular e interesante. Por una parte, la población de cada especie estará directamente asociada al estado del ecosistema en que habita, y en ese sentido la acción humana de presión sobre el territorio, boscoso usualmente, determinará el stock de la especie disponible para la cacería. Por otra parte, la legislación, en el caso de Colombia y muchos otros países, hace de la cacería una actividad subterránea, ilegal y adscrita a una serie de normas sociales, tradiciones y elementos culturales que van a regular la conservación o la sobreexplotación de la especie. En muchas ocasiones, existe una disonancia entre los objetivos de conservación y prohibición en la ley, y otros valores culturales de aprovechamiento y consumo.

Estos elementos ecológicos de relación directa entre el capital natural y la población de la especie en cuestión, y de disonancias entre los aspectos legales y culturales asociados, van a determinar una inmensa complejidad, que apenas se está comenzando a descifrar, sobre el papel que cumplen la cacería y el consumo de carne de monte en Colombia y en muchas otras sociedades. 
En la medida en que la cacería, comercialización y consumo de carne de monte siga cumpliendo un papel importante en la dieta alimentaria y en la generación de empleos e ingresos para los comerciantes y restaurantes, seguirá siendo válido y necesario su estudio para comprender esta multiplicidad de dimensiones económicas, culturales y ecológicas.

Este documento llena una buena parte de las brechas y vacíos que existen sobre el conocimiento de estas tres grandes dimensiones (económica, cultural y ecológica) de la cadena de comercio de la carne de monte. Precisamente, un valor agregado de este estudio es que reconstruyó las rutas que recorre la carne de monte desde los cazadores hasta el consumidor final en varias regiones de Colombia, con el fin de comprender también esa diversidad ecológica, cultural y económica del país, expresada en la variedad de especies que se cazan, las rutas que siguen y cómo, a pesar de restricciones e impedimentos legales, llegan a seguir siendo parte de la dieta de muchos consumidores en ciudades y poblaciones rurales de Colombia.

Uno de los acervos más interesantes del documento está en lo metodológico. El lector encontrará una combinación de métodos para acercarse a un tema difícil, con frecuencia ilegal, y que por ende genera desconfianza entre informantes e investigadores. Los investigadores logran, a través de una estrategia que describen en el texto, un proceso de construcción de confianza con los informantes hasta poder desentrañar la complejidad de la actividad de cacería, de los mercados y del consumo final de la carne de monte.

Otro valor agregado de este estudio está en la cobertura regional del país, que los investigadores recorrieron para comprender la cadena productiva que va desde los montes hasta las mesas en las ciudades, incluyendo Bogotá, donde se percibe la mayor capacidad del Estado para ejercer la prohibición y restringir su comercialización y consumo.

Esta investigación es además una invitación a profundizar en las muchas dimensiones que aún quedan por descubrir sobre el mundo de la carne de monte. En lo ecológico, será necesario descifrar el papel que cumplen las estrategias de conservación de bosques en lo que respecta a la frecuencia e intensidad de la cacería de carne de monte por parte de las comunidades que habitan y circundan las áreas protegidas de Colombia. Es probable que una expansión del sistema de áreas protegidas, desde parques nacionales hasta resguardos indígenas, consejos comunitarios afrocolombianos y reservas de la sociedad civil, implique una mayor oferta de aves, reptiles y animales silvestres que forman parte de la dieta de carne de monte. Por ende, surge una disyuntiva para estas comunidades, que eventualmente pueden beneficiarse de su extracción y consumo por un ecosistema conservado que aumentará sus poblaciones, pero dentro de un sistema legal que no solo restringe la cacería de especies silvestres en áreas protegidas sino que prohíbe su comercialización. En esta misma dimensión ecológica, llama la atención que una fracción importante de las especies que se cazan, comercializan y consumen no se encuentre dentro de las categorías más urgentes de conservación en las listas rojas para Colombia. Esto es interesante porque surge una pregunta sobre la posible causalidad de esta relación. ¿Es porque no están amenazadas que su mayor población hace más bajos los costos para los cazadores $\mathrm{y}$, por tanto, más frecuente su cacería? $\mathrm{O}$, más bien, ¿es porque la actividad de caza frecuente y el mayor conocimiento de estas especies que se cazan con frecuencia hacen que se den manejos más sostenibles de ellas por parte de quienes las aprovechan? Aquí nacen preguntas importantes sobre el papel que el uso con conservación pueda tener en un manejo de la fauna silvestre cuando existen comunidades humanas que se pueden beneficiar a la vez del consumo y de su conservación. Una de las piezas más importantes, también a partir del trabajo de campo y las entrevistas en profundidad con los cazadores, es la investigación realizada por Vargas y Bello (2008) para comprender esas estrategias de manejo que se dan desde los cazadores y las dificultades de los sistemas regulatorios de prohibición que los acechan.

En la dimensión económica, surgen igualmente preguntas importantes asociadas a la cacería y sus costos. En un estudio experimental en campo realizado con cazadores en Ecuador ${ }^{1}$ (Sirén et al. 2006), se exploró hasta qué punto los cazadores tradicionales estarían interesados en

1 En el que participó el autor de este prólogo. 
complementar o sustituir su actividad de cacería con la generación de otras fuentes de proteína no provenientes de la cacería, y el efecto que tendría ofrecer alternativas de manejo de especies cárnicas en la finca para reducir la presión sobre la cacería. Precisamente, en el presente documento, el lector encontrará la misma multiplicidad de actividades que complementan los ingresos de los cazadores identificados y entrevistados.

Posteriormente, Sirén et al. (2013), en un nuevo estudio $^{2}$ con otros diseńos experimentales, exploran el componente que se ha denominado la "fricción por la distancia", entendida como el costo marginal creciente para el cazador debido a distancias más largas para sus jornadas de cacería. Esta fricción podría también ser parte del análisis de los costos para los cazadores asociados a las distancias necesarias para capturar la carne de monte que se pongan como meta en su jornada diaria. En el presente estudio, un componente que hace surgir varias preguntas tiene relación con los precios identificados y, sobre todo, con la dispersión tan amplia de estos de región a región, sin un aparente patrón particular excepto que tal vez el mercado de Bogotá, por estar mas vigilado, implique costos mayores para proveer a los consumidores de carne de monte. Ello genera nuevas interrogantes sobre qué determina los precios de la carne de monte para los cazadores, los comerciantes y los consumidores finales, lo que permitiría comprender mejor los márgenes de rentabilidad en cada punto de la cadena productiva.

En la dimensión cultural y legal, se deben abrir puertas de investigación sobre la disonancia o armonía entre la ley y las prácticas culturales asociadas a la cacería y consumo de la carne de monte. Los sistemas regulatorios de prohibición entran frecuentemente en disonancia con las prácticas culturales de cacería y consumo de carne de monte, dado que los primeros han surgido principalmente de esquemas legales conservacionistas, en ocasiones importados, mientras que los segundos son el resultado de la evolución de normas sociales que persisten entre las poblaciones a través de mitos y tabús asociados a esta práctica, además de condicionantes económicos que inciden en encontrar en la carne de monte una alternativa proteica para aquellos a quienes sus ingresos no les permiten criarla o adquirirla en el mercado.

En resumen, este documento es una invitación a entrar en un mundo poco estudiado, pero entretejido en la vida cotidiana de pobladores rurales y urbanos que viven de la cacería y disfrutan de la carne de monte como parte de su sistema alimentario. La relación entre las especies que forman parte de la dieta de muchos y el estado de los ecosistemas en donde habitan, el sistema de normas culturales que determinan estas prácticas y la importancia económica de quienes hacen de la cacería o de su comercialización parte de sus ingresos diarios, serán parte del reto de comprender mejor cómo convivimos con la naturaleza, y si es posible usarla para conservarla, como parte de una estrategia mas armónica con los sistemas sociales contemporáneos.

\section{Referencias}

Sirén AH, Cárdenas JC, Hambäck P y Parvinen K. 2013. Distance Friction and the Cost of Hunting in Tropical Forest. Land Economics [University of Wisconsin Press] 89(3):558-74.

Sirén AH, Cárdenas JC y Machoa JD. 2006. The Relation between Income and Hunting in Tropical Forests: An Economic Experiment in the Field. Ecology and Society 11(1):44. http://www.ecologyandsociety.org/vol11/ iss 1/art 44/

Vargas N y Bello R. 2008. Secreteando al zorro. ¿Una vía de reconciliación entre las realidades y ficciones del manejo de fauna silvestre? Bogotá D. C., Colombia: Fundación Natura Colombia. 193 p.

2 En el que participó el autor de este prólogo. 


\section{Introducción}

Los bosques tropicales son una importante fuente de sustento para las comunidades rurales en todo el mundo. Particularmente, el uso de la fauna silvestre y su consumo se encuentran ligados a los medios de vida y tradiciones de las comunidades que los habitan. En muchas regiones tropicales, el consumo y el comercio de la fauna silvestre o carne de monte garantizan la seguridad alimentaria de las comunidades y constituyen una fuente importante de aportes a la economía local (Nasi et al. 2008). Se estima que en Colombia 140 especies de vertebrados silvestres son usadas como alimento por comunidades indígenas, afrocolombianas y campesinas; sin embargo, los estudios sobre caza son puntuales y se han realizado de manera desarticulada (Vargas-Tovar 2014). La mayoría de los estudios sobre carne de monte se han enfocado en la caza y el producto de las faenas desde un punto de vista biológico: especies objeto de aprovechamiento, usos, artes, métodos y cuantificación de las capturas. Por otro lado, los estudios antropológicos se han centrado en las ideas, las prácticas y las concepciones de los grupos étnicos y sociales respecto a la fauna (Vargas-Tovar 2014). Sin embargo, los aspectos relacionados con el comercio y la dinámica de los mercados de carne de monte son aún poco conocidos, tal vez por su carácter ilegal, por la falta de interés por parte de la comunidad científica, porque son difíciles de explorar dada su clandestinidad, o porque se consideran insignificantes.

Algunos estudios puntuales ofrecen una perspectiva cuantificada del comercio de fauna. Mancera y Reyes (2008) demuestran la existencia del comercio de carne de monte a partir de los reportes de decomisos de fauna practicados por las autoridades ambientales, pero también subrayan que esos valores subestiman significativamente el mercado, puesto que los decomisos probablemente solo representan entre $1 \%$ y $10 \%$ del total comercializado. En la Amazonia colombiana, las comunidades rurales venden casi la mitad de lo que cazan, tanto para la compra de alimentos que no se producen localmente (pollo, carne, fríjoles, arroz, azúcar, pan, sal, café, cebolla, aceite, pasta, cerveza) como para la compra de productos básicos (jabón, detergente, útiles escolares, ropa, baldes, platos), así como de elementos de caza (gasolina, cigarrillos, fósforos, cartuchos, baterías, linternas, motocicletas o partes) (Quiceno et al. 2014; Ortega 2014). Las especies más cazadas son los mamíferos, las aves y los reptiles. En la región Andina, la cacería comercial es casi insignificante en términos de biomasa, pero especies tales como ardillas, otros roedores y aves son comercializadas en las épocas de escasez de producción agrícola (Casas-Ramírez 2007). El único estudio que ha llegado a cuantificar la biomasa comercializada en zona urbana en Colombia es el de van Vliet et al. (2014), el cual demostró, sobre la base de datos de monitoreo participativo, que cerca de $400 \mathrm{~kg}$ de carne de monte fueron comercializados en 20 días durante el año 2013.

Los datos existentes permiten suponer la presencia de un comercio de carne de monte en varias regiones de Colombia. Sin embargo, no se cuenta con información suficiente para orientar la toma de decisiones en términos del manejo de esta cadena de mercado informal. Las instituciones a cargo del manejo de la fauna requieren de información precisa sobre las especies y la biomasa comercializadas, las rutas de abastecimiento, los actores involucrados y las motivaciones del consumo de carne de monte en medios urbanos, no solo para tomar decisiones sobre el control, sino también para explorar posibilidades de uso sostenible. En este contexto, el presente estudio busca mostrar un panorama general sobre el comercio de la carne de monte en las cinco regiones naturales de Colombia (Tabla 1), con un énfasis particular en la descripción cualitativa de los actores y usuarios de la cadena, las rutas de abastecimiento, las especies comercializadas y los precios de venta en comparación con otras fuentes de proteínas. 
El estudio busca responder las siguientes preguntas:

- ¿Cuáles son los lugares dónde se desarrolla el mercado de carne de monte en zonas urbanas?

- ¿Quiénes son los actores involucrados en las cadenas de mercado de carne de monte hacia las ciudades?
- ¿Cuáles son las especies comercializadas en cada región y cuál es su valor en las economías locales?

- ¿Cuáles son las áreas fuente de la fauna silvestre comercializada y las rutas de acceso y distribución de la carne de monte hacia la ciudad?

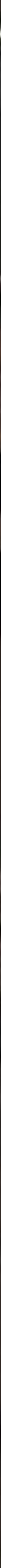




\section{Descripción de la zona de estudio y metodología}

\subsection{Zona de estudio}

Se seleccionaron ciudades dentro de las cinco regiones de Colombia, considerando los criterios siguientes:

1. Una representatividad geográfica de las cinco regiones naturales de Colombia (Caribe, Andina, Pacífica, Orinoquia y Amazónica) y las cuencas hidrográficas correspondientes.
El estudio se llevó a cabo en las cinco regiones naturales de Colombia (Tabla 1), con recorridos y diálogos semiestructurados en 21 municipios de Colombia (Figura 1).

2. Ciudades pequeñas a medianas de un tamańo poblacional de entre 5.000 y 150.000 habitantes que mantengan una relación urbana rural activa a través de las plazas de mercado y los mercados campesinos. La integración

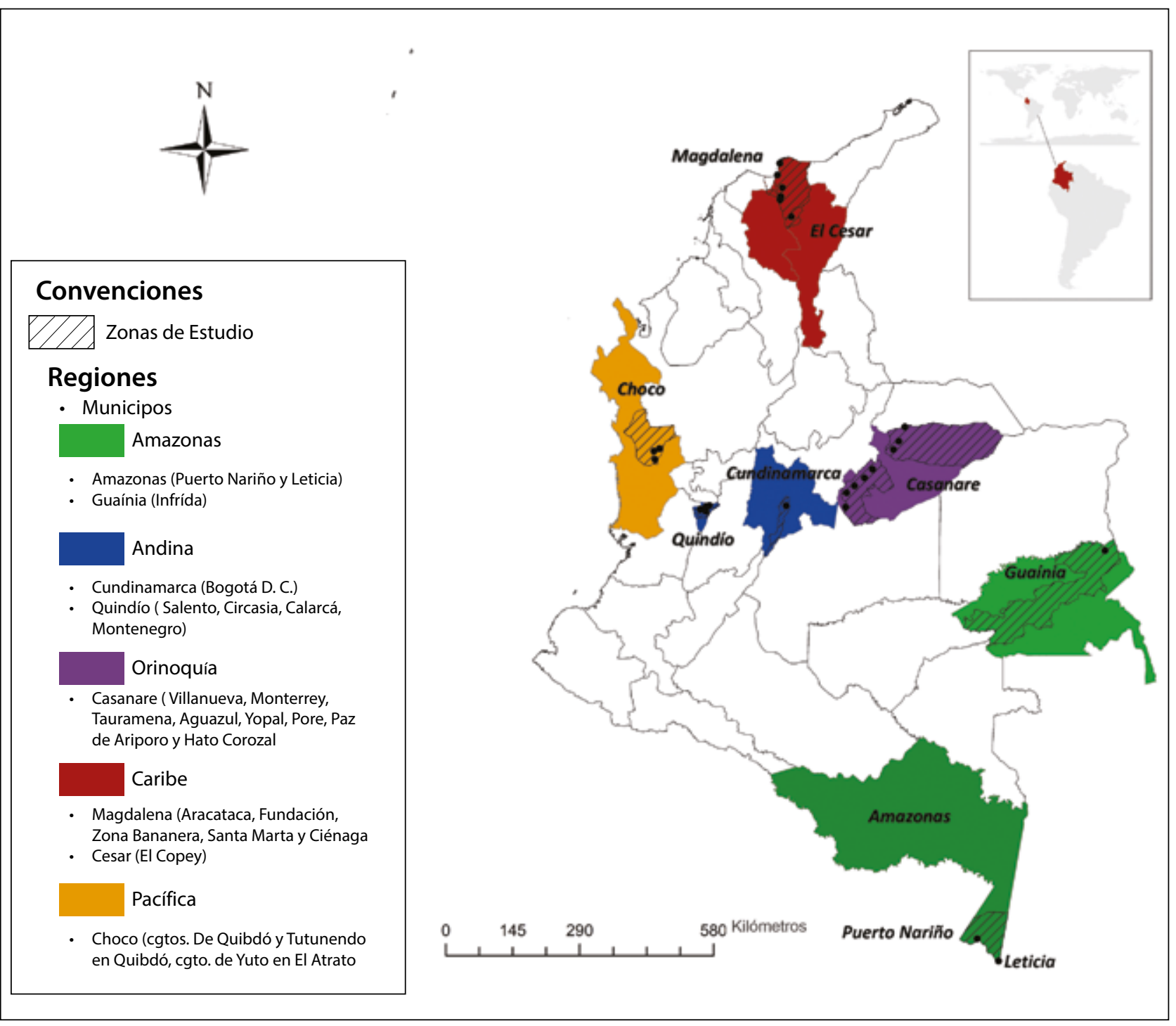

Figura 1. Zona de estudio en Colombia. 
Tabla 1. Biomas, sistemas ambientales territoriales y sitios visitados.

\begin{tabular}{|c|c|c|c|c|c|c|}
\hline Región & $\begin{array}{l}\text { Área de } \\
\text { estudio }\end{array}$ & $\begin{array}{l}\text { Grandes biomas } \\
\text { (IDEAM et al. 2007) }\end{array}$ & $\begin{array}{l}\text { Sistemas } \\
\text { ambientales } \\
\text { territoriales } \\
\text { (Carrizosa- } \\
\text { Umaña 2014) }\end{array}$ & $\begin{array}{l}\text { Cuencas } \\
\text { hidrográficas } \\
\text { (Salazar- } \\
\text { Holguín et al. } \\
\text { 2013) }\end{array}$ & $\begin{array}{l}\text { Población } \\
\text { (N.º de } \\
\text { habitantes) }\end{array}$ & $\begin{array}{l}\text { Área } \\
\left(\mathrm{km}^{2}\right)\end{array}$ \\
\hline \multirow[t]{3}{*}{ Amazónica } & $\begin{array}{l}\text { Inírida - } \\
\text { Guainía }\end{array}$ & $\begin{array}{l}\text { Bosque húmedo } \\
\text { tropical }\end{array}$ & $\begin{array}{l}\text { Selva } \\
\text { Amazónica y }\end{array}$ & C. del Orinoco & 15.676 & 17.000 \\
\hline & $\begin{array}{l}\text { Leticia - } \\
\text { Amazonas }\end{array}$ & & Orinoquense & $\begin{array}{l}\text { C. del } \\
\text { Amazonas }\end{array}$ & 37.832 & 109.6 \\
\hline & $\begin{array}{l}\text { Puerto Nariño - } \\
\text { Amazonas }\end{array}$ & & & & 6.983 & 1.800 \\
\hline \multirow[t]{5}{*}{ Andina } & $\begin{array}{l}\text { Bogotá - } \\
\text { Cundinamarca }\end{array}$ & $\begin{array}{l}\text { Bosque húmedo } \\
\text { tropical }\end{array}$ & Sistema Central & $\begin{array}{l}\text { C. del } \\
\text { Magdalena- }\end{array}$ & $6.763,33$ & 1.775 \\
\hline & $\begin{array}{l}\text { Salento - } \\
\text { Quindío }\end{array}$ & $\begin{array}{l}\text { Bosque seco tropical, } \\
\text { bosque húmedo } \\
\text { tropical }\end{array}$ & $\begin{array}{l}\text { Occidente } \\
\text { Cafetero }\end{array}$ & Cauca & 7.001 & 378 \\
\hline & $\begin{array}{l}\text { Circasia - } \\
\text { Quindío }\end{array}$ & $\begin{array}{l}\text { Bosque seco tropical, } \\
\text { bosque húmedo } \\
\text { tropical }\end{array}$ & & & 26.705 & 91 \\
\hline & $\begin{array}{l}\text { Calarcá - } \\
\text { Quindío }\end{array}$ & $\begin{array}{l}\text { Bosque seco tropical, } \\
\text { bosque húmedo } \\
\text { tropical }\end{array}$ & & & 75.628 & 219 \\
\hline & $\begin{array}{l}\text { Montenegro - } \\
\text { Quindío }\end{array}$ & $\begin{array}{l}\text { Bosque seco tropical, } \\
\text { bosque húmedo } \\
\text { tropical }\end{array}$ & & & 38.714 & 149 \\
\hline \multirow[t]{8}{*}{ Orinoquia } & $\begin{array}{l}\text { Yopal - } \\
\text { Casanare }\end{array}$ & $\begin{array}{l}\text { Bosque húmedo } \\
\text { tropical }\end{array}$ & $\begin{array}{l}\text { Piedemonte } \\
\text { llanero y }\end{array}$ & C. del Orinoco & 103.754 & 2.771 \\
\hline & $\begin{array}{l}\text { Villanueva - } \\
\text { Casanare }\end{array}$ & & $\begin{array}{l}\text { Orinoquia } \\
\text { inundable }\end{array}$ & & 20.730 & 825 \\
\hline & $\begin{array}{l}\text { Monterrey - } \\
\text { Casanare }\end{array}$ & & & & 11.421 & 879 \\
\hline & $\begin{array}{l}\text { Tauramena - } \\
\text { Casanare }\end{array}$ & & & & 15.699 & 2.607 \\
\hline & $\begin{array}{l}\text { Aguazul - } \\
\text { Casanare }\end{array}$ & & & & 33.172 & 148 \\
\hline & Pore - Casanare & & & & 7.490 & 780 \\
\hline & $\begin{array}{l}\text { Paz de Ariporo } \\
\text { - Casanare }\end{array}$ & & & & 26.915 & 13.800 \\
\hline & $\begin{array}{l}\text { Hato Corozal - } \\
\text { Casanare }\end{array}$ & & & & 9.618 & 5.518 \\
\hline \multirow[t]{3}{*}{ Caribe } & $\begin{array}{l}\text { Aracataca - } \\
\text { Magdalena }\end{array}$ & $\begin{array}{l}\text { Bosque seco tropical, } \\
\text { bosque húmedo } \\
\text { tropical }\end{array}$ & $\begin{array}{l}\text { Sierra Nevada } \\
\text { de Santa Marta } \\
\text { y sus vertientes }\end{array}$ & $\begin{array}{l}\text { C. del } \\
\text { Magdalena- } \\
\text { Cauca }\end{array}$ & 34.929 & 1.755 \\
\hline & $\begin{array}{l}\text { Santa Marta - } \\
\text { Magdalena }\end{array}$ & $\begin{array}{l}\text { Bosque seco tropical, } \\
\text { bosque húmedo } \\
\text { tropical }\end{array}$ & & $\begin{array}{l}\text { C. del Caribe, } \\
\text { C. del } \\
\text { Magdalena- } \\
\text { Cauca }\end{array}$ & 414.387 & 2.393 \\
\hline & $\begin{array}{l}\text { Zona Bananera } \\
\text {-Magdalena }\end{array}$ & $\begin{array}{l}\text { Bosque seco tropical, } \\
\text { bosque húmedo } \\
\text { tropical }\end{array}$ & & $\begin{array}{l}\text { C. del } \\
\text { Magdalena- } \\
\text { Cauca }\end{array}$ & 56.404 & 479 \\
\hline
\end{tabular}


Tabla 1. Continuado

\begin{tabular}{|c|c|c|c|c|c|c|}
\hline Región & $\begin{array}{l}\text { Área de } \\
\text { estudio }\end{array}$ & $\begin{array}{l}\text { Grandes biomas } \\
\text { (IDEAM et al. 2007) }\end{array}$ & $\begin{array}{l}\text { Sistemas } \\
\text { ambientales } \\
\text { territoriales } \\
\text { (Carrizosa- } \\
\text { Umaña 2014) }\end{array}$ & $\begin{array}{l}\text { Cuencas } \\
\text { hidrográficas } \\
\text { (Salazar- } \\
\text { Holguín et al. } \\
\text { 2013) }\end{array}$ & $\begin{array}{l}\text { Población } \\
\text { (N. }{ }^{\circ} \text { de } \\
\text { habitantes) }\end{array}$ & $\begin{array}{l}\text { Área } \\
\left(\mathbf{k m}^{2}\right)\end{array}$ \\
\hline & $\begin{array}{l}\text { Fundación - } \\
\text { Magdalena }\end{array}$ & $\begin{array}{l}\text { Bosque seco tropical, } \\
\text { bosque húmedo } \\
\text { tropical }\end{array}$ & & $\begin{array}{l}\text { C. del } \\
\text { Magdalena- } \\
\text { Cauca }\end{array}$ & 56.107 & 931 \\
\hline & $\begin{array}{l}\text { Ciénaga - } \\
\text { Magdalena }\end{array}$ & $\begin{array}{l}\text { Bosque seco tropical, } \\
\text { bosque húmedo } \\
\text { tropical }\end{array}$ & & $\begin{array}{l}\text { C. del Caribe, } \\
\text { C. del } \\
\text { Magdalena- } \\
\text { Cauca }\end{array}$ & 100.908 & 1.212 \\
\hline & $\begin{array}{l}\text { El Copey - } \\
\text { Cesar }\end{array}$ & $\begin{array}{l}\text { Bosque seco tropical, } \\
\text { bosque húmedo } \\
\text { tropical }\end{array}$ & & $\begin{array}{l}\text { C. del } \\
\text { Magdalena- } \\
\text { Cauca }\end{array}$ & 24.368 & 968 \\
\hline Pacífica & $\begin{array}{l}\text { Corregimientos } \\
\text { de Quibdó y } \\
\text { Tutunendo } \\
\text { en Quibdó y } \\
\text { corregimiento } \\
\text { de Yuto en El } \\
\text { Atrato. }\end{array}$ & $\begin{array}{l}\text { Bosque húmedo } \\
\text { tropical }\end{array}$ & $\begin{array}{l}\text { Litoral del } \\
\text { Pacífico }\end{array}$ & C. del Caribe & *109.121 & $* 3.337$ \\
\hline
\end{tabular}

* Corresponde únicamente a Quibdó.

de Bogotá, ciudad de más de 6 millones de habitantes, se debió a la conexión que mantiene con las demás regiones del país en la distribución y el acopio de productos alimenticios (Tabla 1).

3. Presencia de zonas boscosas alrededor de estas ciudades: Colombia cuenta con un territorio conformado por tres grandes biomas: (a) Gran bioma del desierto tropical, (b) Gran bioma del bosque seco tropical y (c) Gran bioma del bosque húmedo tropical. Estos grandes biomas agrupan 32 tipos de biomas y 311 tipos de ecosistemas continentales y costeros de acuerdo con aspectos climáticos, geopedológicos y de cobertura actual del territorio (IDEAM et al. 2007). Dada la complejidad social y ambiental de Colombia, Carrizosa-Umaña (2014) describe el territorio mediante 19 sistemas ambientales territoriales. Nuestro estudio se focalizó en dos grandes biomas y seis sistemas ambientales territoriales (Tabla 1).

4. Seguridad para realizar recorridos y desplazamientos en áreas urbanas periurbanas y rurales: se eligieron áreas de Colombia en donde fuera posible realizar investigación sin mayores riesgos de seguridad y de fácil acceso a partir de las ciudades medias seleccionadas.
Se buscó contactar investigadores de la zona que confirmaran la presencia de plazas de mercado activas y mercados de productos de los bosques aledaños.

Este estudio presenta los resultados de cada región a manera de estudios de caso, para el posterior análisis en profundidad del comercio de carne de monte en Colombia.

\subsection{Descripción metodológica}

El levantamiento de información se llevó a cabo durante 100 días (alrededor de 15 días efectivos en cada sitio de estudio), entre septiembre y octubre de 2013, para Leticia y Puerto Narińo (Amazonas); y entre julio y noviembre de 2014 y enero de 2015, para los demás sitios. Este trabajo combinó la observación participante en los primeros recorridos que se hicieron para generar un contacto inicial con los posibles informantes clave, con las visitas y las entrevistas abiertas a los vendedores y comerciantes, así como a los consumidores identificados. Se visitaron los mercados de los centros poblados y las vías principales de los municipios aledaños, un total de 535 sitios visitados con potencial de venta 
de carne de monte, distribuidos de la siguiente manera: 34 plazas de mercado, 295 restaurantesasaderos, 64 carnicerías, 2 pescaderías, 46 puestos en la calle, 69 puestos de comida, 11 tiendas de barrio y 14 comunidades-caseríos (Anexo 1).

\subsubsection{Observación participante}

La observación participante se realizó durante los 10-15 días de permanencia en cada sitio, con recorridos diarios. A la mayoría de los actores se les explicó en forma transparente el objetivo del estudio: analizar la importancia de la carne de monte en los mercados locales urbanos; una vez explicado el objetivo del estudio, se esperó el momento más oportuno para no crear desconfianza. Cuando los actores del mercado manifestaron reticencia para hablar de ello, no se insistió en recolectar más información. Sin embargo, gracias a las visitas diarias, los actores fueron mostrando cada vez más confianza y curiosidad en participar de esta investigación.

\subsubsection{Entrevistas abiertas}

Durante estos recorridos y mientras se compartía la comida, se conversó con los dueños y comensales sobre los platos locales y tradicionales, sus comidas favoritas y las de mayor demanda. Se preguntó directamente por carne de monte, "marisca ${ }^{3 \text { " o }}$ "carne salvaje" a los vendedores en las plazas de mercado, a las personas en las cocinas y ayudantes de los puestos de comida y a algunos comensales: ¿Hay carne de monte? ¿Se ve todavía la carne de monte por estas plazas? Busco carne y comidas tradicionales, ¿se consigue algo de carne de monte?, ¿Quién sabe preparar aún la carne de monte? ¿Desde dónde viene esta carne? ¿Quiénes la traen? ¿Qué medios de transporte utilizan? ¿Qué dias y en qué horarios llega la carne de monte? ¿Cuánto cuesta el plato? Estas preguntas se hicieron también en las visitas realizadas a los almacenes con oferta de cárnicos, pollos congelados y embutidos, y a las pescaderías. Se visitaron diariamente las plazas de mercado con oferta de carne de monte, así como los restaurantes y puestos de comida que ofertan esta carne, preguntando: ¿Qué carne llegó hoy? ¿Cómo se llama el animal? ¿Desde dónde viene? ¿Quién fue el proveedor? ¿Cómo lo contactó a usted? ¿Cuánto fue el precio de compra por kilogramo? ¿Cuánto es el precio de venta? Y, si era posible, las cantidades diarias de carne de monte en cada sitio. Para cada sitio visitado, actor entrevistado y recorrido realizado, se mantuvo un registro diario y hora a hora. Se documentó fotográficamente cada sitio y se pidió permiso para fotografiar los casos en que la carne de monte estaba presente. Finalmente, con la ayuda de los conocedores identificados, cazadores y vendedores, y en un mapa con los municipios y corregimientos aledaños a los sitios visitados, se buscó establecer las principales rutas de abastecimiento y transporte de la carne de monte en cada localidad.

\subsubsection{Bola de nieve}

Una vez que se logró establecer un vínculo de confianza a través de la observación participante con algunos comercializadores de carne de monte, se procedió a preguntarles si podían referenciar a otras personas participantes de la cadena de mercado. En muchas ocasiones, los informantes llevaron a los investigadores donde estas otras personas o se las presentaron, para que no sintieran desconfianza. Se consideró una muestra representativa para el estudio cuando ninguna persona nueva era referenciada como participante de la cadena de mercado en cada una de las localidades visitadas. 


\section{Sitios de venta y distribución de la carne de monte}

En las cinco regiones visitadas, el comercio de la carne de monte ocurre en sitios específicos y de acceso restringido al público en general, dentro de los sitios visitados. Se encontró venta de carne de monte en 145 sitios del total visitado $(\mathrm{N}=535)$ (Tabla 2). Los lugares con oferta corresponden a 11 plazas de mercado, 48 restaurantes, 3 carnicerías, 44 puestos ambulantes, 22 puestos de comida, 6 tiendas de barrio y 11 sitios adicionales dispersos en los caseríos alrededor de los lugares visitados, tales como graneros y tiendas de abarrotes, donde se compra la carne de monte para luego venderla a intermediarios o casas de familia.

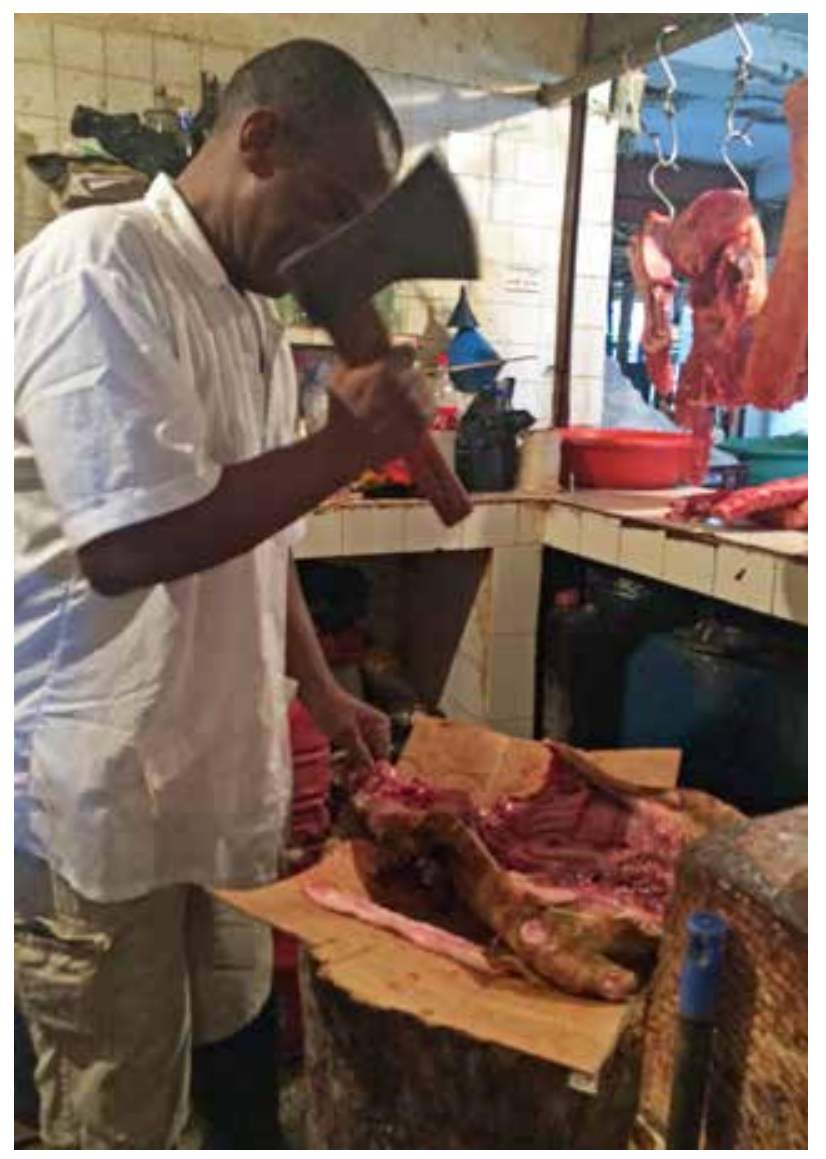

Vendedor de carne de monte en plaza de mercado. Quibdó, Chocó. (Foto por Maria Paula Quiceno)

\subsection{Plazas de mercado}

En algunas plazas de mercado del país aún se encuentra venta de carne de monte viva, fresca, ahumada y salada. En 11 plazas de mercado del total visitado $(\mathrm{N}=34)$ se encontró venta de carne de monte. El recorrido y seguimiento de las plazas permitió identificar 55 puestos en plazas de mercado $(\mathrm{N}=1.257)$ con oferta permanente de esta carne durante el tiempo de desarrollo del estudio (Tabla 3). En todos los casos, los vendedores mantienen contacto directo a través del celular con cazadores, quienes actúan como proveedores permanentes, $\mathrm{o}$ con familiares cazadores; o reciben las visitas muy esporádicas de algún cazador que pasa a vender la carne que no fue consumida en su comunidad.

\subsubsection{Región Amazónica}

En la región Amazónica, la venta de carne de monte en plazas es frecuente y fue ofertada de manera casi constante durante el periodo de recolección de información por los vendedores de pescado fresco, principalmente vendedores de pirarucú (Arapaima gigas). La venta se da de manera discreta y contactando a los clientes por celular, a quienes se les avisa sobre la oferta de animales para el día. Entre las 6 a. m. y las 11 a. m. se vende casi la totalidad de la carne fresca que permanece almacenada en contenedores con hielo. La carne de monte salada o ahumada puede durar de un día para otro, y cuando hay gran cantidad, los vendedores guardan refrigerado el excedente, en sus casas.

En la región de Guainía, la plaza de mercado se encuentra abandonada. La venta esporádica de la carne de monte se registra en el área periurbana de El Paujil, comercializada directamente por los cazadores indígenas o por intermediarios. Los informantes afirman que, dado que este punto de venta se encuentra en el interior del resguardo El Paujil, los controles son muy escasos. La carne de monte se ofrece a las 6 a. m. y a las 4 p. m., horas en que 
Tabla 2. Sitios con venta de carne de monte en cada lugar visitado.

\begin{tabular}{|c|c|c|c|c|c|c|c|c|}
\hline $\begin{array}{l}\text { Región } \\
\text { geográfica }\end{array}$ & $\begin{array}{l}\text { Lugar } \\
\text { visitado }\end{array}$ & $\begin{array}{l}\text { Plaza de } \\
\text { mercado }\end{array}$ & $\begin{array}{l}\text { Restaurante/ } \\
\text { asadero }\end{array}$ & Carnicería & $\begin{array}{l}\text { Puestos } \\
\text { ambulantes }\end{array}$ & $\begin{array}{l}\text { Puestos } \\
\text { de } \\
\text { comida }\end{array}$ & $\begin{array}{l}\text { Tiendas } \\
\text { de } \\
\text { barrio }\end{array}$ & $\begin{array}{l}\text { Comunidades/ } \\
\text { caseríos }\end{array}$ \\
\hline \multirow[t]{3}{*}{ Amazónica } & Leticia & 1 & 13 & 0 & 0 & 14 & 0 & 0 \\
\hline & Inírida & 0 & 4 & 0 & 0 & 3 & 0 & 0 \\
\hline & $\begin{array}{l}\text { Puerto } \\
\text { Nariño }\end{array}$ & 1 & 9 & 0 & 0 & 0 & 0 & 0 \\
\hline \multirow[t]{5}{*}{ Andina } & Bogotá & 3 & 0 & 0 & 4 & 0 & 0 & 0 \\
\hline & Calarcá & 0 & 0 & 0 & 0 & 0 & 0 & 0 \\
\hline & Montenegro & 0 & 0 & 0 & 0 & 0 & 0 & 0 \\
\hline & Circasia & 0 & 1 & 0 & 0 & 0 & 0 & 0 \\
\hline & Salento & 0 & 0 & 0 & 0 & 0 & 0 & 0 \\
\hline \multirow[t]{8}{*}{ Orinoquia } & Yopal & 1 & 1 & 1 & 0 & 0 & 1 & 0 \\
\hline & Aguazul & 0 & 0 & 0 & 0 & 0 & 1 & 0 \\
\hline & $\begin{array}{l}\text { Paz de } \\
\text { Ariporo }\end{array}$ & 1 & 1 & 0 & 0 & 0 & 0 & 0 \\
\hline & Villanueva & 0 & 1 & 1 & 0 & 0 & 0 & 0 \\
\hline & Tauramena & 0 & 0 & 0 & 0 & 0 & 0 & 0 \\
\hline & Monterrey & 0 & 2 & 1 & 0 & 0 & 0 & 0 \\
\hline & $\begin{array}{l}\text { Hato } \\
\text { Corozal }\end{array}$ & 0 & 0 & 0 & 0 & 0 & 0 & 0 \\
\hline & Pore & 0 & 0 & 0 & 0 & 0 & 1 & 0 \\
\hline \multirow[t]{7}{*}{ Caribe } & Santa Marta & 1 & 0 & 0 & 0 & 0 & 0 & 0 \\
\hline & Ciénaga & 0 & 1 & 0 & 0 & 0 & 0 & 0 \\
\hline & $\begin{array}{l}\text { Zona } \\
\text { Bananera }\end{array}$ & 0 & 1 & 0 & 0 & 0 & 0 & 0 \\
\hline & Fundación & 0 & 5 & 0 & 0 & 3 & 3 & 2 \\
\hline & Aracataca & 1 & 0 & 0 & 0 & 0 & 0 & 1 \\
\hline & Algarrobo & 0 & 0 & 0 & 0 & 0 & 0 & 0 \\
\hline & El Copey & 1 & 2 & 0 & 0 & 0 & 0 & 0 \\
\hline Pacífica & Quibdó & 1 & 7 & 0 & 40 & 2 & 0 & 8 \\
\hline Total & & 11 & 48 & 3 & 44 & 22 & 6 & 11 \\
\hline
\end{tabular}

Tabla 3. Plazas de mercado y puestos visitados con venta de carne de monte.

\begin{tabular}{llcc}
\hline Región geográfica & Lugar visitado & $\begin{array}{l}\text { Plazas de mercado con venta de } \\
\text { carne de monte }\end{array}$ & $\begin{array}{l}\text { Puestos de venta y/o comida de } \\
\text { carne de monte }\end{array}$ \\
\hline Amazónica & Leticia & 1 & 26 \\
& Puerto Nariño & 1 & 2 \\
Andina & Bogotá & 3 & 3 \\
Orinoquia & Yopal & 1 & 9 \\
& Paz de Ariporo & 1 & 3 \\
Caribe & Santa Marta & 1 & 1 \\
& Aracataca & 1 & 1 \\
\multirow{3}{*}{ Pacífica } & El Copey & 1 & 1 \\
\hline Total & Quibdó & 1 & 9 \\
\hline
\end{tabular}




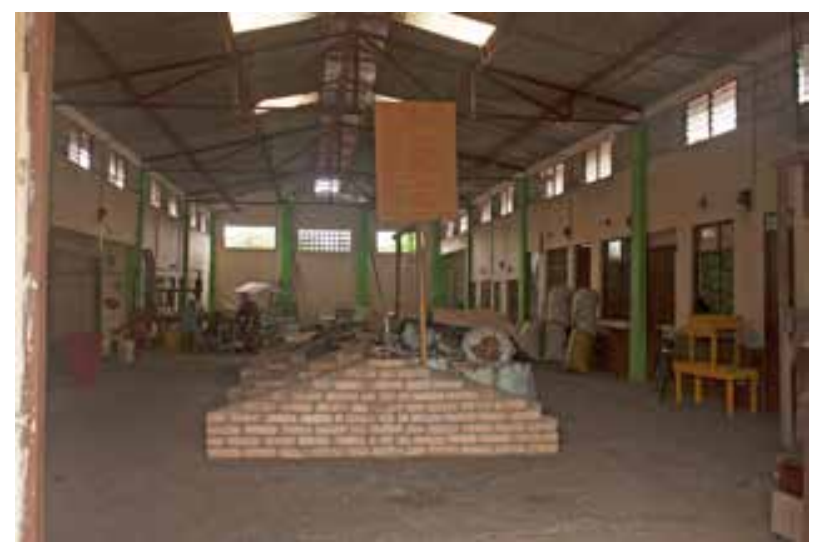

Plaza de mercado abandonada. Inírida, Guainía. (Foto por Daniel Cruz)

los consumidores visitan el lugar. En otros mercados de Inírida diferentes al del resguardo El Paujil no se registraron vendedores de carne de monte debido a los frecuentes controles y a la ausencia de infraestructura de la plaza de mercado. Este comercio está más relacionado con la venta por encargo, puerta a puerta o en restaurantes de fin de semana.

\subsubsection{Región Orinoquia}

En la región Orinoquia visitada, la carne de monte se vende principalmente en dos plazas de mercado de Yopal y Paz de Ariporo. Estas plazas cuentan con un área especial para el mercado campesino, en donde se ubican los vendedores de carne de monte, adicional a los graneros o ventas de pescado. Las demás plazas de mercado de los municipios de Villanueva, Monterrey, Aguazul y Pore no reportaron venta de carne de monte durante la visita. La presencia de supermercados con oferta de frutas, verduras y carnes de la zona ha hecho que se pierdan el interés y la tradición de acudir a las plazas de mercado. Sin embargo, los vendedores reportan consumo regular y comercio de carne de monte a través de encargo directo.

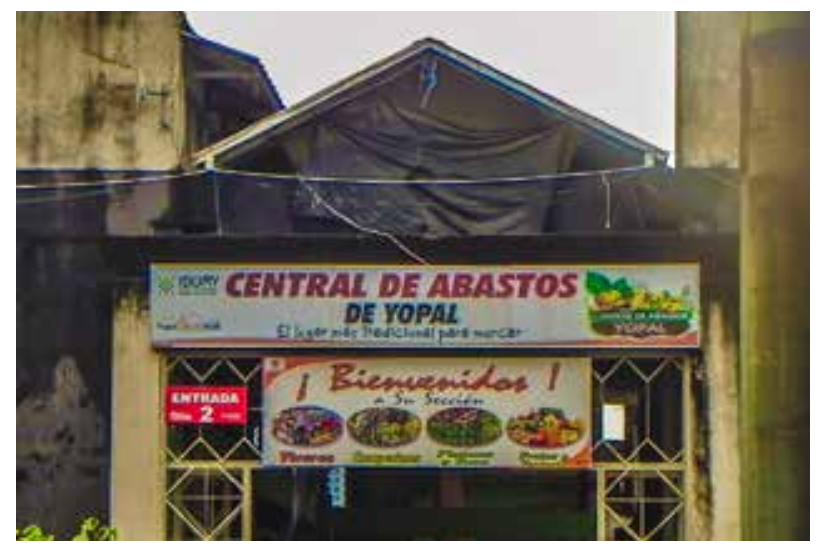

Plaza de mercado. Yopal, Casanare. (Foto por Jessica Moreno)

\subsubsection{Región Caribe}

La carne de monte para la venta se encontró en las tres plazas visitadas: Santa Marta, Aracataca y El Copey. En la plaza de mercado de Santa Marta (sección El Pueblito) hay un puesto de venta de carne de monte. Este corresponde a un espacio de venta de verduras y algunas semillas y condimentos de la región. En Aracataca, hay un puesto de venta de carne de monte que corresponde a una ebanistería, y en El Copey hay una carnicería en la plaza de mercado que vende carne de monte. En el caso de Aracataca, una ebanistería identificada ofrece la carne de monte y el vendedor mantiene contacto con al menos tres cazadores proveedores, quienes desde los bosques cercanos traen en días alternos algún animal.

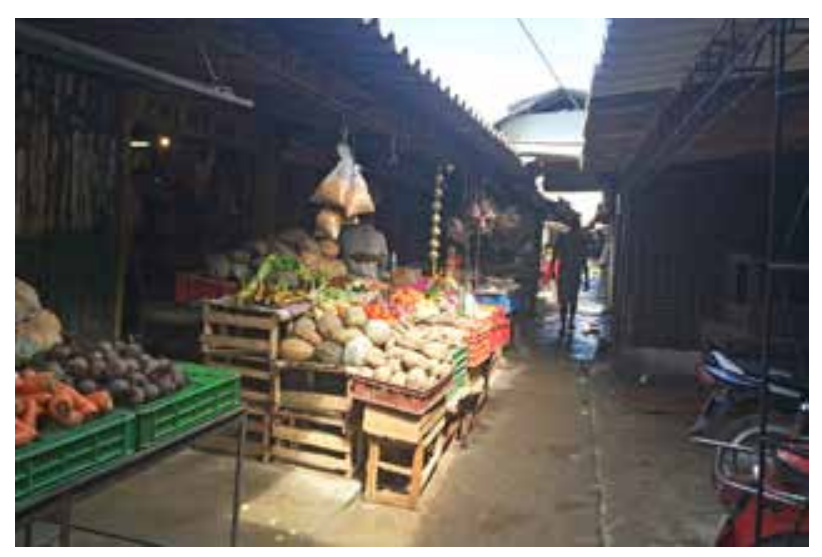

Plaza de mercado. Fundación, Magdalena.

(Foto por Maria Paula Quiceno)

\subsubsection{Región Pacífica}

A diferencia de lo que ocurre en las demás zonas, la plaza de mercado en la región Pacífica (Quibdó, Chocó) es vibrante y permanece como el centro de distribución de frutas locales, pescados y plátanos. Del total de puestos visitados $(\mathrm{N}=136)$, se encontró oferta de carne de monte en nueve sitios: cuatro carnicerías con oferta adicional de pollos y pescados, y cinco puestos de comida donde se ofrecen platos con carne de monte, pescado, res o pollo. La carne de monte llega generalmente al puerto sobre el río Atrato, donde se encuentra la plaza de mercado.

\subsubsection{Región Andina}

En la región Andina cafetera, la carne de monte se consigue por encargo en las galerías o plazas de mercado, y con los transportadores locales que se ubican alrededor de la plaza de mercado. El encargo se hace a los campesinos de las "cejas de los montes" 


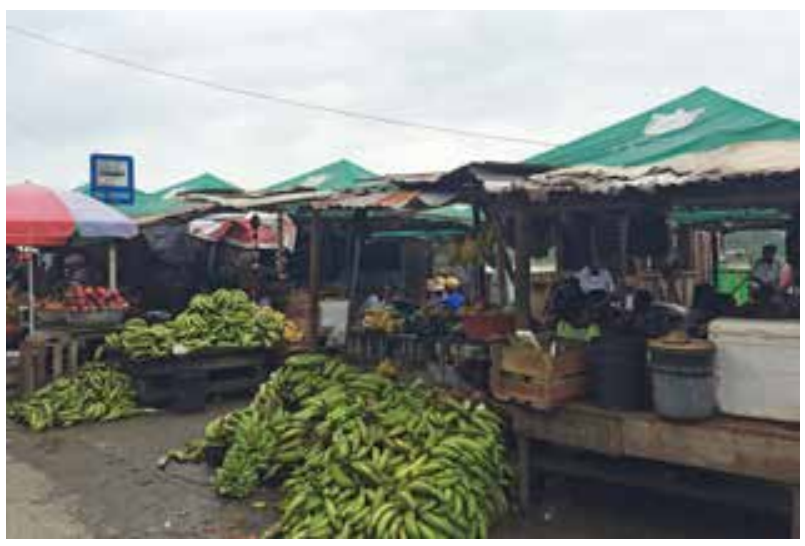

Plaza de mercado. Quibdó, Chocó. (Foto por Maria Paula Quiceno)

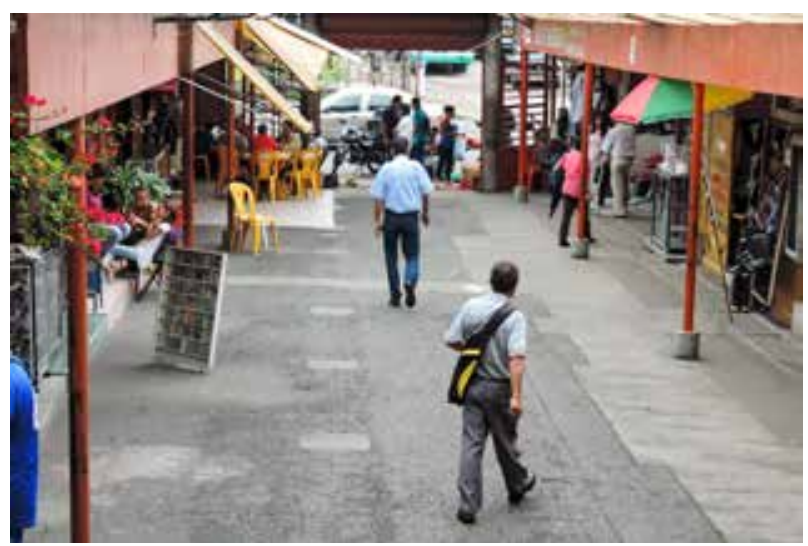

Plaza de mercado Armenia. Quindío. (Foto por Eliceo Matapí Yucuna)

(bosques), quienes ofrecen servicio de caza de control en predios donde se reporta que algún animal está dañando los cultivos. La carne se entrega a cambio del control o se deja para los dueños; el cazador recibe un jornal de trabajo equivalente a casi $\mathrm{COP}^{4} 35.000\left(\mathrm{USD}^{5} 15\right)$.

En Bogotá D. C., se confirmó la venta de carne de monte en tres plazas de mercado del total visitado $(\mathrm{N}=13)$. Adicionalmente, se reportaron posibles ventas en otras dos plazas de mercado. Estas plazas son consideradas tradicionales y cuentan con mercados campesinos o áreas para los productos no convencionales en donde ocurre la venta de carne de monte, que se oferta de manera especial junto con gallinas campesinas, huevos criollos, patos, pavos reales, piscos (Meleagris sp.), gansos, conejos, curíes (Cavia sp.), palomas, codornices, faisanes, perros, gatos y aves ornamentales

4 Pesos colombianos.

5 Dólares estadounidenses. pequeñas. Los animales en las plazas de mercado de Bogotá se venden de preferencia enteros y a veces vivos, de manera rápida y con cita previa, dados la prohibición y el constante control en las plazas por encargados de las oficinas de sanidad y miembros de la Policía Ambiental, quienes además de decomisar la carne, imponen multas y sanciones, que incluyen perder el puesto en la plaza de mercado.

\subsection{Restaurantes y asaderos}

Del total de restaurantes y asaderos visitados en los recorridos realizados $(\mathrm{N}=295)$, se encontraron 48 restaurantes con oferta de carne de monte entre sus platos del día y en el menú, o con venta especial y discreta para sus clientes de confianza (Tabla 2).

\subsubsection{Región Amazónica}

En Leticia, los restaurantes compran la carne de monte en las plazas de mercado de Leticia y Tabatinga, o directamente a cazadores de confianza

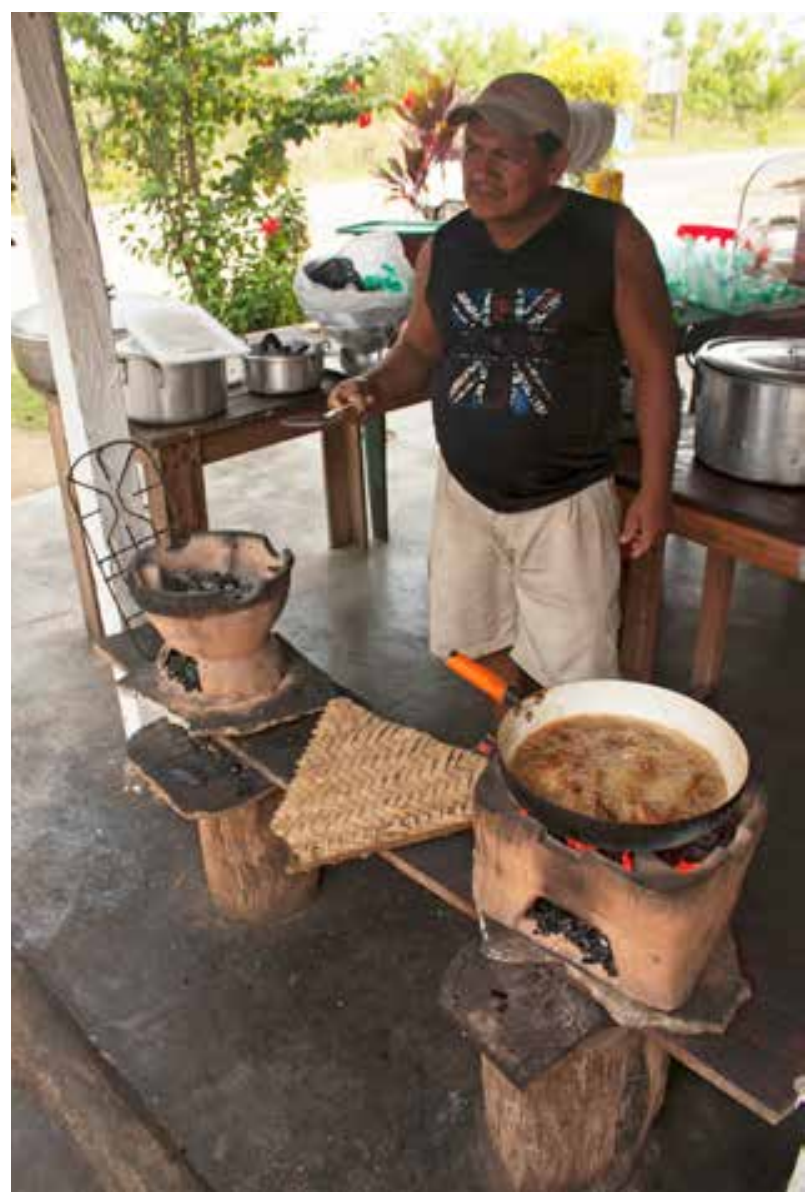

Preparación de carne de boruga. Inírida, Guainía. (Foto por Daniel Cruz) 


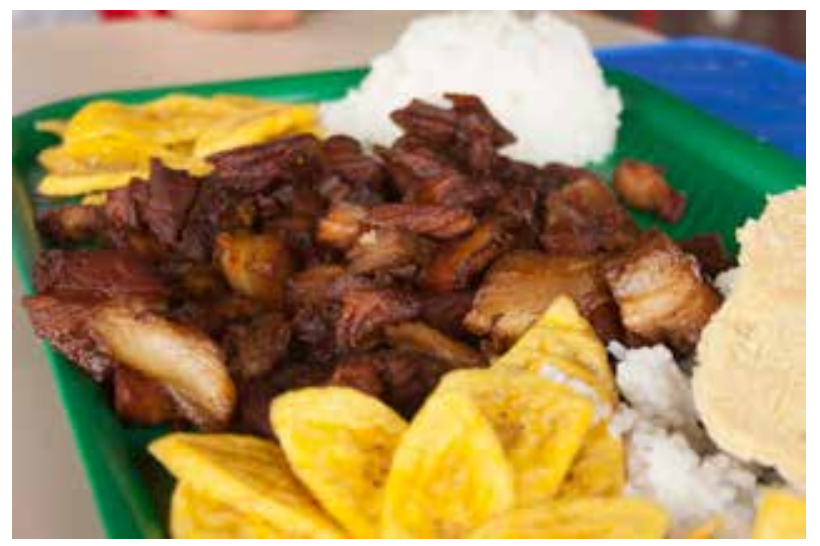

Plato con carne de boruga. Inírida, Guainía. (Foto por Daniel Cruz)

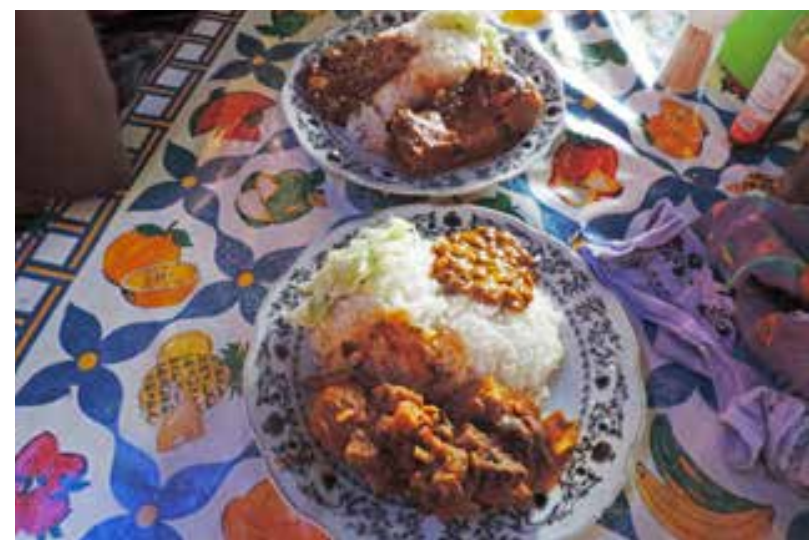

Plato con carne de guartinaja. Quibdó, Chocó. (Foto por Maria Paula Quiceno)

que los proveen desde las áreas periurbanas, especialmente de la zona de "Los Kilómetros". Una tercera parte de los platos que se venden son de carne de monte y el resto suelen ser pollo, res y pescado. Los restaurantes formales que venden carne de monte son comunes a lo largo de la vía periurbana, abren por lo general durante el fin de semana y están asociados a balnearios o sitios turísticos para las familias locales y los turistas. Los restaurantes formales pagan un alquiler y por lo general sus clientes son colonos de ingresos medios y altos, y turistas. Aunque en Puerto Nariño el uso de carne de monte está más asociado con el consumo familiar, se evidencia que esporádicamente algunos turistas la encargan a los restaurantes cuando quieren probar alimentos típicos de la región. Algunos restaurantes compran cuando los cazadores o intermediarios llegan a su establecimiento ofreciendo la carne.

En Inírida, los restaurantes y asaderos están localizados a lo largo de la calle principal de la ciudad y ofrecen pollo asado, platos a la carta y

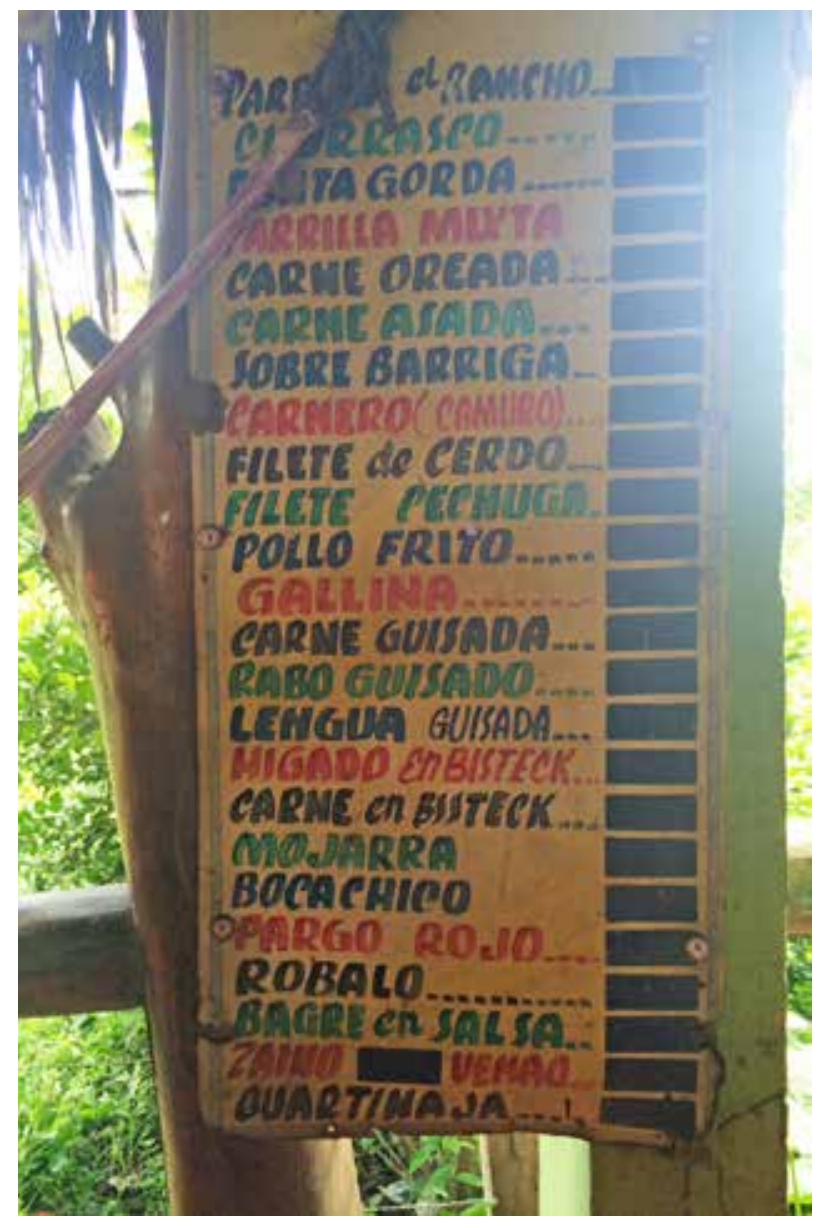

Menú con oferta de zaino, venado, guartinaja. Vía Fundación - Santa Marta, Magdalena. (Foto por Maria Paula Quiceno)

almuerzos caseros con carne, pescado y pollo. Como resultado de los controles, la venta de carne de monte en restaurantes dentro del casco urbano de Inírida es reducida. Incluso cuando los cazadores de las comunidades llegan a ofrecer carne de monte a estos restaurantes, los dueños prefieren no aceptarla para evitar ser sancionados por las autoridades. Por tal razón, los resguardos de Coco Viejo y El Paujil tienen restaurantes que ofrecen carne de monte exclusivamente los fines de semana. Los cazadores de las comunidades cercanas ofrecen la carne de lapa (Cuniculus paca) principalmente a los dueños de estos restaurantes, que son mestizos e indígenas.

En el asentamiento fronterizo de Amanavén, ubicado en frente del pueblo venezolano de San Fernando de Atabapo, se ofrecen platos de carne de monte a un precio más bajo para colombianos y venezolanos que viajan hacia Puerto Ayacucho a través del río Orinoco o en dirección a Inírida o el Guaviare. Estos restaurantes tienen una amplia oferta de platos típicos a la carta, en donde los peces y la gallina criolla son los preferidos. 


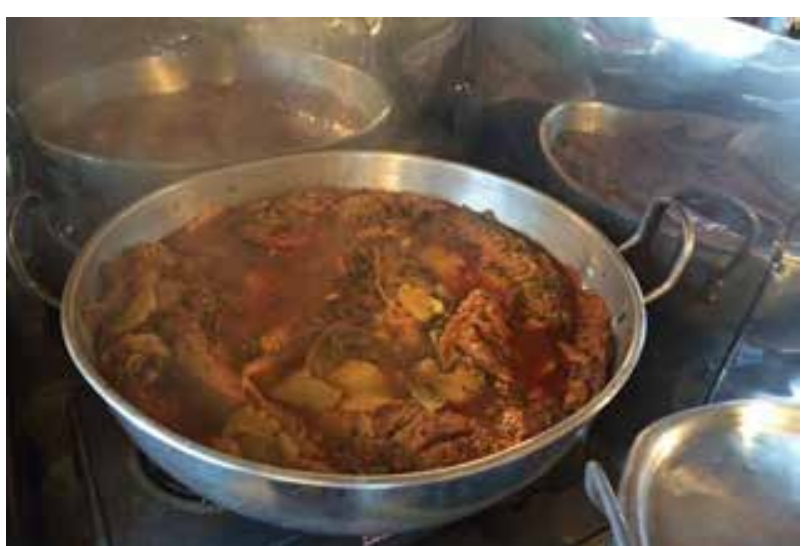

Preparación de zaino al vapor. Quibdó, Chocó. (Foto por Maria Paula Quiceno)

\subsubsection{Región Andina}

En la región Andina incluyendo Bogotá, la oferta de carne de monte en restaurantes es casi inexistente, con excepción de 3 o 4 asaderos que persisten en la oferta del chigüiro (Hydrochoerus hydrochaeris) asado en Bogotá con precios que oscilan entre COP 18.000 (USD 8) y COP 25.000 (USD 11) por plato, a pesar de los constantes controles de la Policía Ambiental y de las certificaciones sobre la legalidad del zoocriadero proveedor de carne que los dueńos deben mostrar. En la Zona Cafetera, la carne de monte es una oferta especial en un asadero en la vía al Valle del Cauca.

\subsubsection{Región Orinoquia}

En la región Orinoquia, la oferta de carne de monte es visible, aun cuando se hace de manera discreta ante los turistas o forasteros. Los restaurantes ofrecen carne de monte entre sus platos del día: algunos la incluyen en la carta, mientras que otros la ofrecen a sus clientes fijos o a turistas y transportadores. Los restaurantes suelen localizarse sobre las vías principales de entrada a los municipios, lo que les permite contar con una mayor clientela.

\subsubsection{Región Caribe}

En la región Caribe, los restaurantes y asaderos que ofertan carne de monte se ubican a lo largo de las carreteras principales que conectan las vías hacia Santa Marta y hacia el Cesar, y en los balnearios a orillas de los ríos. Esta carne se considera especial y un lujo que con frecuencia se halla dentro de la oferta del menú en los asaderos adonde suelen llegar los transportadores de carga pesada, los viajeros y los turistas del interior del país que se dirigen hacia la costa, así como los ganaderos y lugareńos de la zona. De otro lado, existen familias que abren asaderos en su casa, en los barrios periféricos, y en ellos son frecuentes los platos de carne de monte y las comidas típicas. Normalmente, estas familias tienen una conexión directa con familias de cazadores, o sus miembros son transportadores de carga que durante sus recorridos compran la carne de monte en las comunidades aledańas a precios bajos y ofrecen cada dos o tres días platos con carne de monte.

\subsubsection{Región Pacífica}

De igual manera, en el Chocó, los restaurantes donde se oferta la carne de monte, en el casco urbano de Quibdó, son considerados lujosos. Estos restaurantes se relacionan con procesos comunitarios y redes de mujeres o dueños asociados a la actividad minera y maderera, quienes ofrecen platos tradicionales, entre los que "La guagua a las finas hierbas del Pacífico" es uno de los más frecuentes, con un valor de hasta COP 45.000 (USD 20) por plato. La mayoría de los clientes son turistas interesados en la comida regional, políticos de la región y empresarios de las compraventas de oro y platino. Estos últimos suelen ofrecer la carne de monte en grandes reuniones y almuerzos especiales.

En contraste, en los barrios periurbanos y en los poblados aledaños a la ciudad, aparecen restaurantes sencillos que comúnmente ofrecen platos con carne de monte. Las dueñas son mujeres, quienes en los garajes y bajos de las casas abren espacios para la venta de platos del día. Los esposos son cazadores o cuentan con familiares que proveen la carne durante las faenas de pesca, extracción maderera o minera en donde se emplean.

\subsection{Puestos de comida, vendedores ambulantes y otras modalidades}

Del total de sitios visitados $(\mathrm{N}=204)$

correspondientes a carnicerías, puestos de comida (dentro y fuera de la plaza de mercado), venta de víveres en la calle, tiendas de barrio y abarrotes en las comunidades y los caseríos visitados, se encontró carne de monte en 86 lugares (Tabla 4). 
De estos lugares, 44 corresponden a puestos en la calle con venta de pescado fresco o carnes, y 22 sitios corresponden a puestos de comida en la calle, los cuales se ubican por lo general en las afueras de las plazas de mercado o alrededor del parque más cercano a la plaza de mercado.

Los puestos de comida y los vendedores ambulantes suelen ubicarse cerca de las plazas de mercado y ofrecen principalmente platos con pollo, res y pescado, y a escondidas ofrecen platos con carne de monte. La mayoría de estos son atendidos por mujeres que abren durante las horas del desayuno y el almuerzo. Estos puestos de comida en la calle cuentan con pequeñas estufas o equipos que mantienen la comida caliente, con mesas y/o sillas para los clientes. Las carnicerías y tiendas de barrio identificadas con venta de carne de monte, se dedican principalmente al comercio de carne de res y cerdo, en el caso de las carnicerías, y a la venta de víveres, granos y productos de ebanistería, en el caso de las tiendas de barrio.

Tabla 4. Puestos de comida y vendedores ambulantes.

\begin{tabular}{|c|c|c|c|c|c|c|c|c|c|c|c|}
\hline \multirow[t]{2}{*}{ Región geográfica } & \multirow[t]{2}{*}{ Lugar visitado } & \multicolumn{2}{|c|}{ Carnicería } & \multicolumn{2}{|c|}{$\begin{array}{l}\text { Puestos en la } \\
\text { calle }\end{array}$} & \multicolumn{2}{|c|}{$\begin{array}{l}\text { Puestos de } \\
\text { comida }\end{array}$} & \multicolumn{2}{|c|}{$\begin{array}{l}\text { Tiendas de } \\
\text { barrio }\end{array}$} & \multicolumn{2}{|c|}{$\begin{array}{l}\text { Comunidades } \\
\text { y caseríos }\end{array}$} \\
\hline & & A & B & A & B & A & B & A & B & A & B \\
\hline \multirow[t]{3}{*}{ Amazónica } & Leticia & 0 & 0 & 0 & 0 & 14 & 14 & 0 & 0 & 0 & 0 \\
\hline & Inírida & 9 & 0 & 0 & 0 & 14 & 3 & 1 & 0 & 0 & 0 \\
\hline & Puerto Nariño & 0 & 0 & 0 & 0 & 12 & 0 & 0 & 0 & 0 & 0 \\
\hline Andina & Bogotá & 0 & 0 & 6 & 4 & 0 & 0 & 0 & 0 & 0 & 0 \\
\hline \multirow[t]{5}{*}{ Orinoquia } & Yopal & 1 & 1 & 0 & 0 & 0 & 0 & 1 & 1 & 0 & 0 \\
\hline & Aguazul & 0 & 0 & 0 & 0 & 0 & 0 & 1 & 1 & 0 & 0 \\
\hline & Villanueva & 1 & 1 & 0 & 0 & 0 & 0 & 0 & 0 & 0 & 0 \\
\hline & Monterrey & 1 & 1 & 0 & 0 & 0 & 0 & 0 & 0 & 0 & 0 \\
\hline & Pore & 0 & 0 & 0 & 0 & 0 & 0 & 1 & 1 & 0 & 0 \\
\hline \multirow[t]{2}{*}{ Caribe } & Fundación & 8 & 0 & 0 & 0 & 15 & 3 & 4 & 3 & 2 & 2 \\
\hline & Aracataca & 0 & 0 & 0 & 0 & 0 & 0 & 0 & 0 & 1 & 1 \\
\hline Pacífica & Quibdó & 19 & 0 & 40 & 40 & 2 & 2 & 0 & 0 & 11 & 8 \\
\hline Total & & 64 & 3 & 46 & 44 & 69 & 22 & 11 & 6 & 14 & 11 \\
\hline
\end{tabular}

$A=$ sitios visitados.

$\mathrm{B}=$ sitios con venta de carne de monte. 


\section{Usuarios de la cadena de comercio de carne de monte}

Durante el periodo de realización del presente estudio, se identificaron un total de 285 usuarios directos en la cadena de mercado de carne de monte en los sitios visitados. De ellos, 55\% corresponde a hombres y $45 \%$ a mujeres, entre cazadores $(30 \%)$, vendedores en restaurantes (27\%), vendedores en plazas de mercado (21\%), vendedores en puestos de comida o restaurantes informales $(8 \%)$ incluyendo vendedores ambulantes o puestos en la calle (7\%), y otros actores como intermediarios o vendedores en carnicerías y tiendas de barrio (7\%).

\subsection{Cazadores}

Para las cinco regiones visitadas, se identificaron un total de 86 cazadores (Tabla 5), quienes a su vez reportaron alrededor de 193 cazadores conocidos como parte de la cadena de mercado.

La mayoría de cazadores son hombres campesinos, afrodescendientes e indígenas. También se identificó a mujeres y niños cazadores en las regiones Pacífica y Caribe, respectivamente, quienes debido a la situación de conflicto armado y dificultad de acceso a los alimentos, deben proveer de carne de monte a la familia como complemento de los cultivos básicos.

Tabla 5. Cazadores identificados y reportados.

\begin{tabular}{lccc}
\hline Región & \multicolumn{2}{c}{ Cazadores identificados } & $\begin{array}{c}\text { Cazadores } \\
\text { reportados }\end{array}$ \\
\cline { 2 - 4 } & Femenino & Masculino & 27 \\
Amazónica & 2 & 59 & 1 \\
Andina & 0 & 2 & 6 \\
Orinoquia & 0 & 0 & 52 \\
Caribe & 0 & 2 & 107 \\
Pacífica & 1 & 20 & $\mathbf{1 9 3}$ \\
\hline Total & $\mathbf{3}$ & $\mathbf{8 3}$ & \\
\hline
\end{tabular}

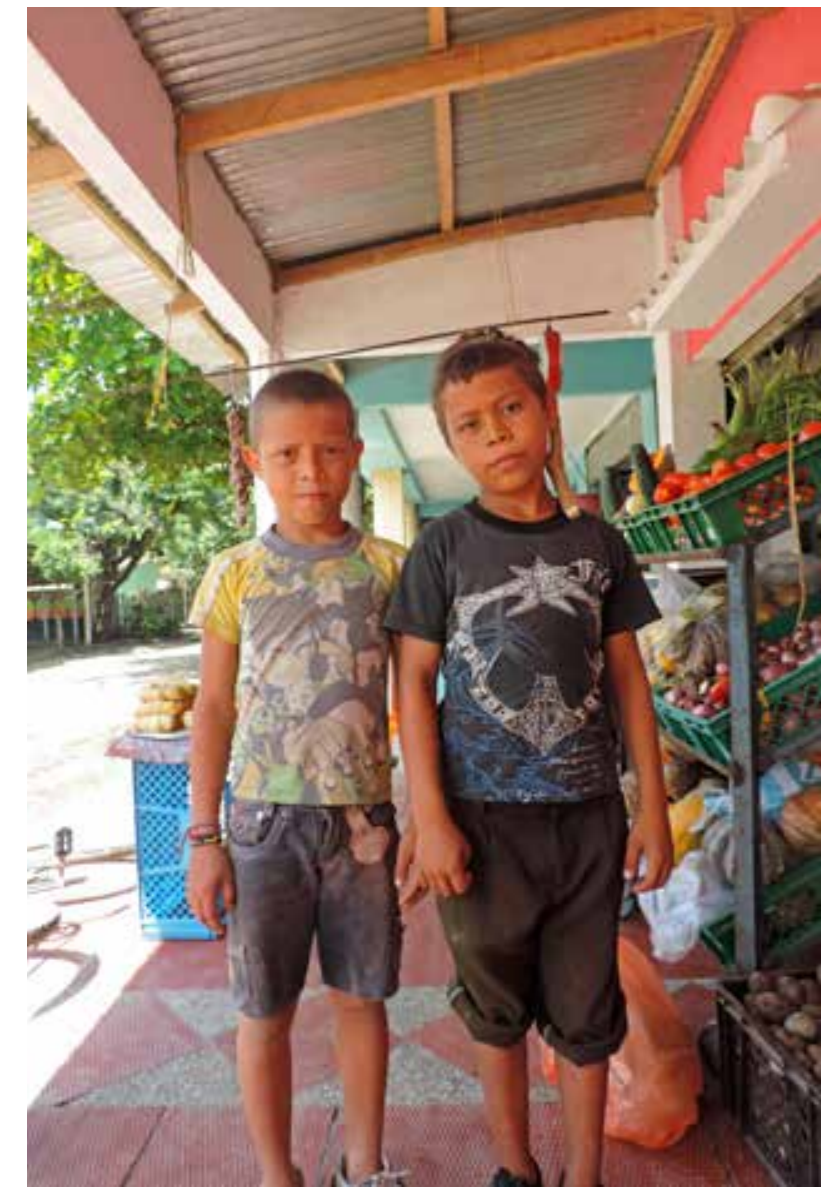

Aprendices de cazador. Tucurinca, Zona Bananera Magdalena. (Foto por Maria Paula Quiceno)

En general, se puede identificar dos tipos de cazadores que proveen carne de monte en las regiones visitadas: los cazadores diversificados, aquellos que utilizan la cacería como una actividad complementaria u oportunista frente a otras actividades como la ganadería, la agricultura, la minería, la extracción maderera, entre otras, por un lado; y, de otro lado, los cazadores especializados, aquellos que realizan la cacería como una actividad primordial para sus ingresos económicos y que por lo general cuentan con clientes fijos, como 


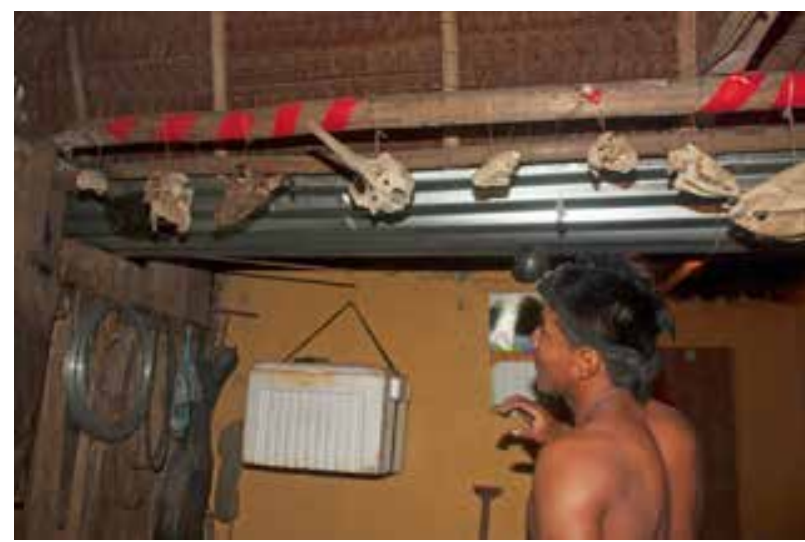

Cazador. Comunidad La Ceiba, Guainía. (Foto por Daniel Cruz)

restaurantes, plazas de mercado, intermediarios y familias con alto poder adquisitivo, quienes encargan grandes cantidades de carne de monte. Los cazadores especializados invierten en su actividad de caza (perros, escopeta, moto o caballos); por ejemplo, en el Chocó, los cazadores comerciales pagan hasta COP 5.000.000 (USD 2.200) por un perro de cacería.

\subsection{Vendedores en plazas de mercado, ambulantes, restaurantes, asaderos, puestos de comida e intermediarios}

Se identificó a un total de 199 personas a lo largo de la cadena de mercado de carne de monte en los municipios visitados de las cinco regiones del país. De ellos, el $62 \%$ son mujeres y el $38 \%$ son hombres (Tabla 6), en su mayoría vendedores en restaurantes, plazas de mercado y puestos de comida.

Tabla 6. Total de actores identificados en la cadena de mercado de las cinco zonas visitadas.

\begin{tabular}{lcc}
\hline Tipo de actores & Femenino & Masculino \\
\hline $\begin{array}{l}\text { Vendedores en plaza } \\
\text { de mercado }\end{array}$ & 41 & 20 \\
$\begin{array}{l}\text { Vendedores en } \\
\text { restaurantes/asaderos }\end{array}$ & 43 & 37 \\
$\begin{array}{l}\text { Vendedores en puestos } \\
\text { de comida }\end{array}$ & 21 & 3 \\
$\begin{array}{l}\text { Vendedores ambulantes } \\
\text { Intermediarios }\end{array}$ & 16 & 3 \\
$\begin{array}{l}\text { Vendedores en } \\
\text { carnicerías }\end{array}$ & 2 & 4 \\
\hline Total & 123 & 9 \\
\hline
\end{tabular}

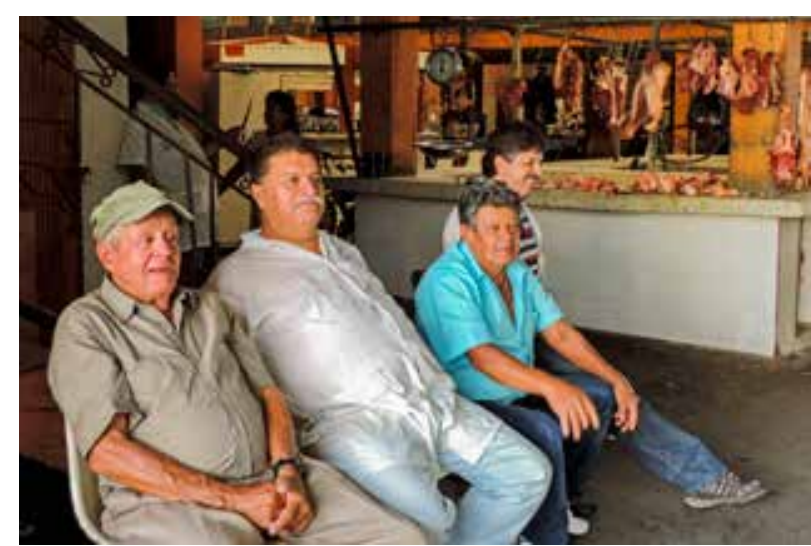

Vendedores de plaza de mercado. Circasia, Quindío. (Foto por Eliceo Matapi Yucuna.)

Los vendedores en plazas de mercado tienen puestos donde se venden principalmente granos, pescado o verduras, mientras que en restaurantes y puestos de comida los actores tienen como oferta principal platos típicos de la región. La cadena de mercado funciona sobre la base de la confianza y las referencias entre cazadores, compradores en plazas de mercado y familias a través del celular o compartiendo la carne de monte. La cadena de

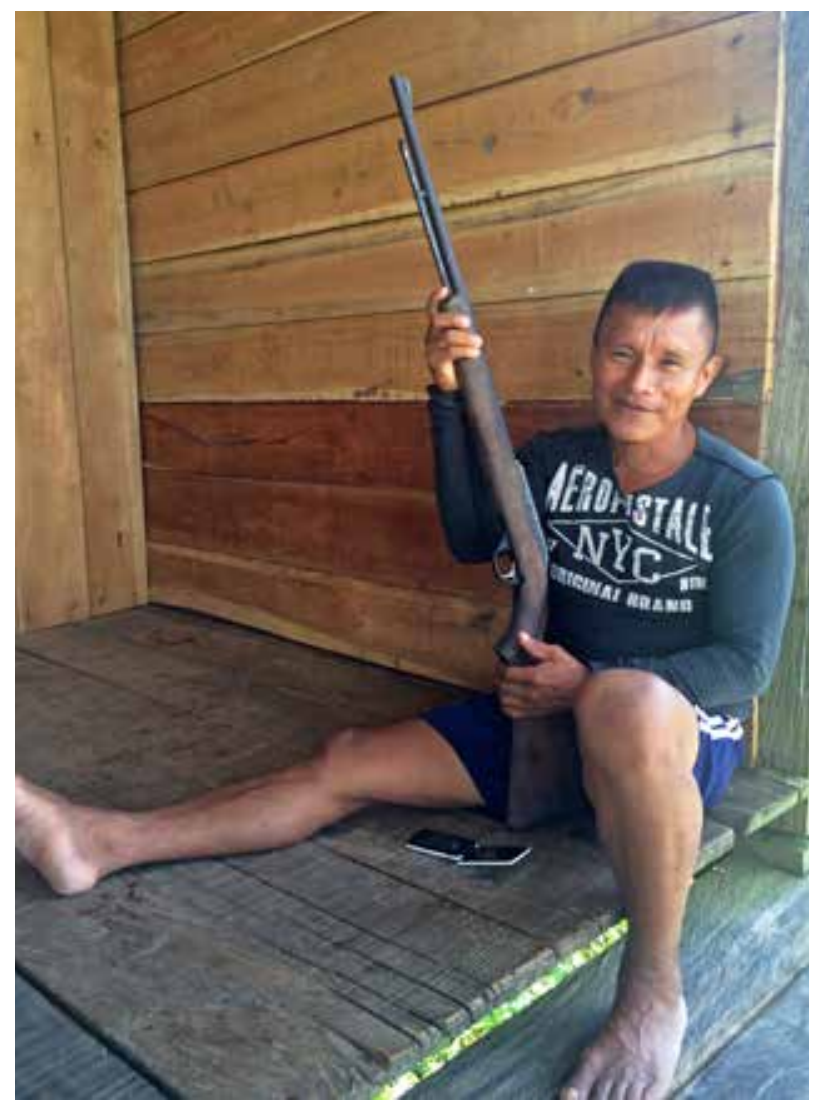

Cazador Emberá-Chamí. Zona periurbana de Quibdó. Chocó. (Foto por Maria Paula Quiceno) 


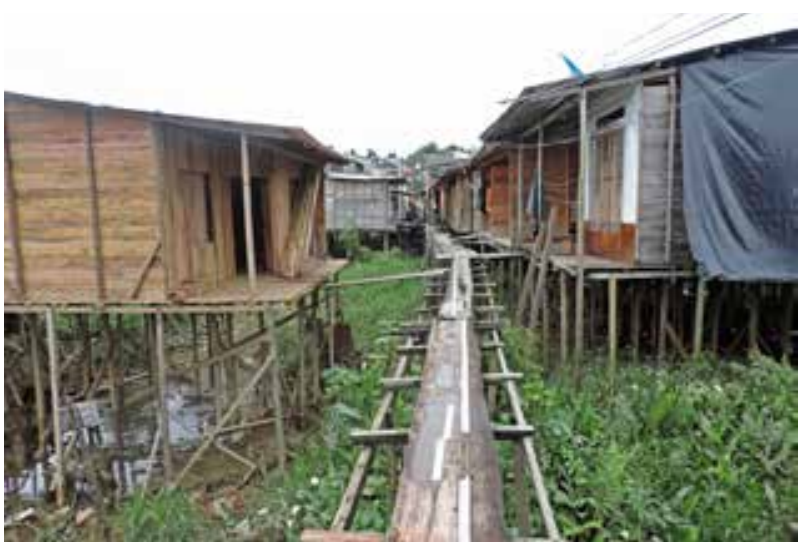

Barrio periurbano. Quibdó, Chocó. (Foto por Maria Paula Quiceno)

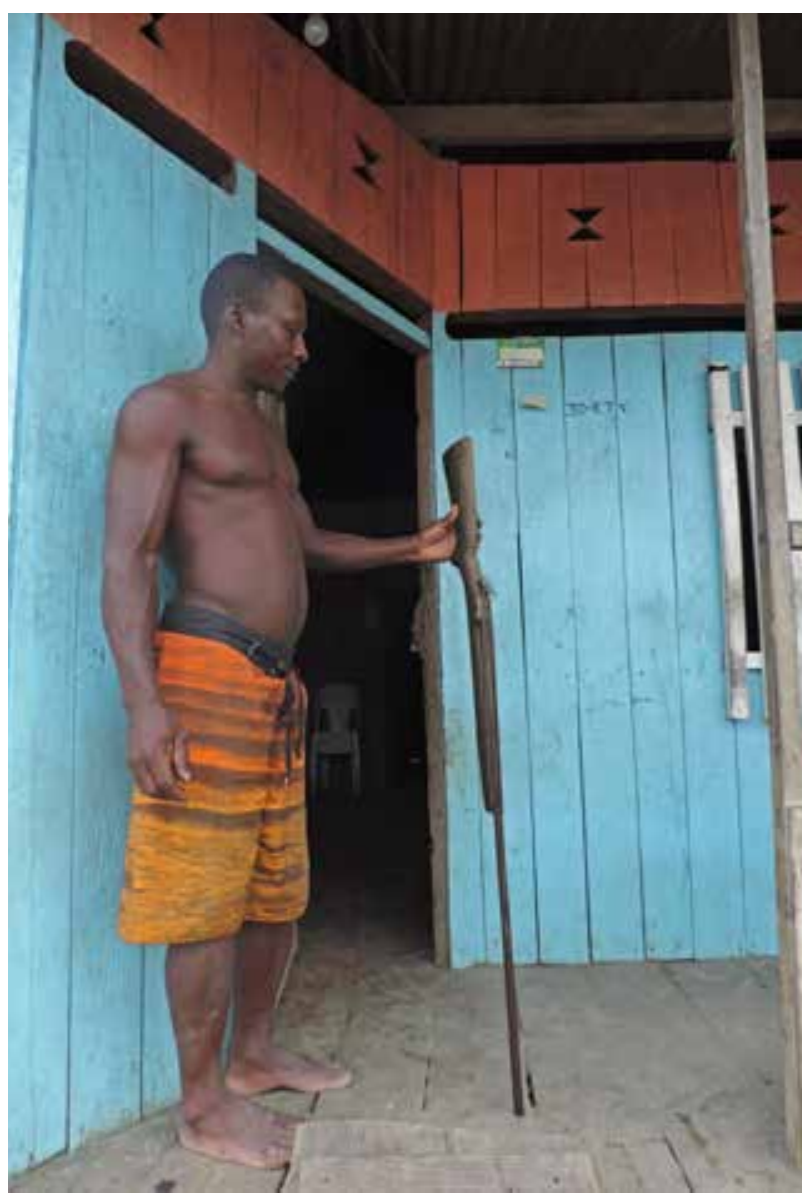

Cazador afrodescendiente. Zona periurbana Quibdó, Chocó. (Foto por Maria Paula Quiceno)

mercado es moldeada por los eventos de vigilancia y control que realizan en cada región, en mayor o menor medida, la Policía Ambiental y las autoridades ambientales. A manera de ejemplo, la Figura 2 ilustra la cadena de mercado general.

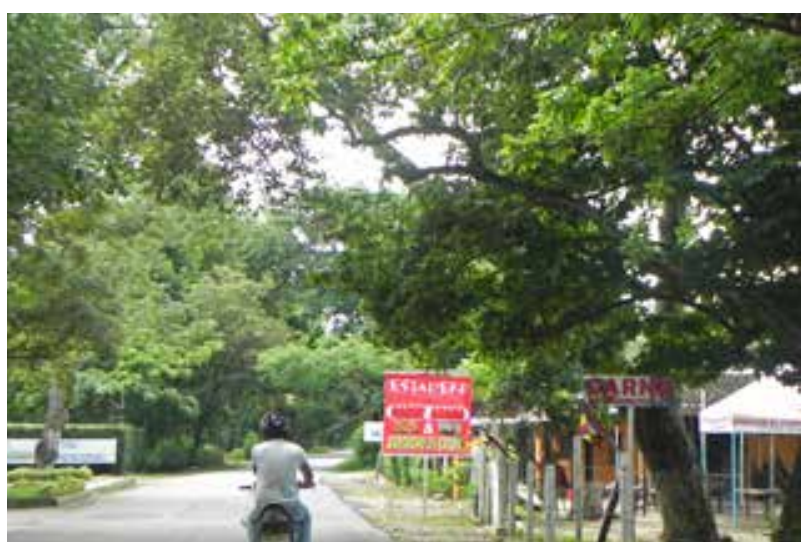

Restaurantes de carretera. Yopal, Casanare. (Foto por Jessica Moreno)

\subsection{Consumidores}

Los compradores de la carne de monte varían desde familias indígenas, afrodescendientes o rurales, hasta intermediarios, restaurantes, puestos de comida, plazas de mercado y familias de los cascos urbanos (Figura 2).

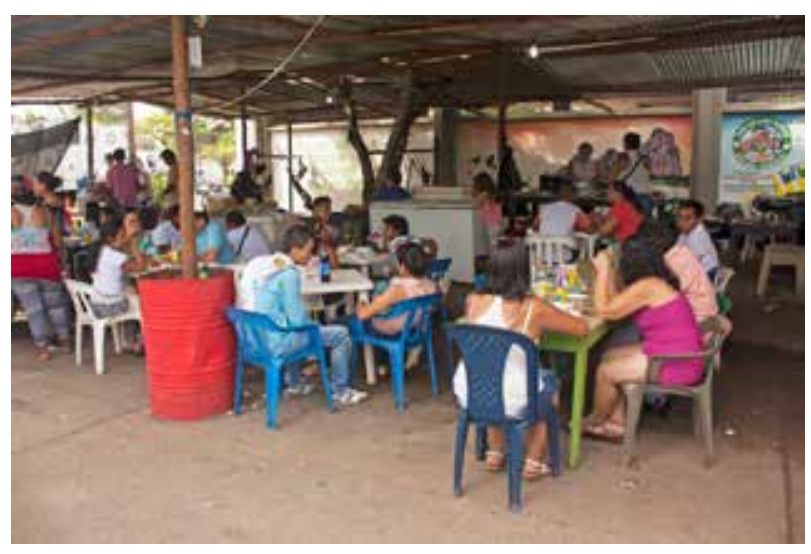

Restaurante en zona periurbana. Inírida, Guainía. (Foto por Daniel Cruz)

En las plazas de mercado y carnicerías, los consumidores suelen ser familias mestizas urbanas, y algunas familias afrodescendientes y campesinas urbanas. En el caso de las tiendas de barrio, los vendedores ambulantes y los puestos de comida, los clientes son mayoritariamente familias afrodescendientes, indígenas y campesinas rurales y urbanas. En los restaurantes, los clientes son en su mayoría familias mestizas urbanas, comerciantes y turistas (Figura 2). 


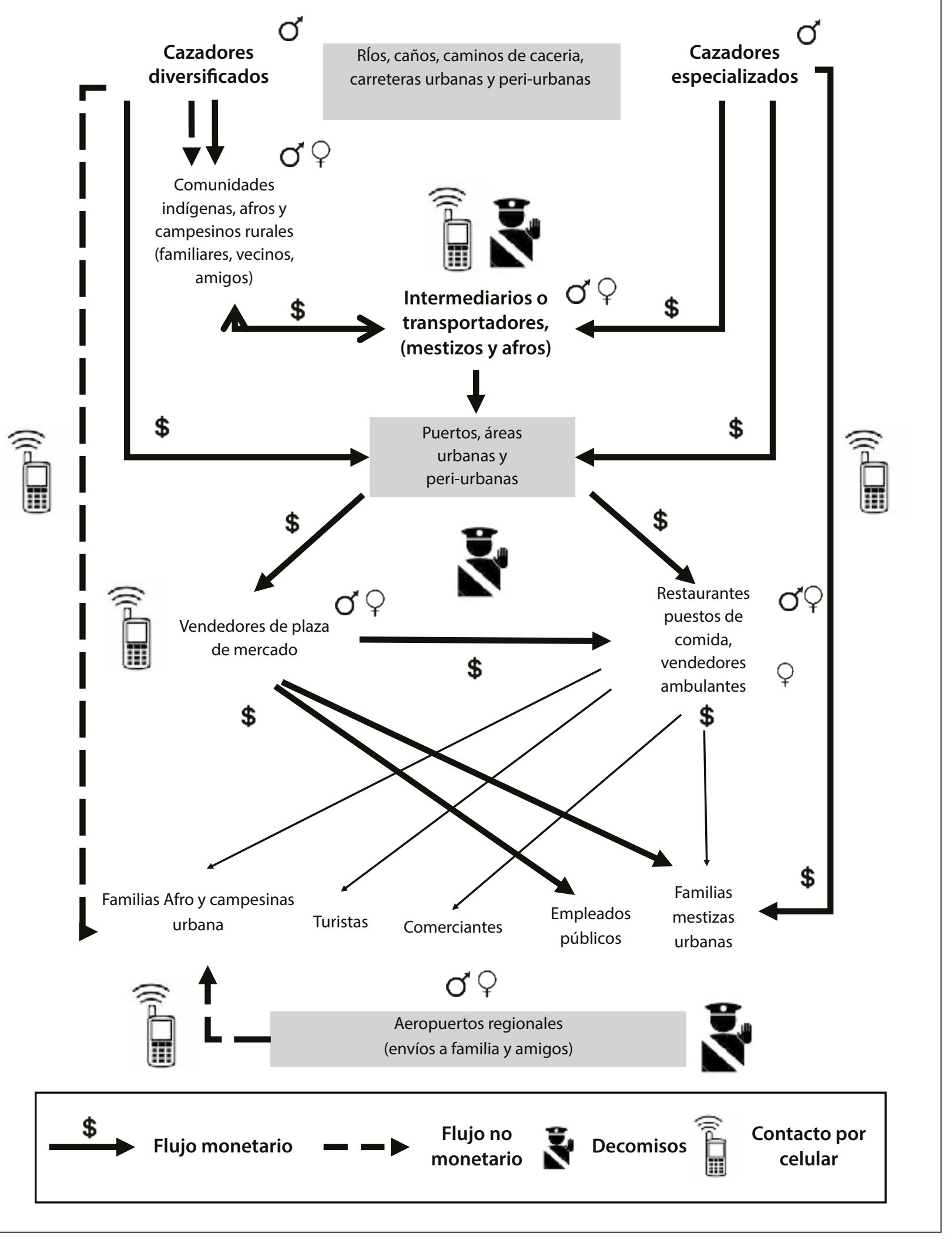

Figura 2. Cadena general de mercado de carne de monte en Colombia. 


\section{Composición de especies en la cadena de mercado de carne de monte}

Se reportaron un total de 85 especies

comercializadas en los municipios visitados en las cinco regiones de Colombia durante el tiempo de muestreo (Tabla 7). Aún es necesario verificar a nivel taxonómico las especies de patos, venados, palomas y tortugas principalmente.

\subsection{Región Amazónica}

En la región Amazónica, se reportaron 20 especies comercializadas durante el periodo de muestreo. Entre las más reportadas se encuentran la lapa o boruga, el venado sabanero y el venado rojo, la danta y el marrano de monte sin collar. La diversidad de especies comercializadas es menor en plazas de mercado y restaurantes, a diferencia de la gran variedad de especies consumidas dentro de las comunidades indígenas.

\subsection{Región Andina}

Para la región Andina, se encontraron 19 especies comercializadas. De ellas, el chigüiro, la boruga, el armadillo, el pato y la paloma silvestre son de especial importancia en Bogotá. También se reportó venta de tortugas pequeñas, tortuga morrocoy grande y cangrejos. De otro lado, la lapa, el gurre o armadillo, la guagua loba, el conejo y el ńeque se comercializan en la región Andina cafetera, generalmente por encargo, en plazas de mercado y con transportadores locales.

\subsection{Región Orinoquia}

En la región de la Orinoquia, la especie más importante para el comercio en los mercados es el chigüiro (Hydrochoerus hydrochaeris), bien sea seco (salado) o fresco. En verano, es factible conseguir venado (Mazama spp. I Odocoileus virginianus), lapa (Cuniculus paca) y

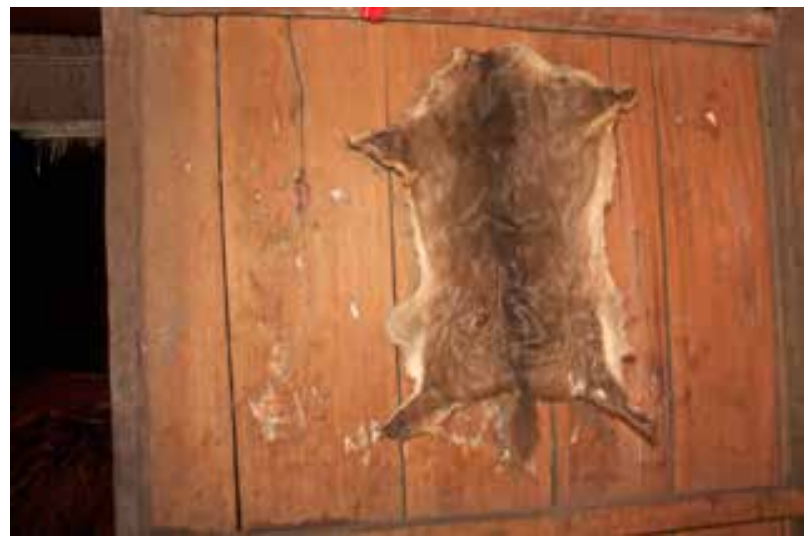

Piel de venado. Comunidad La Ceiba, Guainía. (Foto por Daniel Cruz)

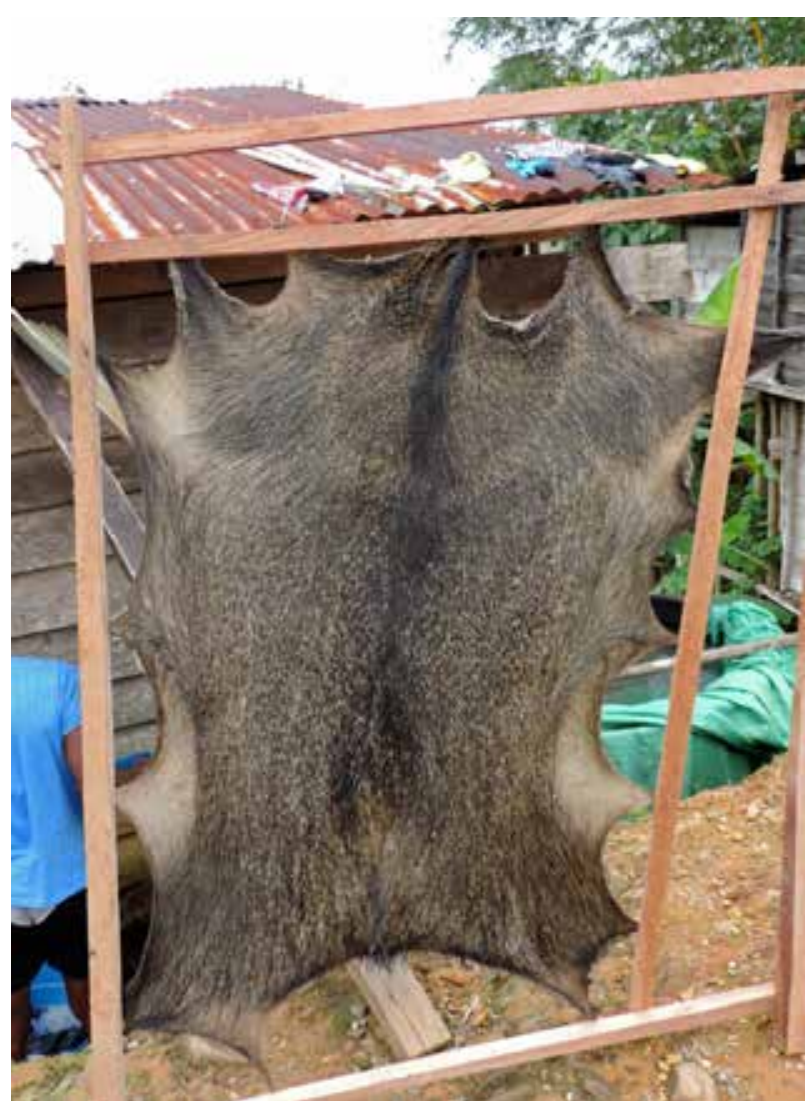

Piel de zaino. Yuto, El Atrato. Chocó. (Foto por Maria Paula Quiceno) 


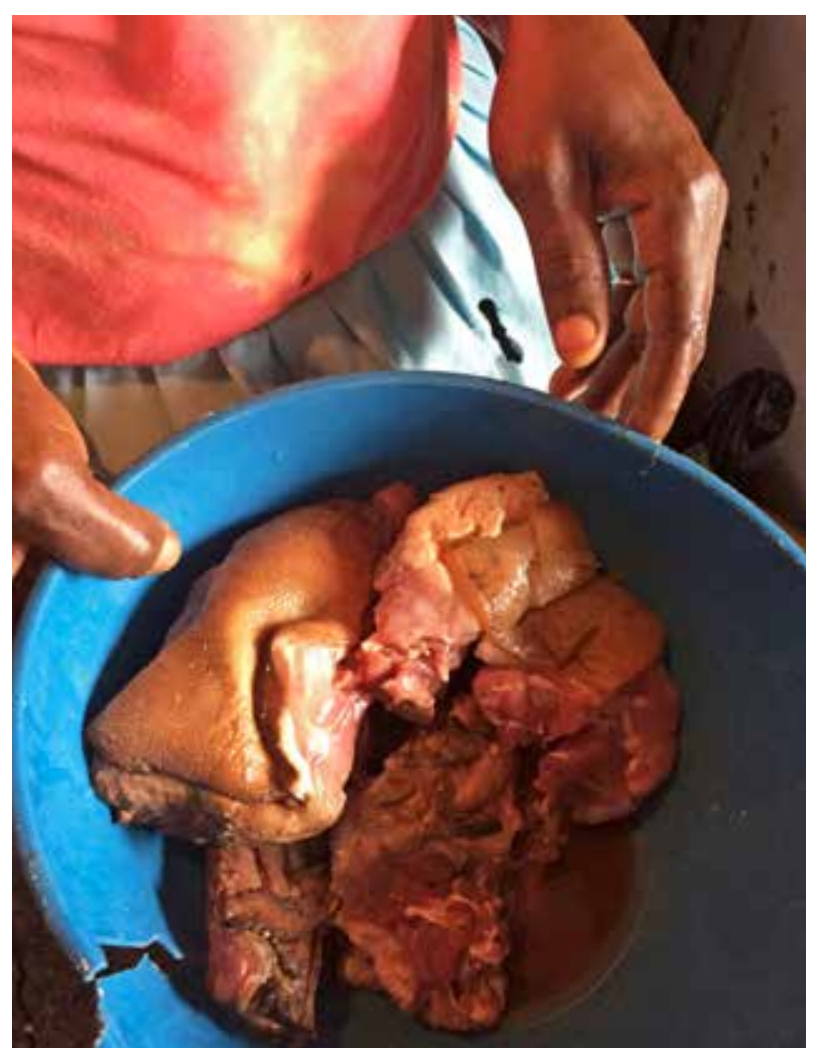

Carne de guartinaja. Quibdó, Chocó. (Foto por Maria Paula Quiceno)

armadillo (Priodontes maximus / Cabassous spp. I Dasypus spp.). El chigüiro figura como el favorito, seguido por el armadillo y la lapa, mientras que el venado se comercializa solo en caso de escasez de los anteriores.

\subsection{Región Caribe}

En la región Caribe visitada, se reportaron al menos 14 especies (según el nombre común) en los mercados. La guartinaja (Cuniculus paca) es la reportada más frecuentemente, seguida del venado (Mazama americana / Odocoileus virginianus) y el zaino (Pecari tajacu). El ponche o chigüiro (Hydrochoerus isthmius), el ñeque (Dasyprocta punctata), los armadillos y los conejos son de reporte esporádico.

\subsection{Región Pacífica}

Para la zona del Quibdó y sus alrededores, se encontraron 28 especies comercializadas. La favorita es la guagua, seguida del ńeque, el armadillo o

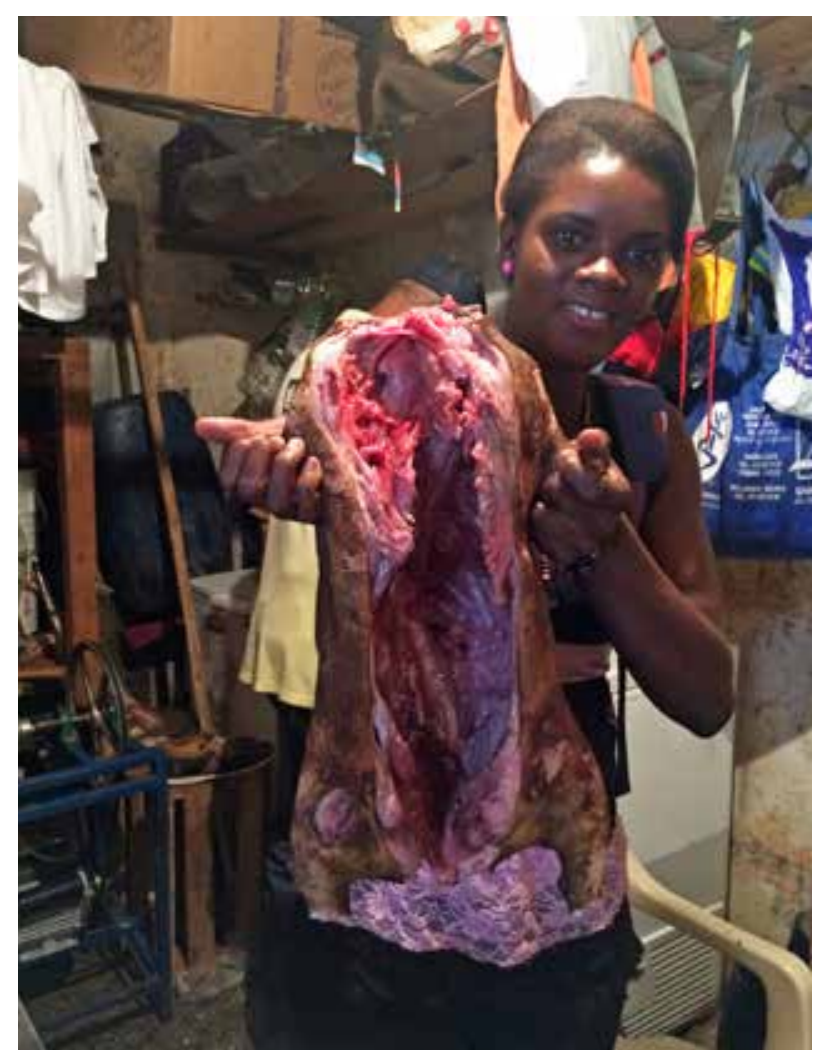

Guartinaja para la venta. Quibdó, Chocó. (Foto por Maria Paula Quiceno)

currundé, el venado, la babilla, el tatabro o zaino, y las tortugas de río (Figura 3). Raras veces se consiguen pavas (Odontophorus spp. / Crax spp.), patos silvestres (Anhinga sp. / Cairina sp.), osos hormigueros (Myrmecophaga tridactyla / Tamandua mexicana), ratones espinosos (Proechimys sp.) y zarigüeyas (Didelphis sp.), que son muy apetecidos pero escasos puesto que generalmente esta carne se queda en las comunidades.

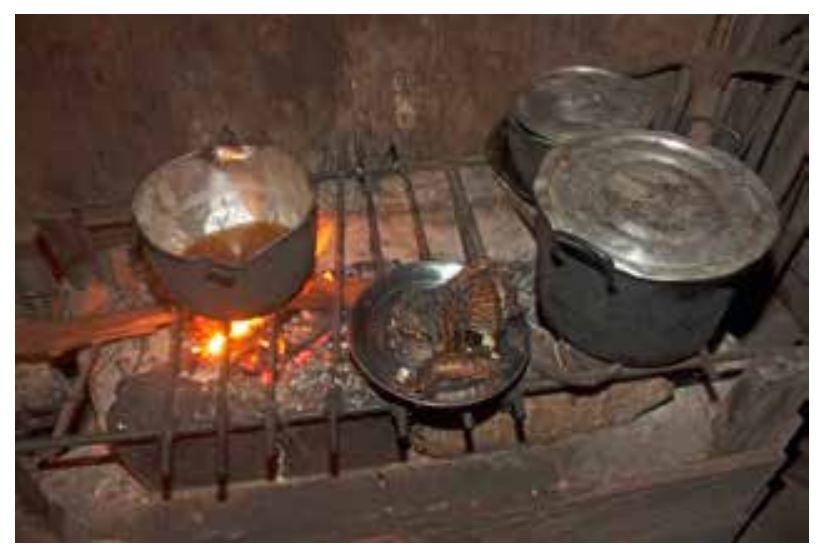

Babilla asada. Inírida Guainía. (Foto por Daniel Cruz) 
Tabla 7. Listado de fauna silvestre reportada en la cadena de mercado.

\begin{tabular}{|c|c|c|}
\hline Grupo & Nombre común & Nombre científico \\
\hline \multicolumn{3}{|l|}{ Amazónica } \\
\hline \multirow[t]{2}{*}{ Aves } & Paujil & Craxsp. \\
\hline & Pava & Penelope jacquacu \\
\hline \multirow[t]{14}{*}{ Mamíferos } & Araguato & Alouatta seniculus \\
\hline & Armadillo, cachicamo & Dasypus sp. \\
\hline & Armadillo trueno & Priodontes maximus \\
\hline & Boruga/lapa & Cuniculus paca \\
\hline & $\begin{array}{l}\text { Cajuche, marrano de monte, marrano de } \\
\text { labio blanco }\end{array}$ & Tayassu pecari \\
\hline & Chigüiro & Hydrochoerus hydrochaeris \\
\hline & Chocuto & Cacajao melanocephalus \\
\hline & Danta & Tapirus terrestris \\
\hline & Guara/picure & Dasyprocta fuliginosa \\
\hline & Venado de monte & Mazama gouazoubira / M. americana \\
\hline & Venado gris & Mazama gouazoubira \\
\hline & Venado rojo & Mazama americana \\
\hline & Venado sabanero & Odocoileus virginianus \\
\hline & Zaino & Pecari tajacu \\
\hline \multirow[t]{4}{*}{ Reptiles } & Babilla & Caiman crocodylus, Caiman crocodylus fuscus \\
\hline & Cachirre & Paleosuchus sp. \\
\hline & Morrocoy & Chelonoidis denticulata \\
\hline & Terecay & Podocnemis expansa \\
\hline \multicolumn{3}{|l|}{ Andina } \\
\hline \multirow[t]{8}{*}{ Aves } & Gansos & \\
\hline & Faisán & PHASIANIDAE \\
\hline & Palomas, torcazas & COLUMBIDAE \\
\hline & Pato moñudo & ANATIDAE \\
\hline & Pato silvestre & ANATIDAE \\
\hline & Pisco & ANSERIFORMES \\
\hline & Pavas & Penelope sp., Ortalis sp. \\
\hline & Pavo real & PHASIANIDAE \\
\hline Crustáceos & Crustáceos & Crustáceo \\
\hline \multirow[t]{8}{*}{ Mamíferos } & Ardilla & Sciurus sp., Microsciurus sp. \\
\hline & Armadillo & Dasypus sp., Cabassous unicinctus, Priodontes maximus \\
\hline & Chigüiro, lancho & Hydrochoerus hydrochaeris \\
\hline & Conejo & LEPORIDAE, Sylvilagus spp., Oryctolagus sp. \\
\hline & Guagua loba & Dinomys branickii \\
\hline & Gurre, armadillo & Dasypus novemcinctus \\
\hline & Lapa, guagua & Cuniculus paca \\
\hline & Picure, guatín & Dasyprocta punctata \\
\hline \multirow[t]{2}{*}{ Reptiles } & Tortuga morrocoy & Chelonoidis carbonaria, C. denticulata \\
\hline & Tortuga pequeña & $\begin{array}{l}\text { Chelonoidis denticulata, Trachemys scripta, } \\
\text { TESTUDINIDAE, EMYDIDAE }\end{array}$ \\
\hline
\end{tabular}


Tabla 7. Continuado

\begin{tabular}{|c|c|c|}
\hline Grupo & Nombre común & Nombre científico \\
\hline \multicolumn{3}{|l|}{ Orinoquia } \\
\hline \multirow[t]{4}{*}{ Mamíferos } & Cachicamo, armadillo & Dasypus spp., Cabassous unicinctus, Priodontes maximus \\
\hline & Chigüiro, capibara & Hydrochoerus hydrochaeris \\
\hline & Lapa & Cuniculus paca \\
\hline & Venado & Mazama spp., Odocoileus virginianus \\
\hline \multicolumn{3}{|l|}{ Caribe } \\
\hline \multirow[t]{3}{*}{ Aves } & Codornices & Subfamilia Odontoforinos \\
\hline & Palomas, torcazas & COLUMBIDAE \\
\hline & Pato pisingo & Dendrocygna autumnalis \\
\hline \multirow[t]{8}{*}{ Mamíferos } & Ardilla & Sciurus sp., Microsciurus sp. \\
\hline & Armadillo & Cabassous centralis, Dasypus novemcinctus \\
\hline & Conejo & LEPORIDAE, Sylvilagus spp., Oryctolagus sp. \\
\hline & Guartinaja & Cuniculus paca \\
\hline & Neque, picure, guatín & Dasyprocta punctata \\
\hline & Ponche, cacó & Hydrochoerus isthmius \\
\hline & Venado & Mazama americana, Odocoileus virginianus \\
\hline & Zaino & Pecari tajacu \\
\hline \multirow[t]{3}{*}{ Reptiles } & Tortuga hicotea & Trachemys callirostris, Rhinoclemmys melanosterna \\
\hline & Tortuga marina & $\begin{array}{l}\text { Eretmochelys imbricata, Caretta caretta, Chelonia } \\
\text { mydas, Dermochelys coriacea, Lepidochelys olivacea }\end{array}$ \\
\hline & Tortuga morrocoy, morrocoya & Chelonoidis carbonaria \\
\hline \multicolumn{3}{|l|}{ Pacífica } \\
\hline \multirow[t]{8}{*}{ Aves } & Loros & PSITTACIDAE, Amazona spp., Aratinga spp. \\
\hline & Pato silvestre & ANATIDAE \\
\hline & Pava de pescuezo rojo & Penelope ortoni \\
\hline & Pavas & Odontophorus spp. \\
\hline & Pavón & Crax rubra \\
\hline & Pavón picoamarillo & Crax daubentoni \\
\hline & Perdiz & Crypturellus sp., Tinamus sp. \\
\hline & Tucán grande, paletón & $\begin{array}{l}\text { Pteroglossus sanguineus, Ramphastos swainsonii, } \\
\text { Ramphastos brevis }\end{array}$ \\
\hline \multirow[t]{13}{*}{ Mamíferos } & Armadillo, colaetrapo, colapelua & Cabassous centralis \\
\hline & Armadillo, currunde & Dasypus novemcinctus, Cabassous centralis \\
\hline & Cajuche, marrano de monte, tatabro & Tayassu pecari \\
\hline & Chigüiro, capibara & Hydrochoerus isthmius \\
\hline & Guagua & Cuniculus paca \\
\hline & Ñeque, picure, guatín & Dasyprocta punctata \\
\hline & Oso hormiguero & Tamandua mexicana, Myrmecophaga tridactyla \\
\hline & Ratones & MURIDAE \\
\hline & Tigre & Panthera onca \\
\hline & Venado & Mazama americana, Odocoileus virginianus \\
\hline & Venado rojo & Odocoileus virginianus; Mazama americana \\
\hline & Venado sabanero & Odocoileus virginianus \\
\hline & Zaino, tatabro & Pecari tajacu \\
\hline
\end{tabular}


Tabla 7. Continuado

\begin{tabular}{lll}
\hline Grupo & Nombre común & Nombre científico \\
\hline Reptiles & Babilla & Caiman crocodylus, Caiman crocodylus fuscus \\
& Bache, guachara, bacharo pimpano & Chelydra serpentina acutirostris \\
& Kinosternon dunni \\
& Tortuga & Lepidochelys olivacea, Chelonia agassizii, Dermochelys \\
& coriacea, Trachemys scripta, Rhinoclemmys spp., \\
& Kinosternon dunni, Eretmochelys imbricata \\
& Rhinoclemys nasuta, R. melanosterna, Trachemys \\
& scripta, Kinosternon dunni \\
& Tortugas de río & Trachemys scripta, Rhinoclemmys melanosterna, $R$. \\
& nasuta \\
& Rhinoclemys nasuta \\
\hline
\end{tabular}

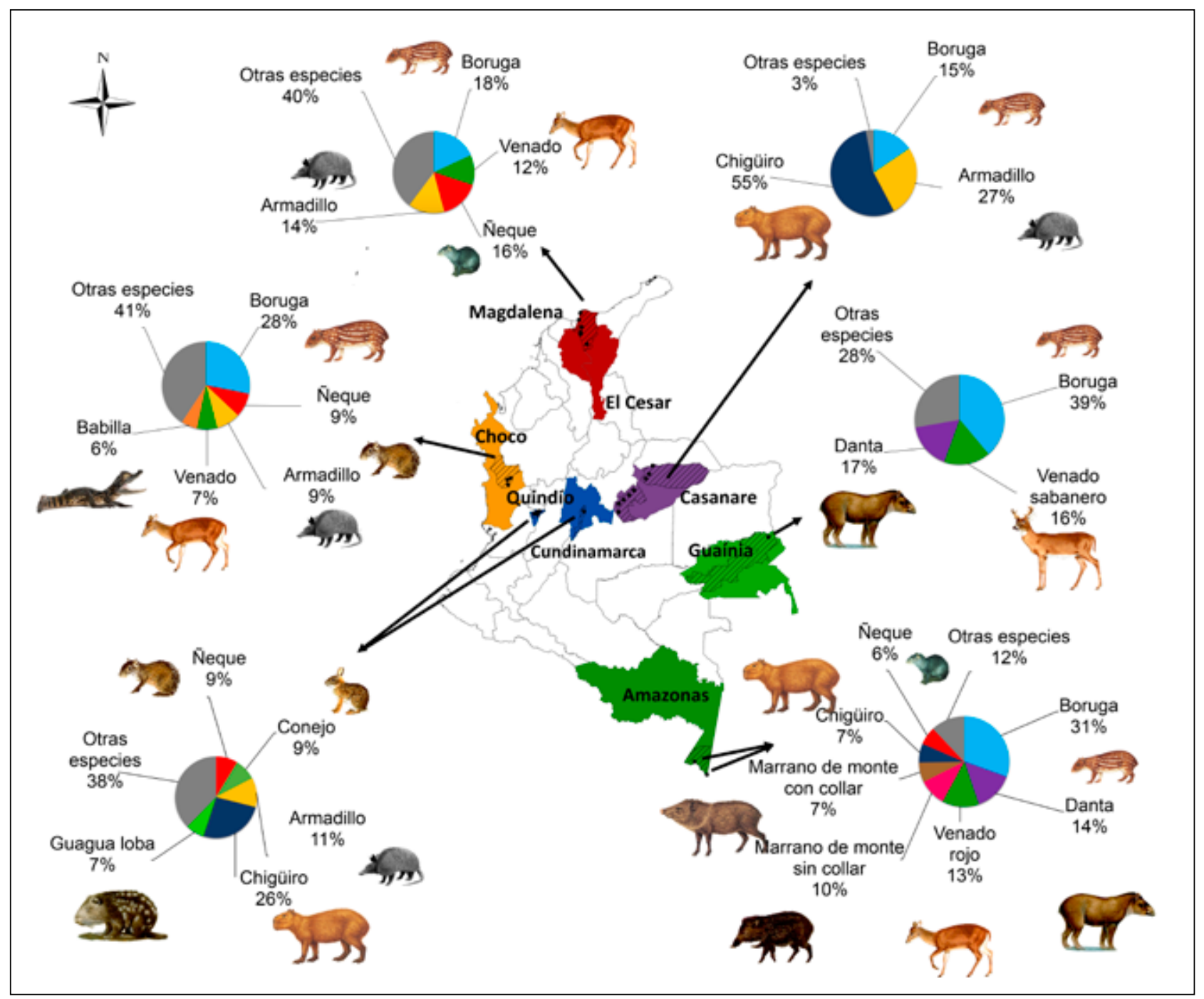

Figura 3. Especies representativas consumidas por región. 


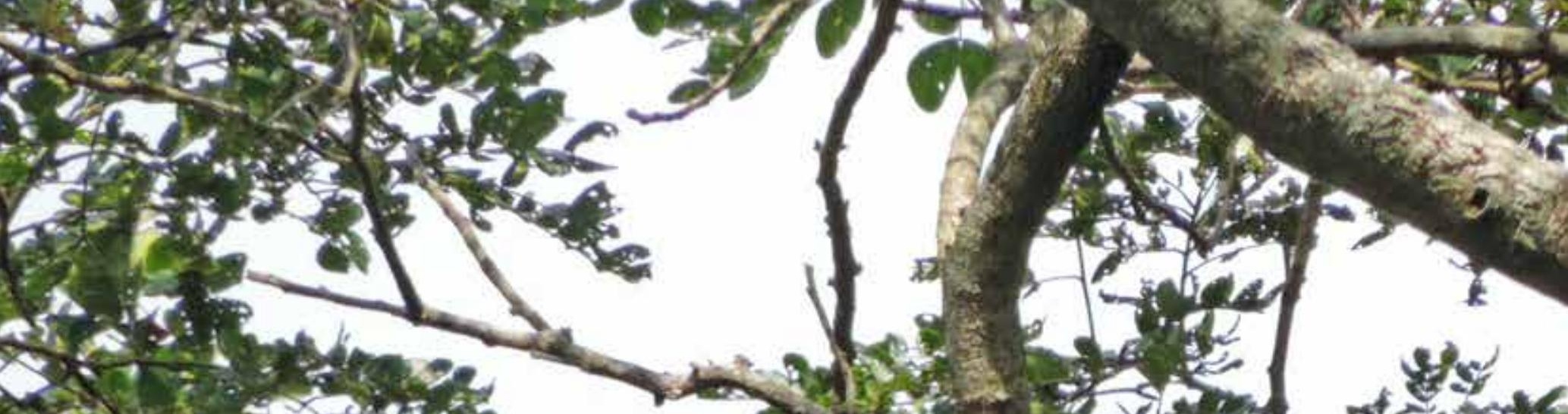

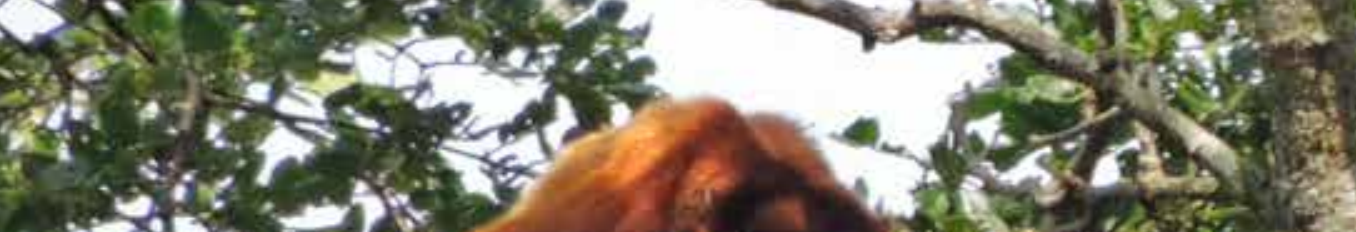

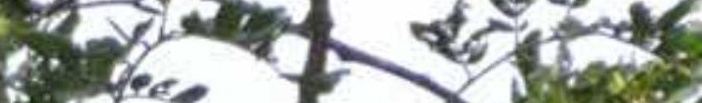
$+x^{2}-1$

x. 1 th

$26 \frac{12}{6}$

$\frac{2}{8}$

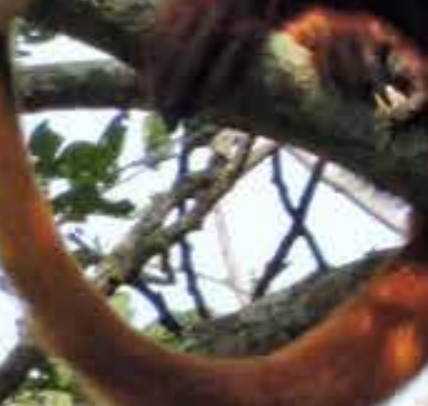

(a)

2523 s. Ander.

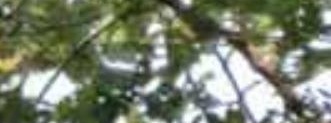

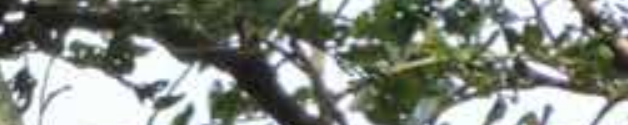

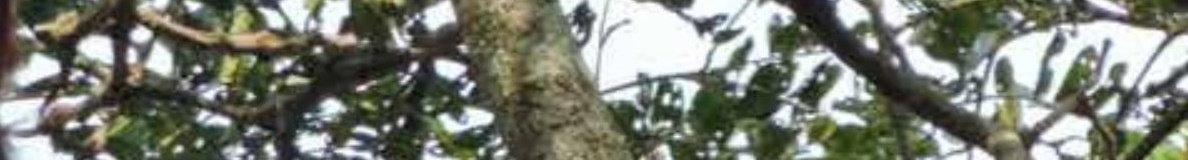
20. \%
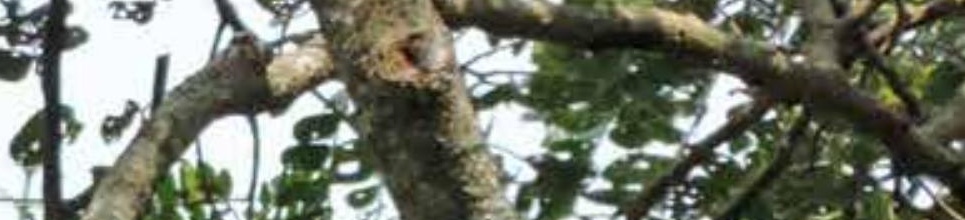

(2) D. 2 (2)

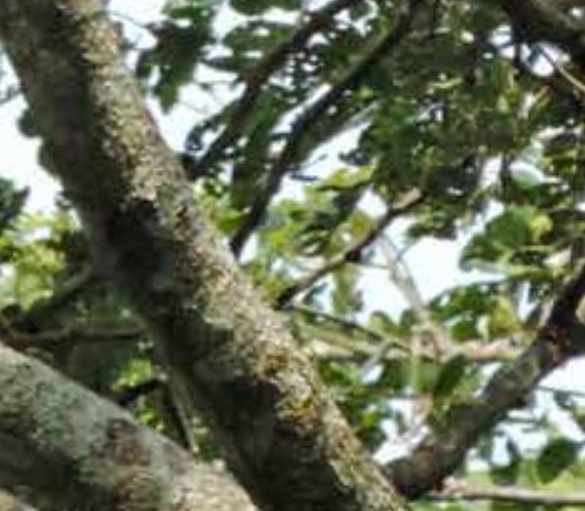

iosity

ted

A

(3)

2

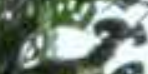

te.

1.

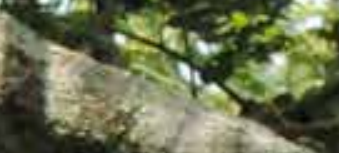

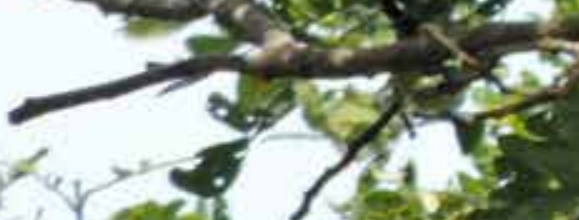

$+18$

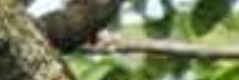
a. 1.

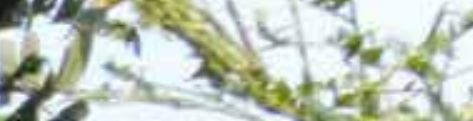

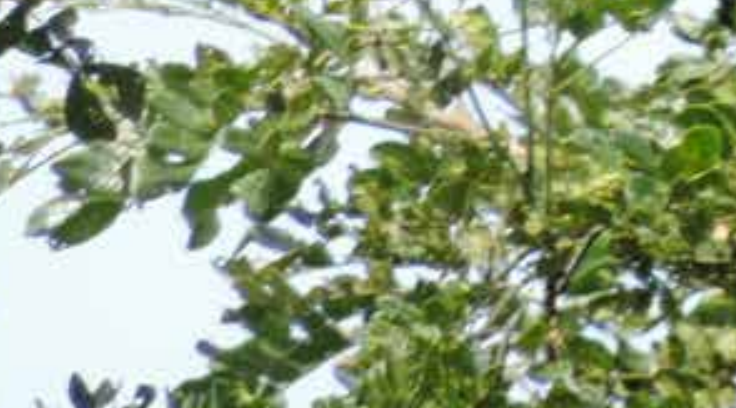

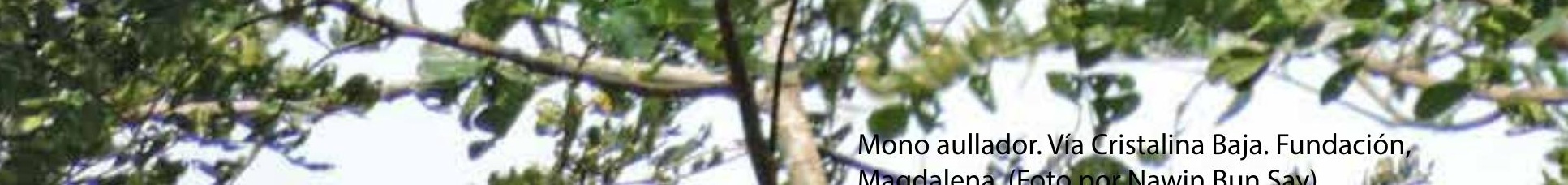
(1) $2 x$ $12 x^{2}$ 


\section{Áreas de captación y rutas de comercio}

Los flujos de carne de monte son determinados por la finalidad de su aprovechamiento. En el caso de la caza de subsistencia, la carne fluye a través de rutas cortas, desde el bosque directamente a la casa del cazador, sus vecinos y familiares en el interior de las comunidades rurales. Cuando los flujos de mercado implican distancias que requieren recorridos de $2 \mathrm{a}$ 3 horas, se seleccionan las especies con mejor valor comercial para la venta y se las transporta hacia los principales centros urbanos a través de caños, ríos, carreteras periurbanas y urbanas, usando una gran variedad de medios de transporte, entre ellos balsas, botes, motocicletas, bicicletas, automóviles, camperos, buses públicos, mulas y camiones.

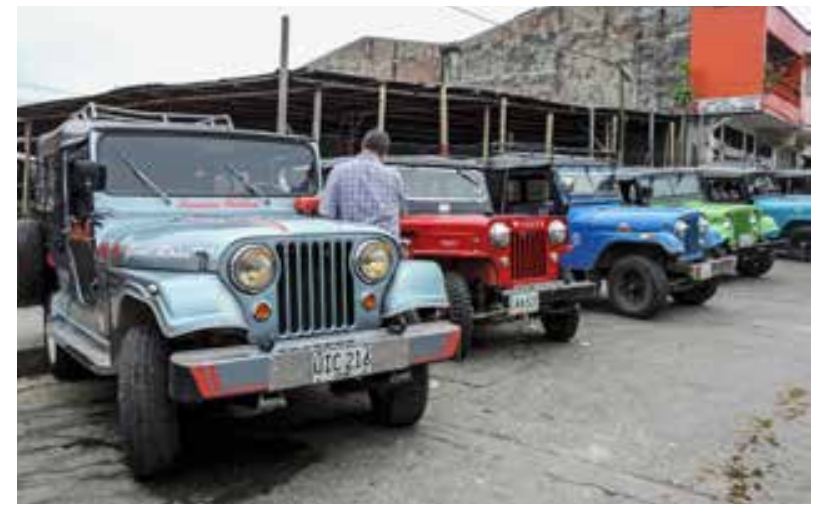

Camperos en plaza de mercado. Circasia, Quindío. (Foto por Eliceo Matapi Yucuna)

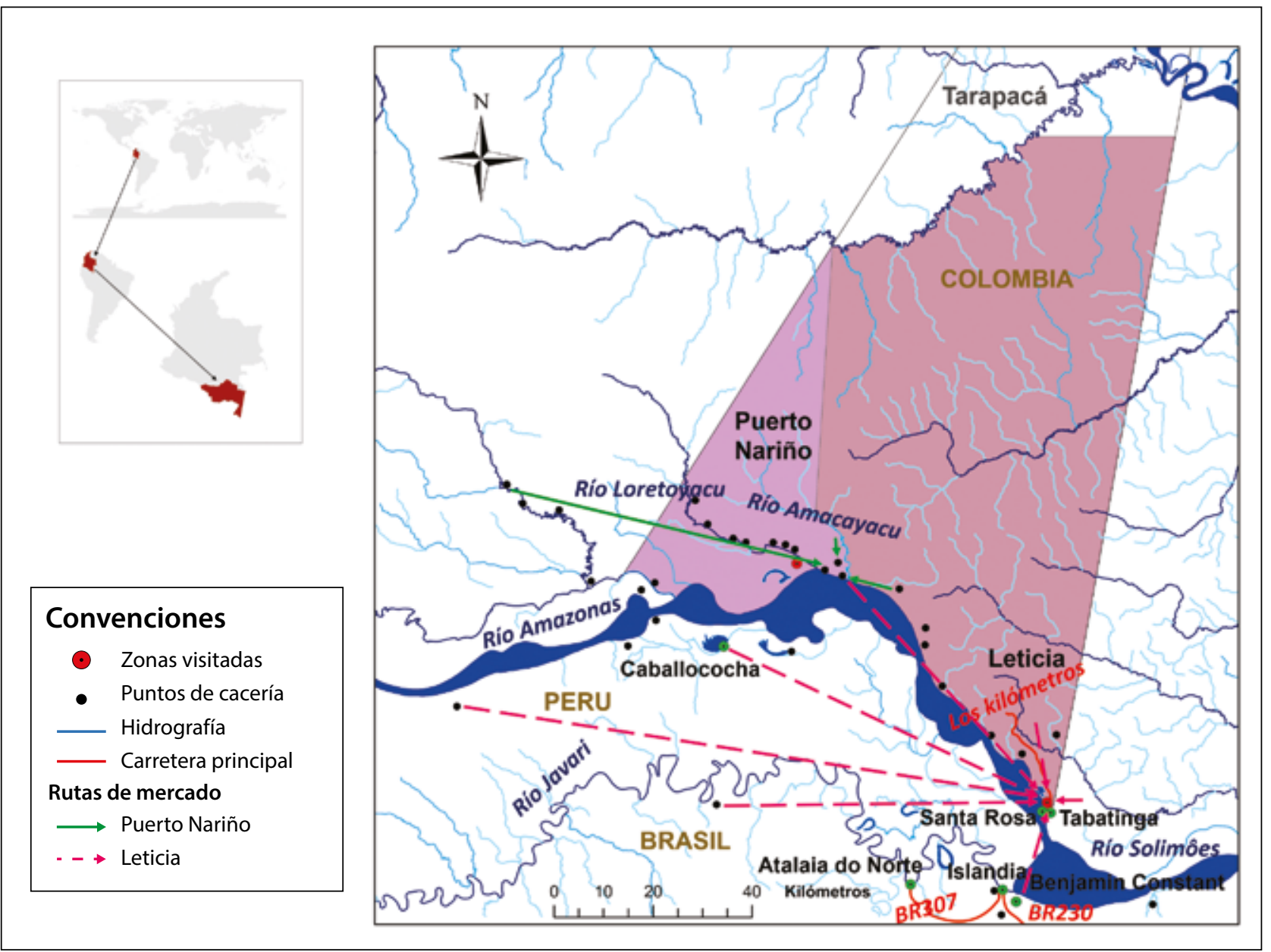

Figura 4. Mapa de rutas de comercio de carne de monte en Leticia y Puerto Nariño. 
Como se observa a continuación, en todos los sitios visitados (a excepción de Bogotá D. C.), el comercio de carne de monte se da en cadenas cortas y localizadas dentro de los departamentos, donde la carne se mueve de las regiones rurales de los municipios hacia los centros poblados más cercanos (Figuras 4-8). En el caso de Bogotá, la carne de monte que se comercializa proviene de diferentes regiones del país y comprende la cadena más larga de este comercio.

\subsection{Región Amazónica}

En Leticia, la carne de monte proviene principalmente de comunidades peruanas ubicadas a lo largo de los ríos Javarí y Amazonas, tales como San Pablo, Caballococha y Santa Rosa. Por el lado colombiano, proviene de comunidades a lo largo del río Amazonas o de las áreas periurbanas de Los Kilómetros. También es común que la carne

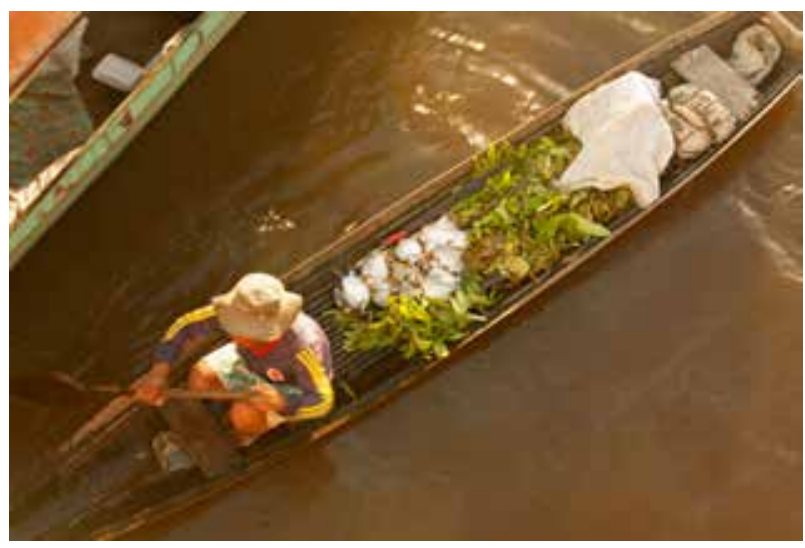

Bote por el río Inírida. Guaínia. (Foto por Daniel Cruz)

de monte llegue desde la parte brasileña del río Javarí. En el caso de Puerto Nariño, los cazadores traen la carne de monte de áreas de cacería asociadas a los ríos Loretoyacu y Amacayacu, además de las áreas de humedal de los lagos de Tarapoto (Figura 4).

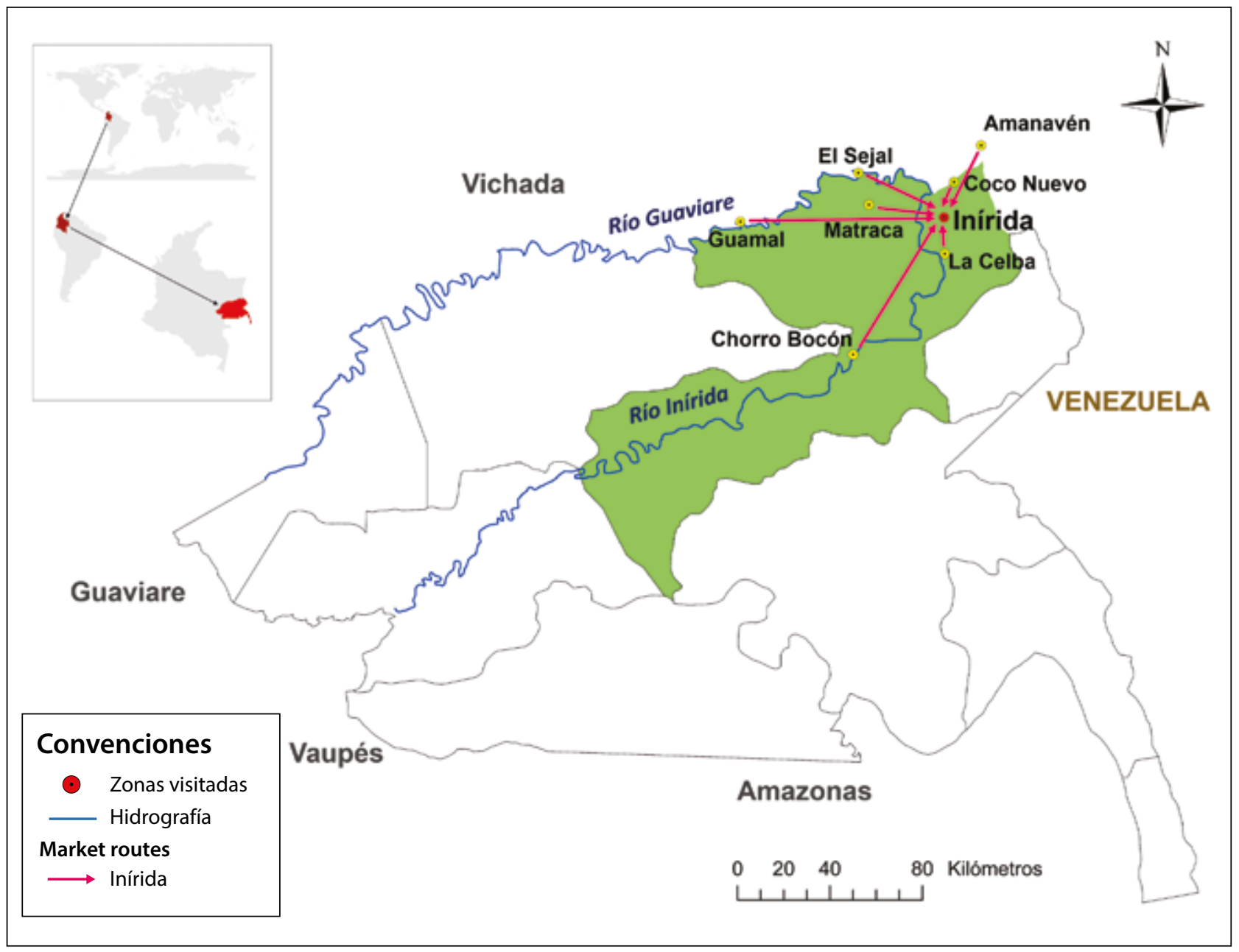

Figura 5. Mapa de rutas de comercio de carne de monte en Inírida, Guainía. 


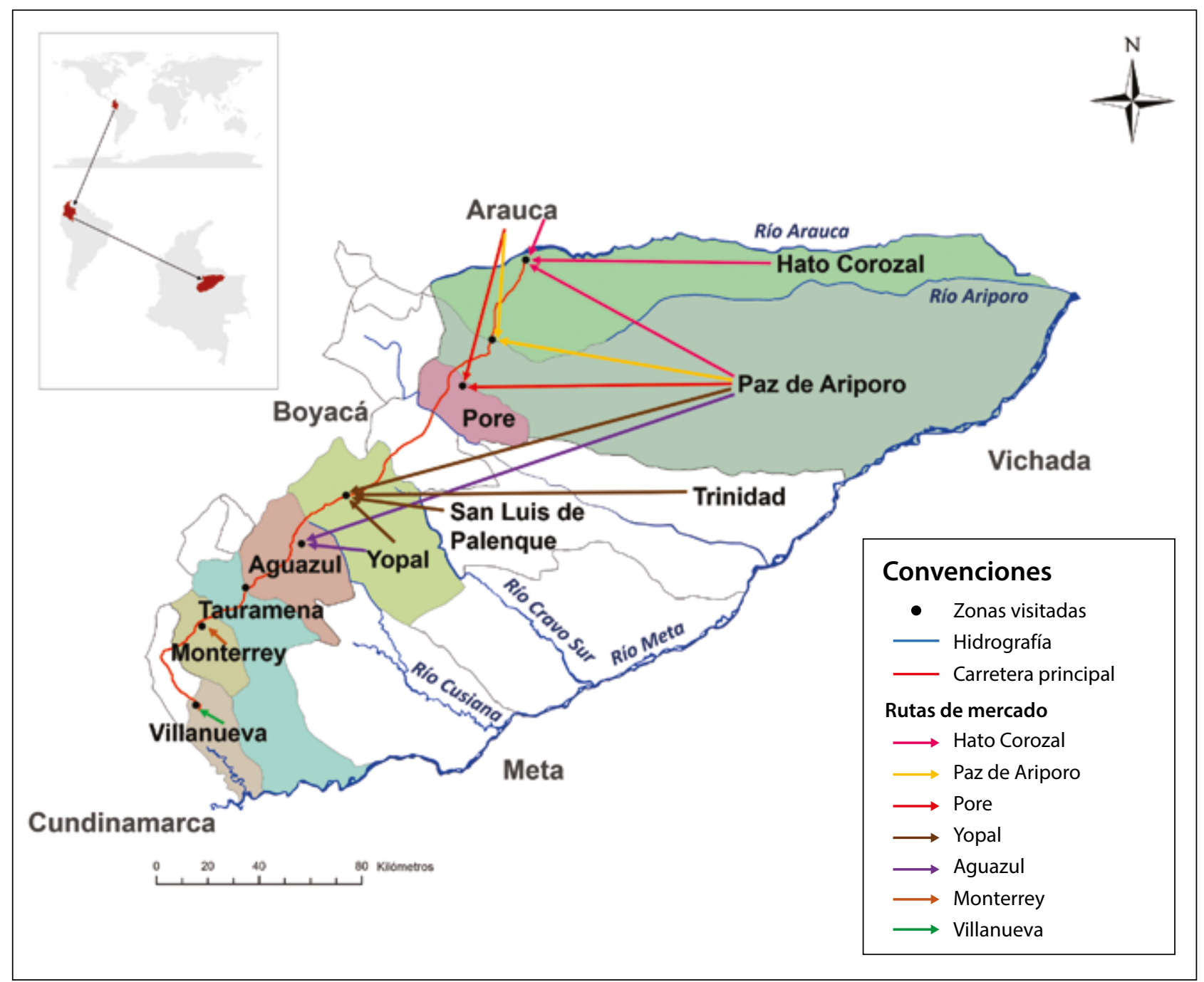

Figura 6. Mapa de rutas de comercio de carne de monte en los municipios de Villanueva, Monterrey, Tauramena, Aguazul, Yopal, Pore, Paz de Ariporo y Hato Corozal (Casanare).

En Inírida, la carne de monte es principalmente consumida en el interior de las comunidades en las áreas de resguardo indígena. Los restaurantes y familias urbanas indígenas y no indígenas de Inírida se proveen de carne silvestre proveniente principalmente de las áreas periurbanas y rurales cercanas de Coco Viejo, El Paujil, Sabanita, Guamal, Caño Vitina y Cunuven, así como de comunidades asentadas a lo largo del río Guaviare (Carrizal, Laguna Cacao, Amanavén, Maviso y Coayare) y del río Inírida (Almidón, Matraca, El Venado, La Ceiba, Caranacoa y Chorrobocón) (Figura 5).

En general, la carne de monte fluye mediante pedidos a través del teléfono celular o a partir de conversaciones en el pueblo, en las que los clientes o familiares la encargan a los cazadores para su próxima visita a Inírida. Existen intermediarios que viajan a lo largo del río comprando una gran variedad de productos en las comunidades, incluyendo carne de monte, que luego ofrecen en los restaurantes o en casas de familia, donde es posible encontrar venta de carne entre vecinos y familiares.

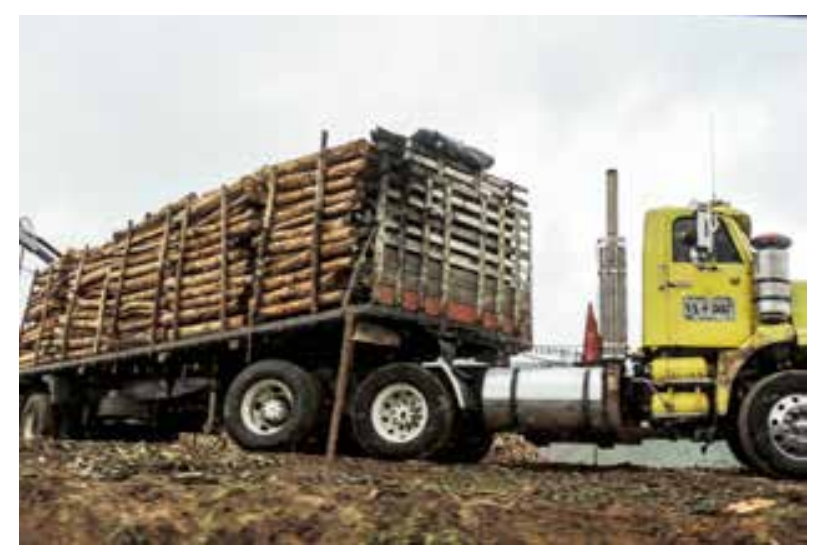

Vía Boquía - Salento. Quindío. (Foto por Eliceo Matapi Yucuna) 


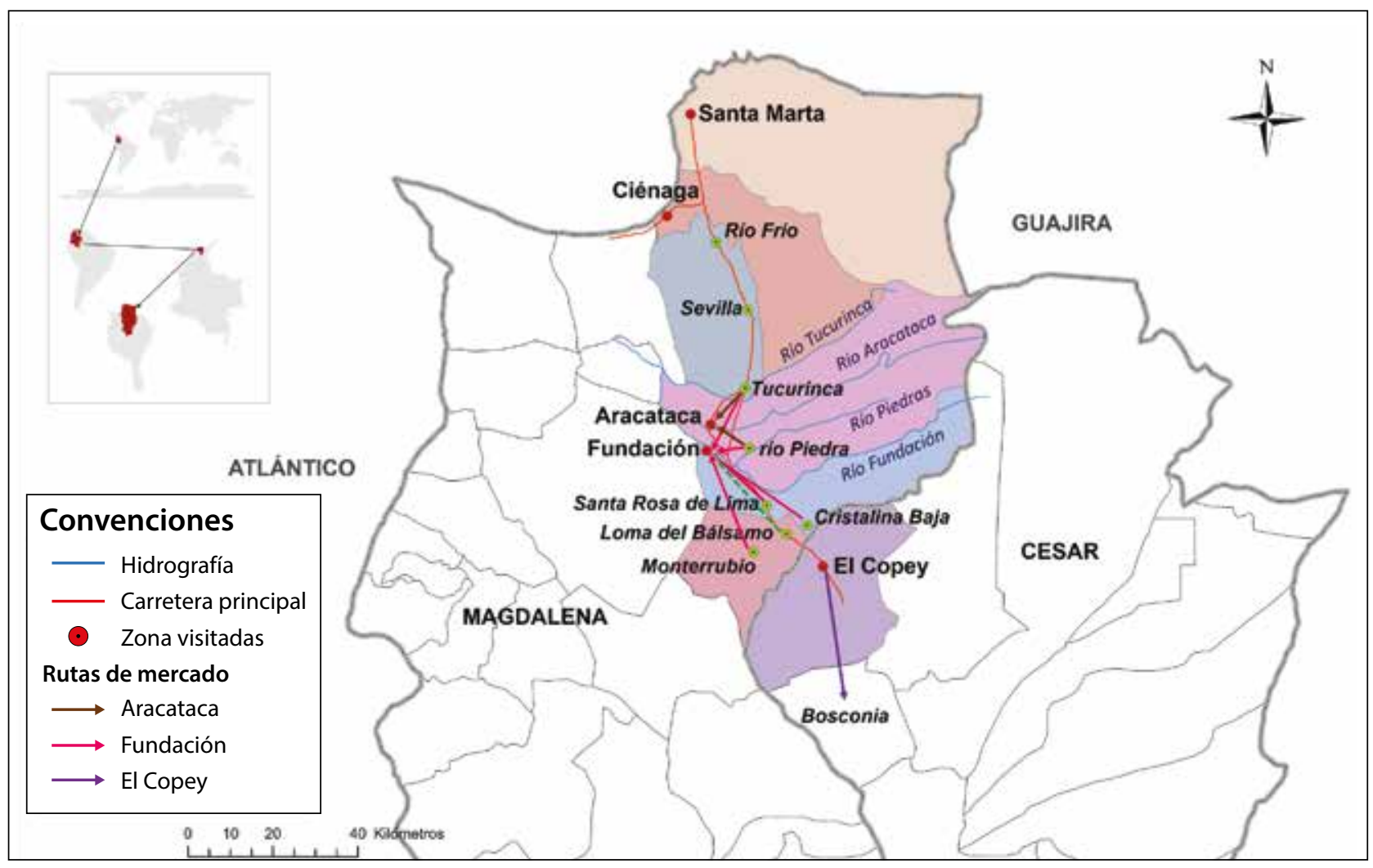

Figura 7. Mapa de rutas de comercio de carne de monte de los municipios de Santa Marta, Ciénaga, Aracataca y Fundación (Magdalena), y El Copey (Cesar).

\subsection{Región Andina}

En la Zona Cafetera andina no existe una cadena de mercado como tal. La carne de monte transita en los "yipaos" $\sin$ pasar por plazas de mercado y se entrega directamente a la familia que la encargó, o se intercambia por otros productos a cambio de la cacería de control del cultivo, principalmente en Circasia y Montenegro, desde donde se conecta con las vías al Valle del Cauca.

En Bogotá, el encargo de la carne de monte en las plazas de mercado se hace con anticipación, y esta se lleva normalmente a través de contactos y transportadores desde regiones aledańas al valle del Magdalena (Melgar, Girardot, Espinal) o los Llanos Orientales (Meta). La carne de chigüiro suele llegar desde diferentes regiones del país, principalmente de la Orinoquia, con los transportadores y entre el pescado, ya que así se puede mantener refrigerada y escondida. También llega carne de monte congelada dentro de neveras con pescado desde las regiones Amazónica y Pacífica, a través de envíos a familiares indígenas o como remesa a los hijos de colonos que estudian en la ciudad. Las áreas

6 Tipo de camperos usados en la zona cafetera para transportar los bultos de café principalmente.

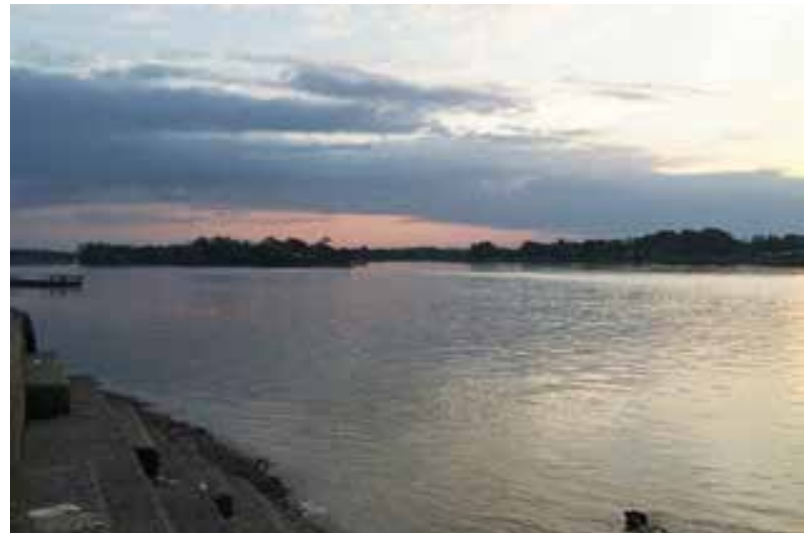

Confluencia ríos Quito y Atrato. Quibdó, Chocó. (Foto por Maria Paula Quiceno)

con complejos de humedales alrededor de Bogotá proveen algunas aves que no son vendidas en las plazas de mercado, sino consumidas directamente en los barrios periféricos al humedal.

\subsection{Región Orinoquia}

En la región Orinoquia visitada, los vendedores obtienen la carne de monte a través del contacto directo con cazadores amigos y familiares dueños o trabajadores de predios y fincas en las sabanas 


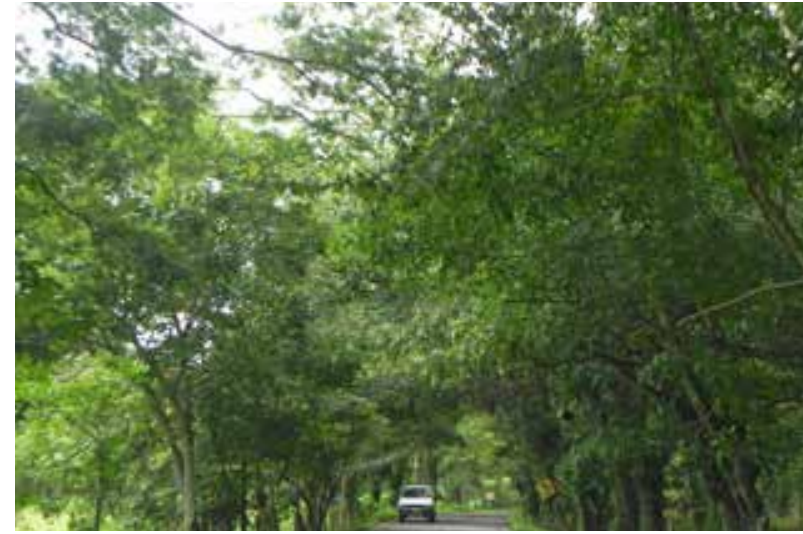

Vía Samán del río. Yopal, Casanare. (Foto por Jessica Moreno)

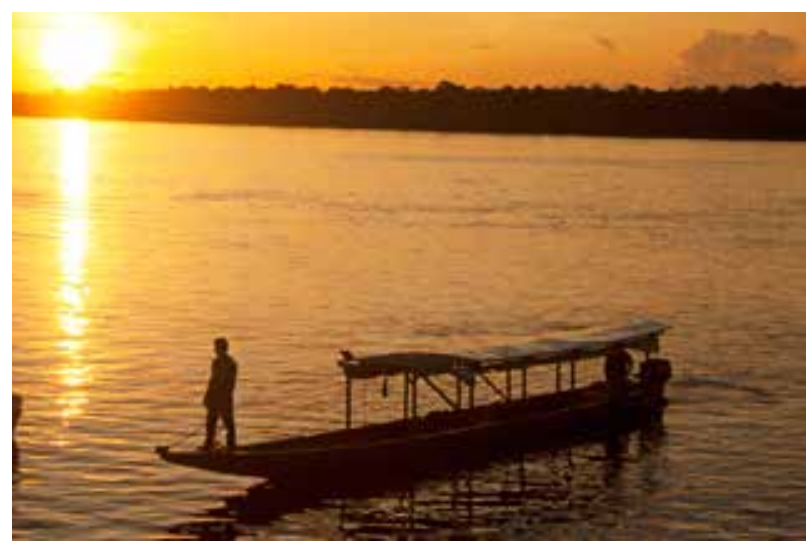

Atardecer río Inírida. Guainía. (Foto por Daniel Cruz)

de los municipios de Trinidad, San Luis y Paz de Ariporo, quienes siempre tienen carne de monte para la venta, ya que la marisca es escasa en los alrededores de las principales ciudades (Figura 6).

En el departamento del Casanare, los restaurantes $\mathrm{y}$ asaderos donde se vende carne de monte, en las inmediaciones de Yopal, Monterrey, Paz de Ariporo y Pore, obtienen la carne en las fincas, con los dueños o con los cazadores que cuidan los hatos y se encargan de su distribución. Desde Hato Corozal también se envía carne de monte hasta Sogamoso, en Boyacá, en taxis con remesas de pescado y víveres de la región (Figura 6).

\subsection{Región Caribe}

Las zonas visitadas en la región Caribe se abastecen de carne de monte principalmente de las estribaciones de la Sierra Nevada. Los

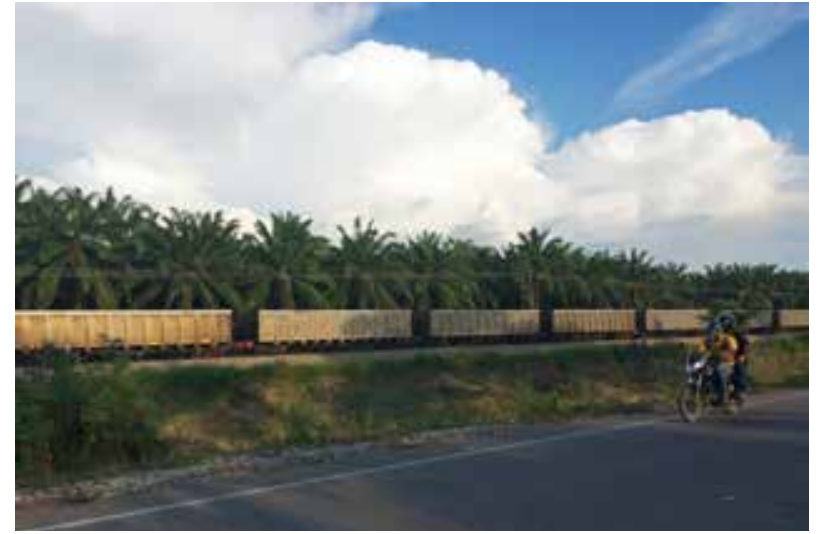

Tren con carbón. Vía Fundación, Magdalena. (Foto por Maria Paula Quiceno)

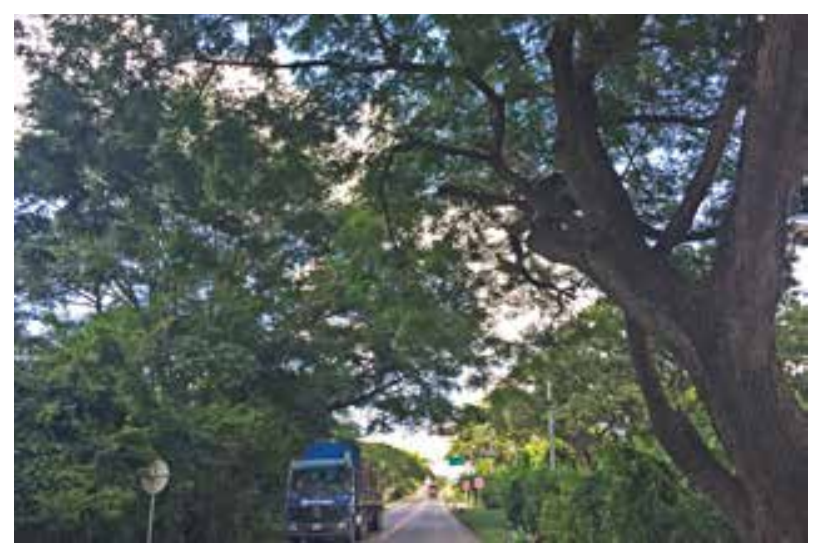

Vía Tucurinca, Magdalena. (Foto por Maria Paula Quiceno)

restaurantes reciben la carne directamente de cazadores conocidos, que pueden ser indígenas o afrodescendientes, quienes cazan especialmente en la temporada baja de la cosecha de café. Según reportan los restaurantes, la oferta de carne de monte disminuye drásticamente entre septiembre y diciembre, temporada en la cual los cazadores están recogiendo café en la Sierra Nevada. En dichos meses, los restaurantes buscan cazadores y transportadores intermunicipales para obtener la carne de monte. En esta zona, los transportadores llevan víveres y encargos, por la vía hacia Santa Marta desde Fundación y desde El Copey hacia Bosconia en el Cesar. También a las veredas aledañas en distancias de 2 a 3 horas, como Cristalina Baja, Santa Rosa de Lima y Tucurinca, donde hay sitios de cacería; desde allí, los transportadores recogen la carne de monte junto con leche, huevos y gallinas criollas (Figura 7). 


\subsection{Región Pacífica}

En Quibdó, la carne de monte fresca llega al puerto desde Munguidó por el río Atrato; desde Samurindo y Dońa Josefa por el río Quito; y desde Tutunendo a Quibdó por carretera a 2 o 3 horas de recorrido desde los resguardos y territorios colectivos. Quibdó cuenta con tres puertos de entrada, de los cuales el principal, al pie de la plaza de mercado, es el sitio de descargue de plátano y de carne de monte. La carne de monte que llega ahumada sigue un recorrido de más de 5 horas por río desde áreas como San Antonio de Padua, cerca de la frontera con el departamento de Antioquia. Mucha de la carne de monte es comprada allí por consumidores e intermediarios de Antioquia y, dada la distancia, no va al mercado de Quibdó. Cuando la carne se envía a Quibdó, va en lancha rápida para evitar que se dañe, o se envía ahumada. Lo mismo sucede con la carne que se caza cerca a la salida hacia el departamento de Risaralda. Allí, los transportadores que traen huevos y pollo congelado compran la carne de monte para llevarla a sus casas o para revenderla en los restaurantes donde suelen parar a pasar la noche durante las jornadas de viaje (Figura 8).

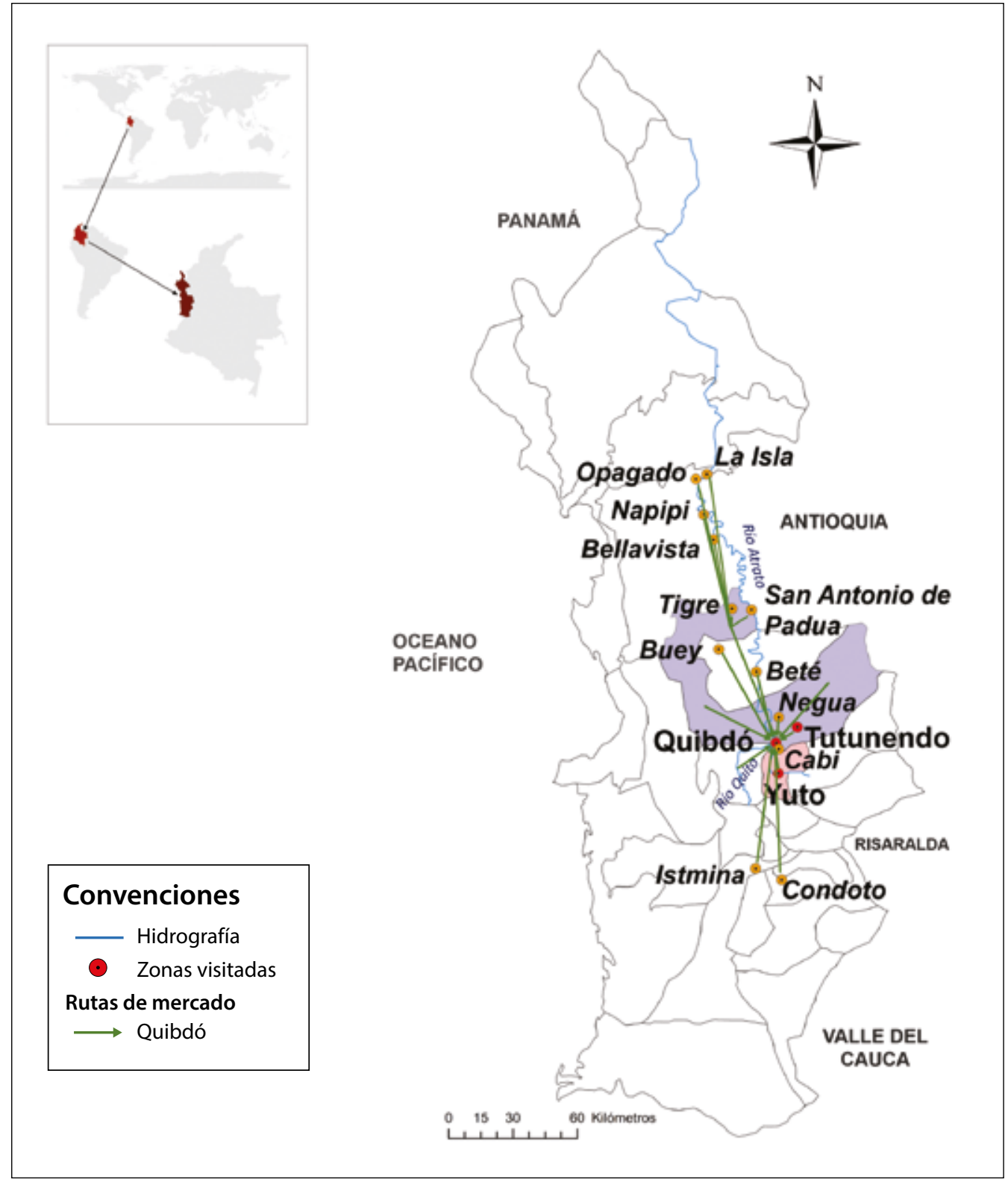

Figura 8. Mapa de rutas de comercio de carne de monte en los corregimientos de Quibdó y Tutunendo, en Quibdó, y en el corregimiento de Yuto, en El Atrato (Chocó). 


\section{Precios de compra y venta de la carne de monte}

La carne de monte muestra una alta variación de precios en un gradiente que va desde las zonas rurales hasta las zonas urbanas. El precio parece estar mediado por los controles ambientales y la preferencia de los clientes con poder adquisitivo por los diversos tipos de carne de monte (Tabla 8).

En las zonas rurales y periurbanas visitadas, la carne de monte se considera una opción básica para el sustento de las comunidades, cuya finalidad principal es el autosustento o la provisión de alimentos al núcleo familiar. Los cazadores venden pavas, armadillos pequeños y ñeques en los restaurantes y puestos de comida de los poblados pequeños. De igual manera, los niños venden palomas, algunas aves como el paletón o tucán, ardillas y conejos en los restaurantes informales y puestos de comida de los caseríos y poblados rurales, después de dejar parte de lo cazado en sus casas para el autoconsumo. En estos lugares, los precios varían entre COP 2.000 (USD 1) y COP 6.000 (USD 2,5) por kilogramo de carne como máximo (Anexo 2).

Cuando se trata de especies con demanda en el mercado urbano, tales como la guagua o boruga (C. paca), el chigüiro (Hydrochoerus sp.), los

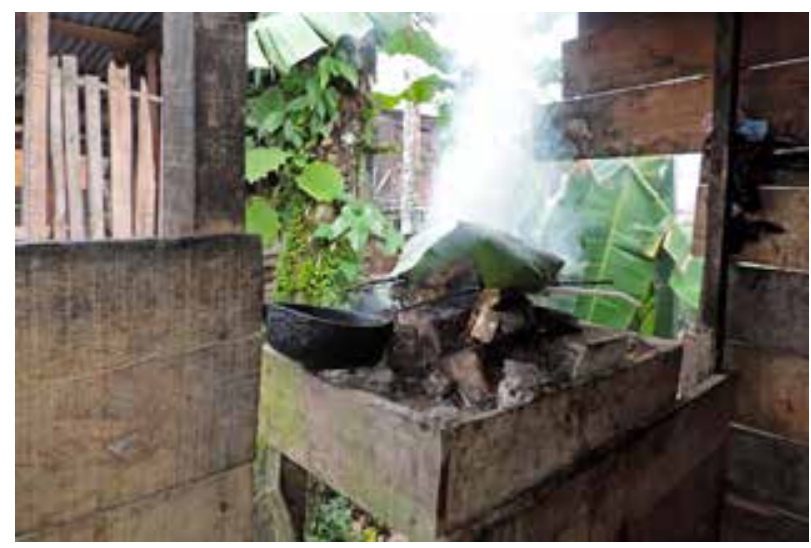

Carne de monte asada. Rio Quito, Chocó. (Foto por Maria Paula Quiceno) marranos de monte (T. pecari y $P$. tajacu), el venado (Mazama spp. y Odocoileus virginianus) y las tortugas (tanto marinas como morrocoy, terecaya, hicotea y bacha), los cazadores prefieren desplazarse al mercado y vender la carne entre sus contactos casi al doble del precio local por cada kilogramo de estas especies, pues vale la pena el riesgo por el margen de ganancia. En ocasiones, los intermediarios son quienes obtienen esta ganancia y recogen grandes cantidades de carne de monte para que valgan la pena el costo y la evasión de los controles.

De otro lado, en los centros urbanos visitados, la carne de monte es considerada una carne de lujo, bien sea por el sabor, por el gusto especial que se le reconoce, o porque es una alternativa natural a la carne de res, de cerdo y de pollo que se produce o llega hasta cada región, aun cuando los precios de estas alternativas comparativamente se encuentren por encima o por debajo del precio de la carne de monte.

En la región Amazónica, por ejemplo, la carne de res cuesta COP 13.000/kg (USD 5,5); y la de pollo, COP $6.500 / \mathrm{kg}$ (USD 2,8); en comparación, la carne de monte cuesta en

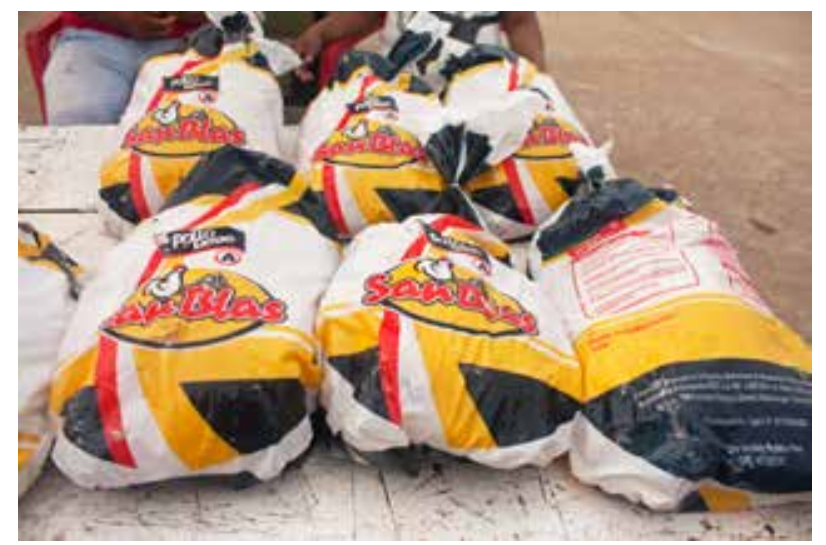

Pollo proveniente de Venezuela. Inírida Guainía. (Foto por Daniel Cruz) 


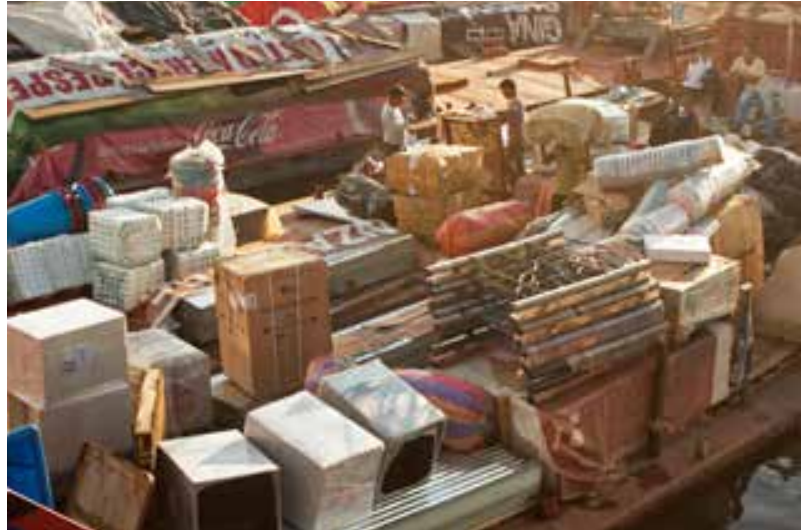

Mercancía en puerto sobre el río Inírida. Guainía. (Foto por Daniel Cruz)

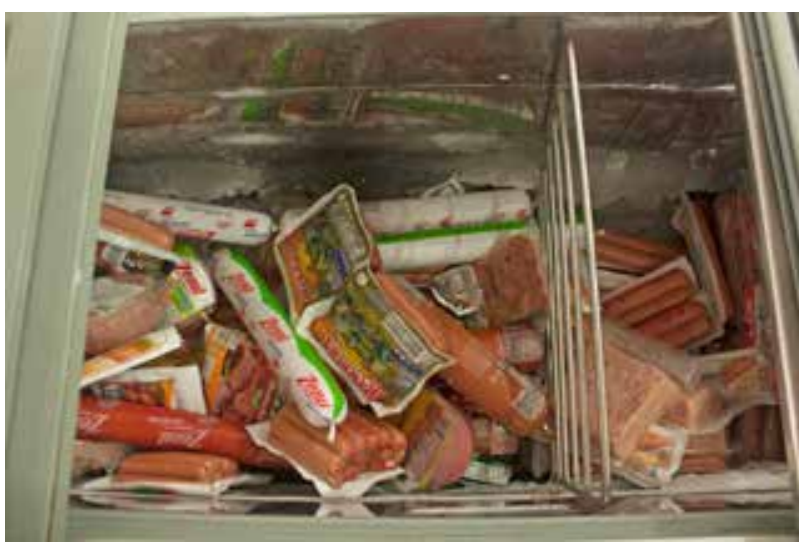

Venta de embutidos. Inírida, Guainía. (Foto por Daniel Cruz)

promedio COP 8.000/kg (USD 3,5), por lo que es menos cara que la carne de res. En cambio, en las regiones Andina y Pacífica, la carne de res cuesta en promedio COP $12.000 / \mathrm{kg}$ (USD 5) y la carne de monte predilecta, como la guagua o guartinaja, puede alcanzar los COP $30.000 / \mathrm{kg}$ (USD 13).

En las regiones Caribe, Andina (Bogotá) y Pacífica, en particular, aparecen los precios más altos identificados para animales como el chigüiro y el armadillo, que oscilan entre COP 100.000 (USD 43) y COP 300.000 (USD 135) por animal entero, respectivamente. La guartinaja, guagua o lapa, alcanza un precio de COP 30.000/ $\mathrm{kg}$ (USD 13) en Fundación, un precio de COP 26.400/kg (USD 11,5) en Bogotá, y un precio

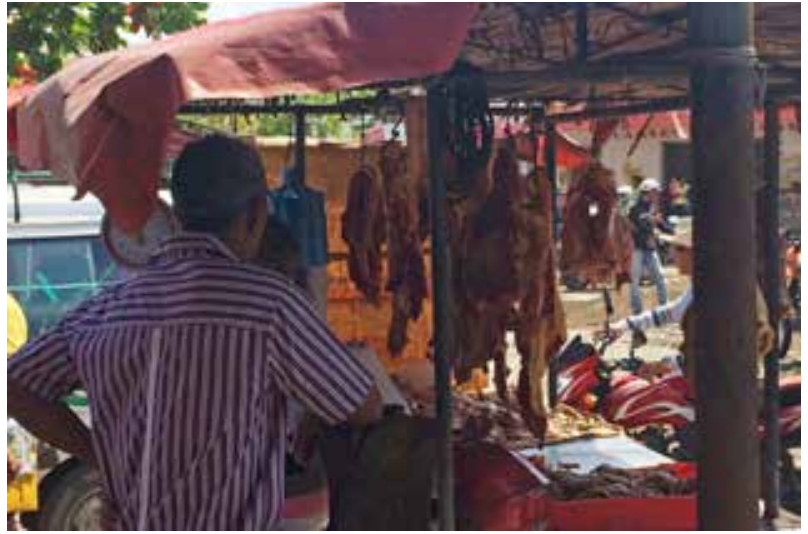

Venta de carne vacuna. Fundación Magdalena. (Foto por Maria Paula Quiceno)

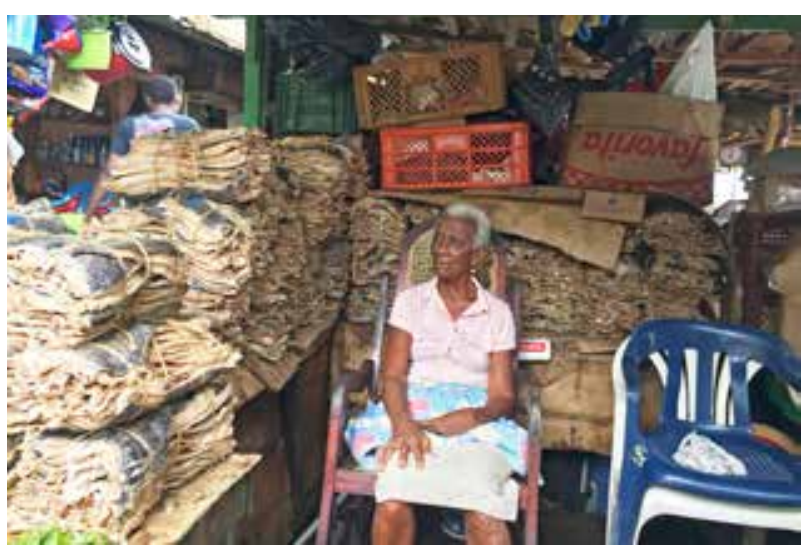

Venta de pescado seco. Quibdó, Chocó. (Foto por Maria Paula Quiceno)

de COP 35.000/kg (USD 15) en Quibdó. Dados los controles existentes en Bogotá, se vende de preferencia el animal entero y en ocasiones el animal vivo para los asaderos.

En Inírida y Yopal, los controles en el casco urbano y en las vías hacen que la carne llegue de manera directa al barrio indígena de Inírida, desde donde se ofrece directamente en las casas de familia a precios de COP $2.500 / \mathrm{kg}$ (USD 1). En este punto de venta, es frecuente que intermediarios compren la carne a los cazadores por el mismo precio o hasta por COP $5.000 / \mathrm{kg}$ (USD 2), para después venderla por el doble en el mismo barrio o en restaurantes del área periurbana, en donde un plato alcanza precios de hasta COP 27.000 (USD 12). 
Tabla 8. Precios promedio de venta de carne de monte en los diferentes eslabones de la cadena de comercio.

\begin{tabular}{|c|c|c|c|c|c|c|c|}
\hline \multirow{2}{*}{ 흠 } & \multirow[b]{2}{*}{$\begin{array}{l}\text { Tipo de carne de } \\
\text { monte }\end{array}$} & \multicolumn{3}{|c|}{ COMPRA (kg, vivos, entera) (COP) } & \multicolumn{3}{|c|}{ Venta (platos) (COP) } \\
\hline & & Presentación & Cazadores & Otros* & $\begin{array}{l}\text { Plaza de } \\
\text { mercado }\end{array}$ & $\begin{array}{l}\text { Puestos de } \\
\text { comida }\end{array}$ & Restaurantes \\
\hline \multirow{23}{*}{ 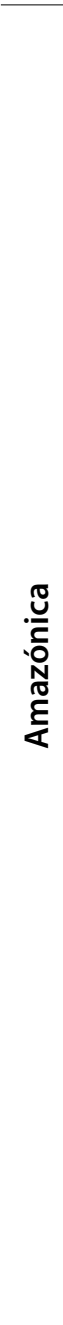 } & $\begin{array}{l}\text { Carne de monte } \\
\text { (sin determinar) }\end{array}$ & & 7.500 & & & & \\
\hline & Armadillo, & Fresca/kg & 8.000 & & 7.000 & 9.000 & 11.500 \\
\hline & & Entera & & & 25.000 & & \\
\hline & Armadillo trueno & Fresca/kg & & & 15.000 & & \\
\hline & Babilla & Fresca/kg & & & 10.000 & & \\
\hline & Boruga/lapa & Fresca/kg & 8.000 & & 10.000 & 7.500 & 11.500 \\
\hline & & Entera & & & 75.000 & & \\
\hline & & Salada/kg & & & 7.000 & & \\
\hline & Cachirre & Fresca/kg & & & 10.000 & & \\
\hline & Cajuche & Fresca/kg & 8.000 & & & & 13.000 \\
\hline & Chigüiro & Fresca/kg & & & 7.000 & & 11.000 \\
\hline & Churuco & Fresca/kg & 8.000 & & & & \\
\hline & Danta & Fresca/kg & 8.000 & & 10.000 & 9.000 & 13.000 \\
\hline & & Entera & & & 166.000 & & \\
\hline & Guatín & Fresca/kg & & & 7.000 & & \\
\hline & Marrano de monte & Fresca/kg & & & 10.000 & & \\
\hline & Mico & Fresca/kg & 8.000 & & & & \\
\hline & Pava de monte & Fresca/kg & & & 10.000 & & \\
\hline & Terecay & Fresca/kg & 8.000 & & & & \\
\hline & & Entera & & & 100.000 & & \\
\hline & & $\begin{array}{l}\text { Huevos/ } \\
\text { sarta/12 }\end{array}$ & & & 14.000 & & \\
\hline & Tortuga & Fresca/kg & 3.000 & & & & \\
\hline & Venado & Fresca/kg & 8.000 & & 12.000 & 9.000 & 15.000 \\
\hline \multirow{9}{*}{$\frac{\stackrel{0}{5}}{\frac{.0}{0}}$} & Chigüiro, lancho & Fresca/kg & & 9.200 & 22.000 & & \\
\hline & & Vivos/unidad & & & 200.000 & & \\
\hline & Cangrejo & Vivos/unidad & & & 1.000 & & \\
\hline & Lapa/guagua & Fresca/kg & & 26.400 & & & \\
\hline & & Vivos/unidad & & & 350.000 & & \\
\hline & Pato moñudo & Vivos/unidad & & & 100.000 & & \\
\hline & Tortuga morrocoy & Vivos/unidad & & & 300.000 & & \\
\hline & Tortugas pequeñas & Vivos/unidad & & & 30.000 & & \\
\hline & Pato & Vivos/unidad & & & 35.000 & & \\
\hline \multirow{5}{*}{ 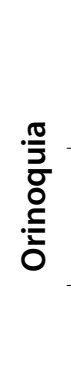 } & $\begin{array}{l}\text { Armadillo/ } \\
\text { cachicamo }\end{array}$ & $\begin{array}{l}\text { Fresca/ } \\
\text { congelada/kg }\end{array}$ & & 12.500 & & & 27.500 \\
\hline & & Entera/kg & & 170.000 & & & \\
\hline & Chigüiro/capibara & $\begin{array}{l}\text { Fresca/ } \\
\text { congelada/ } \\
\text { salada/seca/kg }\end{array}$ & 7.000 & 9.900 & 11.800 & & 25.500 \\
\hline & Lapa & Congelada & & 12.000 & & & 24.000 \\
\hline & & Fresca/entera & & 300.000 & & & \\
\hline
\end{tabular}


Tabla 8. Continuado

\begin{tabular}{|c|c|c|c|c|c|c|c|}
\hline \multirow{2}{*}{ 몽 } & \multirow[b]{2}{*}{$\begin{array}{l}\text { Tipo de carne de } \\
\text { monte }\end{array}$} & \multicolumn{3}{|c|}{ COMPRA (kg, vivos, entera) (COP) } & \multicolumn{3}{|c|}{ Venta (platos) (COP) } \\
\hline & & Presentación & Cazadores & Otros* & $\begin{array}{l}\text { Plaza de } \\
\text { mercado }\end{array}$ & $\begin{array}{l}\text { Puestos de } \\
\text { comida }\end{array}$ & Restaurantes \\
\hline \multirow{14}{*}{$\frac{\mathscr{0}}{\frac{1}{\pi}}$} & Armadillo & $\begin{array}{l}\text { Fresca/ } \\
\text { Ahumada/kg }\end{array}$ & 8.000 & 10.000 & 14.000 & 8.000 & 20.000 \\
\hline & Ponche/cacó & Fresca/kg & & 18.000 & 19.000 & & 13.500 \\
\hline & & Ahumada/kg & & 10.000 & 15.000 & & \\
\hline & Conejo & & & & & 8.000 & 17.500 \\
\hline & Guartinaja & Fresca/kg & 14.300 & 20.000 & 23.000 & & 20.000 \\
\hline & Ñeque/picure/ & Fresca/kg & 20.000 & 14.000 & 14.000 & 8000 & 17.500 \\
\hline & guatín & Ahumada/kg & 8.000 & & 12.000 & & \\
\hline & Pato pisingo & & & & & & 22.500 \\
\hline & $\begin{array}{l}\text { Tortuga morrocoy/ } \\
\text { morrocoya }\end{array}$ & & & & & & 22.500 \\
\hline & Tortuga hicotea & & & & & & 22.500 \\
\hline & Tortuga marina & Fresca/kg & & & 15.000 & & \\
\hline & Venado & Fresca/kg & & 16.000 & 17.000 & & 20.000 \\
\hline & & Ahumada/kg & 8.000 & & 14.000 & & \\
\hline & Zaino & Ahumada/kg & 8.000 & & & & 20.000 \\
\hline \multirow{16}{*}{ 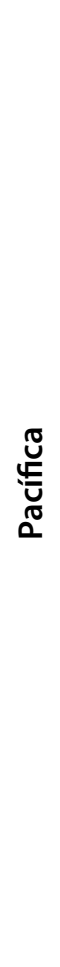 } & Armadillo/ & Fresca/kg & 27.500 & & 6.000 & & 11.000 \\
\hline & $\begin{array}{l}\text { currunde/ } \\
\text { colaetrapo/ } \\
\text { colapelua }\end{array}$ & Entero & 70.000 & & & & \\
\hline & Babilla & Fresca/kg & 2.200 & & 7.900 & 5.500 & \\
\hline & Chigüiro/capibara & & 3.300 & & & & \\
\hline & Guagua & Fresca/kg & 23.100 & & 30.600 & 11.500 & 26.000 \\
\hline & Pava & Fresca/kg & 7.700 & & & & \\
\hline & Pava pescuezo rojo & Entera & 80.000 & & & & \\
\hline & Perdiz & Entera & 20.000 & & & & \\
\hline & $\begin{array}{l}\text { Picure/guatín/ } \\
\text { ñeque }\end{array}$ & Fresca/kg & 23.100 & & & & \\
\hline & Tatabro & Fresca/kg & 15.400 & & & & 11.000 \\
\hline & & Piel/entera & 50.000 & & & & \\
\hline & Tortuga hicotea & Fresca/kg & & & 5.000 & & \\
\hline & Tortuga & Entera & 5.000 & & & & \\
\hline & Venado sabanero & Fresca/kg & 6.250 & & & & \\
\hline & Venado colorado & Fresca/kg & 13.200 & & & & \\
\hline & Zaino/Tatabro & Fresca/kg & 26.400 & & & & \\
\hline
\end{tabular}




\section{Discusión}

El presente estudio buscó mostrar un panorama general del comercio de carne de monte en cinco regiones naturales de Colombia, visitando localidades específicas en cada región. Se identifican como los principales actores de la cadena de mercado de la carne de monte en Colombia a los cazadores, vendedores en plazas de mercado y áreas aledańas, restaurantes y asaderos, y puestos de comida asociados a las plazas de mercado o en las calles alrededor de estas. La estructura de la cadena de mercado es similar a la descrita por van Vliet et al. (2014) en la triple frontera amazónica entre Perú, Colombia y Brasil. Sin embargo en algunas regiones como Salento, Circasia, Calarcá, Fundación, Aracataca, Tauramena, Aguazul e Inírida, las plazas de mercado han sido cerradas o han transitado hacia espacios comerciales de electrodomésticos, almacenamiento de insumos agrícolas, costura y comidas rápidas con la llegada de los supermercados, lo que ha llevado a que la carne de monte pase a ser parte de cadenas de comercio cada vez más difíciles de evidenciar. Buena parte del mercado de carne de monte ocurre en los puestos fuera de la plaza de mercado y está asociado a la venta de pescado y carne de segunda, como hueso y vísceras. En estos casos, la cadena

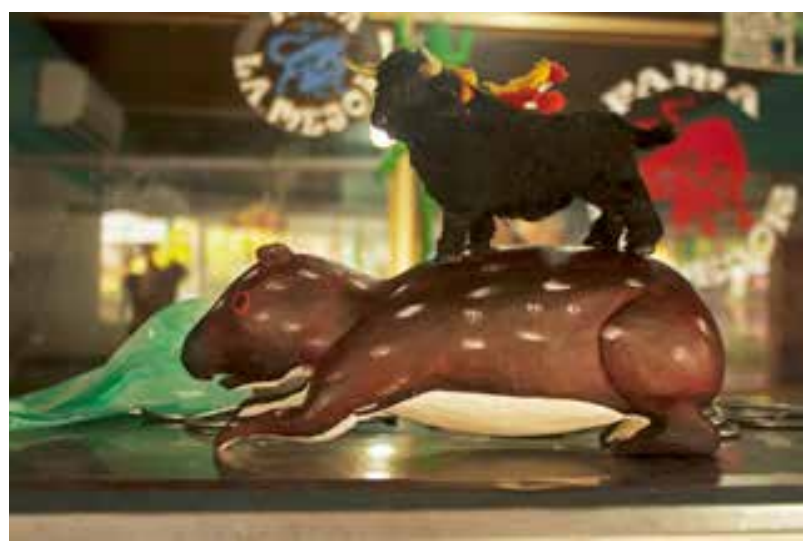

Foto tomada en carnicería de Inírida, Guainía. (Foto por Daniel Cruz) se diversifica mucho más y aparecen como lugares de oferta de carne de monte desde graneros hasta ebanisterías y tiendas de barrio.

Esta venta, al igual que lo evidenciado por Quiceno et al. 2014 es dinamizada por mujeres en su mayoría, quienes representan el 62\% (N=204) de los comerciantes encontrados, distribuidas entre vendedores en plazas de mercado, vendedores ambulantes, restaurantes, puestos de comida e intermediarios; mientras que los hombres representan el 38,2\% de la cadena de mercado, sin considerar a los cazadores. Aun cuando se reporta la existencia de mujeres que participan en la caza, estas lo hacen con fines de subsistencia. Tanto las mujeres como los hombres participan como vendedores de plazas de mercado y puestos en la calle, o almacenes y graneros; sin embargo, las mujeres están a cargo de la preparación de la comida en los restaurantes y puestos de comida, apoyadas muy a menudo por hombres encargados de negociar el abastecimiento de la carne de monte con los cazadores. Se evidencia la importancia de la participación de los niños en las faenas de caza en las regiones Caribe y Pacífica. Al parecer, la cacería practicada por los niños es una forma de aprender

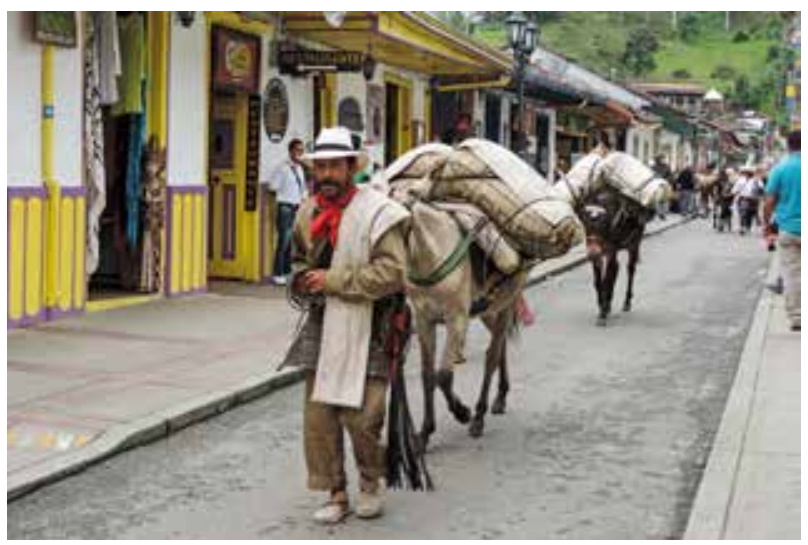

Arrieros. Salento, Quindío. (Foto por Maria Paula Quiceno) 


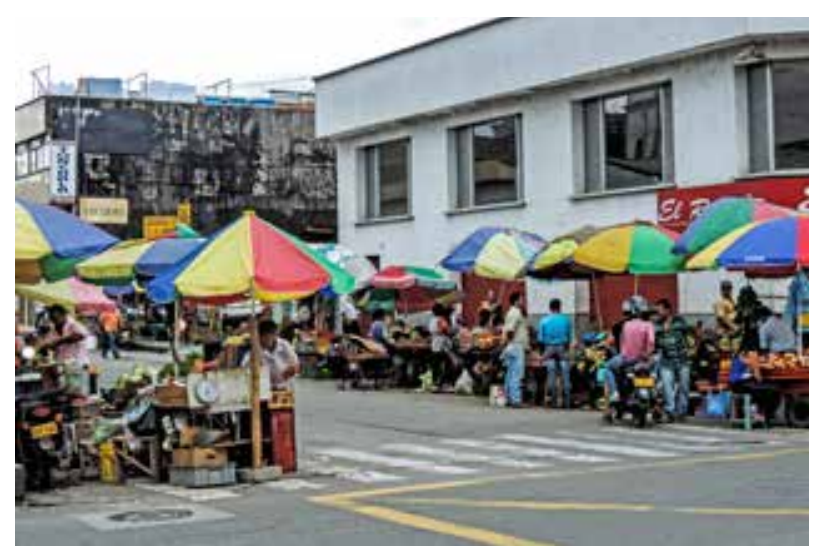

Alrededores de la plaza de mercado de Armenia. Quindío. (Foto por Eliceo Matapi Yucuna)

sobre el bosque y entrenarse en la actividad, como ocurre también en África Central (van Vliet [comunicación personal]).

Los cazadores en Colombia son diversificados y dependen de la carne de monte (y también de otras actividades como la minería, la extracción maderera, la ganadería, la pesca y la agricultura, entre otras) para la provisión de alimentos a su familia, o venden el excedente de carne de monte al mercado local a bajos precios, para con estos recursos suplir necesidades básicas. Algunos cazadores logran lucrarse mucho más con la actividad de cacería y se dotan de perros cazadores, escopeta, moto o caballos, además de un conocimiento detallado de las mejores áreas de caza, para proveer mercados específicos y más lujosos con abundante carne de monte. El estudio confirma la existencia de cazadores urbanos y periurbanos en los sitios visitados, quienes mantienen la conexión con sus familias en las áreas rurales y se desplazan hacia estas para las actividades de caza. Este patrón entre los cazadores también se evidenció en Brasil (van Vliet et al. 2015) y debería analizarse con mayor profundidad.

La clandestinidad de los mercados y su invisibilidad es relativa en las diversas zonas visitadas. El celular es el principal medio de negociación tanto para la realización de pedidos a cazadores e intermediarios, como para la venta en restaurantes, puestos de comida y a los clientes y familias. La interpretación de la ley y su cumplimiento moldean la estructura y el funcionamiento de la cadena de mercado en Colombia, así como la variación de precios, de alguna manera. En Bogotá no se vende carne

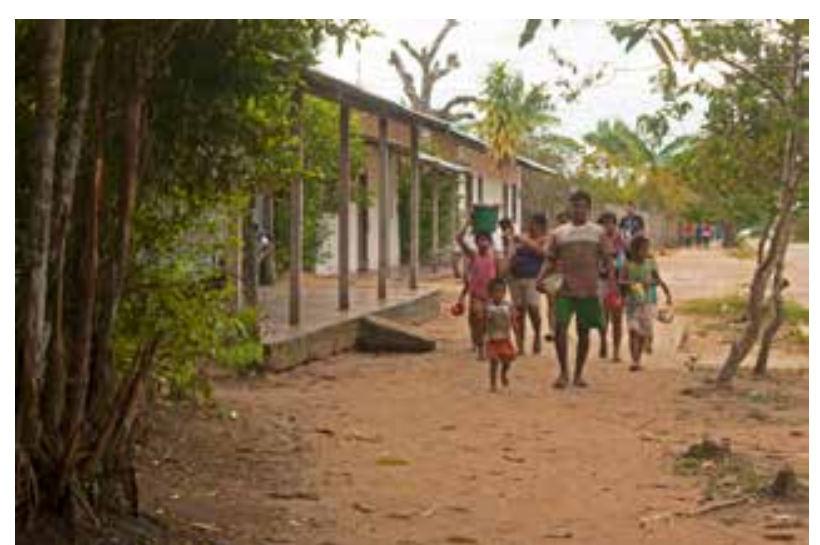

Familia indígena, Resguardo El Paujil, Guainía. (Foto por Daniel Cruz)

de monte por kilogramos: se vende el animal completo a través de encargos anticipados realizados por celular y de manera rápida.

La variación de precios también depende del tipo de clientes, que son desde familias indígenas, afrodescendientes o comunidades rurales, hasta clientes en puestos de comida y restaurantes de mayor precio por plato. En el casco urbano, donde hay un mayor control, la carne de monte es realmente un lujo para quienes están dispuestos a asumir el riesgo de comprar a los intermediarios y en los mercados, a través de contactos telefónicos. En los restaurantes y asaderos de las principales vías del país, esta es ofrecida a los turistas como un plato exótico y único de la región.

Las especies más comercializadas durante el periodo de estudio son: la boruga (Cuniculus paca), el armadillo (Dasypus spp., Cabassous spp., Priodontes maximus), el ñeque (Dasyprocta spp.), el venado (Mazama spp. y Odocoileus virginianus), el chigüiro (Hydrochoerus hydrochaeris), la babilla (Caiman crocodylus), la danta $o$ tapir (Tapirus terrestres), el marrano de monte sin collar (Tayassu pecari) y la guagua loba (Dinomys branickii). La mayoría de la carne silvestre comercializada en los mercados corresponde a fauna que figura como de menor afectación según las Listas Rojas de Colombia (Anexo 3), Cuniculus paca, Dasypus kappleri, Dasypus novemcinctus, Dasypus sabanicola, Cabassous unicinctus, Dasyprocta punctata, Dasyprocta fuliginosa, Mazama americana, Mazama gouazoubira, Hydrochoerus hydrochaeris, Caiman crocodilus y Tayassu pecari no aparecen con reporte de amenaza, o son reportadas como de Preocupación Menor por 
el IAvH (2015), a excepción de Tayassu pecari que aparece en estado vulnerable, mientras que Cabassous centralis, Priodontes maximus, Odocoileus virginianus, Tapirus terrestres y Dinomys branickii aparecen reportadas como casi amenazadas, vulnerable, en peligro y en peligro crítico, respectivamente.

Aunque en el presente estudio no se midieron cantidades de carne de monte comercializadas, se pudo percibir que los sitios con mayor comercio de carne de monte son la región Pacífica (los corregimientos de Quibdó y Tutunendo en Quibdó, el corregimiento de Yuto en El Atrato (departamento del Chocó) y la región Amazónica (Leticia, Puerto Nariño [departamento de Amazonas] e Inírida en Guainía), en las cuales se encuentran los ecosistemas más ricos en términos de biodiversidad (GómezAhumada y Cubillos 2014).

Como se observa en este estudio, el mercado de carne de monte en los sitios visitados se da a través de cadenas cortas de comercio, donde la carne de monte se mueve de las zonas rurales y periurbanas hacia los centros poblados más cercanos. $\mathrm{Al}$ ser un comercio más localizado, facilita la implementación de estrategias de manejo sostenible y control del comercio de carne de monte regional.

Como conclusión final, se propone la necesidad urgente de monitorear estos mercados de manera participativa e innovadora. Es importante conocer los volúmenes por especies y la relación con los mercados en cada región, así como con las áreas boscosas remanentes. Como señalan van Vliet et al. (2012), los datos del monitoreo reportados en estudios similares en diversas regiones del mundo, proporcionan información valiosa a los tomadores de decisiones y a las instituciones ambientales, así como a los centros de investigación, sobre cambios en la composición y presencia de nuevas especies por áreas de interés, así como la presión real sobre grupos de especies con especial importancia para la conservación. Es necesario combinar mecanismos de control con educación hacia el consumidor, y desarrollar opciones de manejo sostenible para las especies de fauna resilientes de fácil adaptación, en los medios de vida de las comunidades rurales en Colombia.

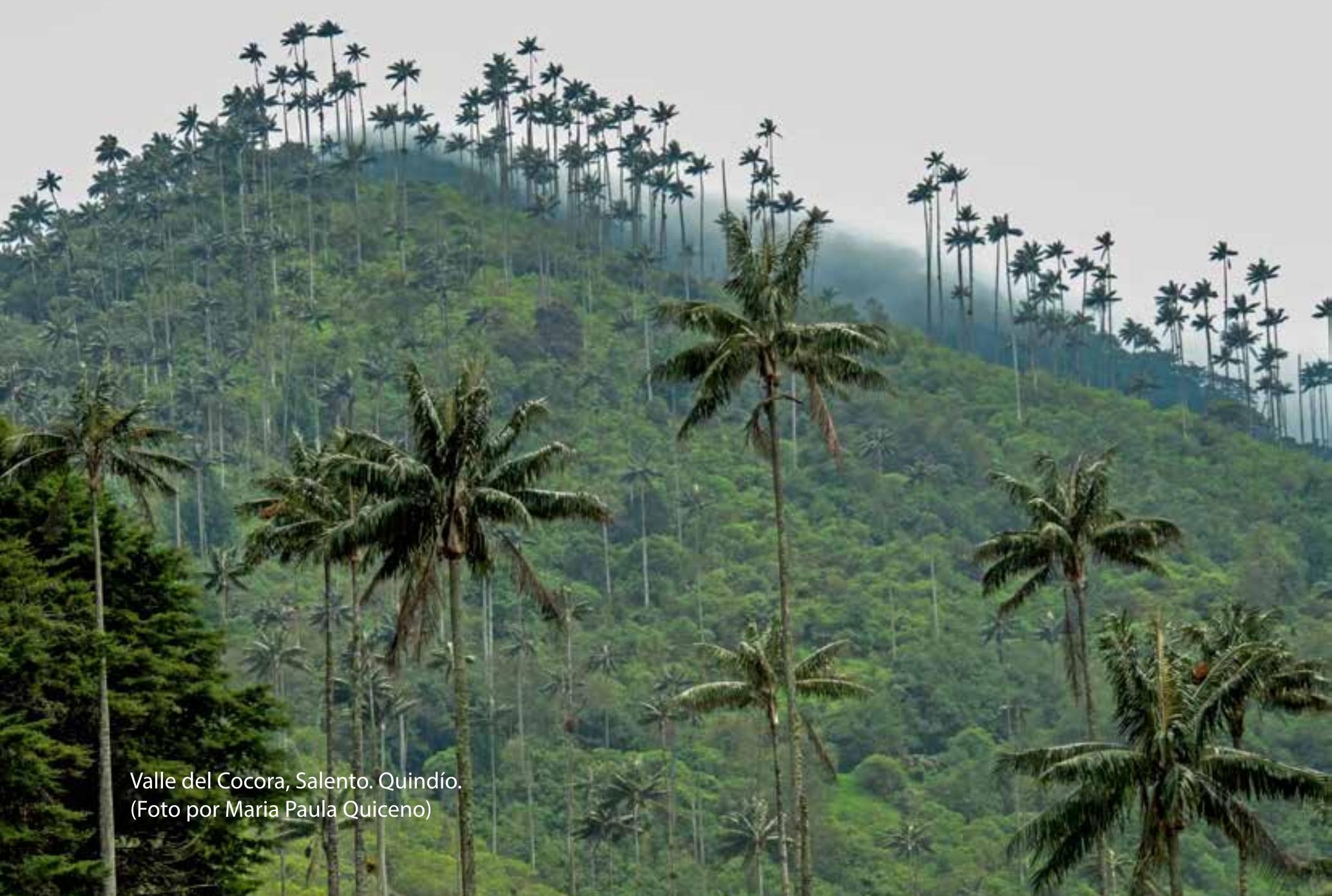




\section{Referencias}

Carrizosa-Umaña J. 2014. Colombia compleja. Bogotá D. C., Colombia: Jardín Botánico de Bogotá José Celestino Mutis. Instituto de Investigación de Recursos Biológicos Alexander von Humboldt. 295 p.

Casas-Ramírez RA. 2007. Patrones de uso de la fauna silvestre por parte de la población asentada en las veredas Alejandría, Cardozo y La Libertad (San Eduardo, Boyacá, Colombia). Tunja, Boyacá, Colombia: Universidad Pedagógica y Tecnológica de Colombia. Facultad de Ciencias, Escuela de Biología. 132 p.

Castańo-Mora OV, ed. 2002. Libro rojo de reptiles de Colombia. Libros Rojos de Especies Amenazadas de Colombia. Bogotá D. C., Colombia: Instituto de Ciencias Naturales - Universidad Nacional de Colombia, Ministerio del Medio Ambiente, Conservación Internacional - Colombia. 160 p.

Gómez-Ahumada MF y Cubillos C. 2014. 102 Sistemas de información sobre biodiversidad de Colombia - SiB Colombia. En Bello JC, Báez M, Gómez MF, Orrego O y Nägele L, eds. Biodiversidad 2014. Estado y tendencias de la biodiversidad continental de Colombia. Bogotá D. C., Colombia: Instituto Alexander von Humboldt.

[IAvH] Instituto Alexander von Humboldt. 2015. SiB - Sistema de Información sobre Biodiversidad de Colombia [online]. http:// www.sibcolombia.net/web/sib/acerca-del-sib

IDEAM, IGAC, IAvH, Invemar, Sinchi I. e IIAP. 2007. Ecosistemas continentales, costeros y marinos de Colombia. Bogotá D. C., Colombia: Instituto de Hidrología, Meteorología y Estudios Ambientales, Instituto Geográfico Agustín Codazzi, Instituto de Investigación de Recursos Biológicos Alexander von Humboldt, Instituto de Investigaciones Ambientales del Pacífico John von Neumann, Instituto de Investigaciones Marinas y Costeras José Benito
Vives De Andréis e Instituto Amazónico de Investigaciones Científicas Sinchi. 276 p. +37 hojas cartográficas.

[IUCN] International Union for Conservation of Nature. 2015. The IUCN Red List of Threatened Species. Version 2015.2 [online]. http://www.iucnredlist.org

Mancera N y Reyes O. (2008). Comercio de Fauna Silvestre en Colombia. Revista Facultad Nacional de Agronomia [Universidad Nacional de Colombia - Medellín] 61(2):4618-4645.

Nasi R, Brown D, Wilkie D, Bennett E, Tutin C, van Tol G y Christophersen T. 2008. Conservation and Use of Wildlife-Based Resources: The Bushmeat Crisis. Technical Series N. ${ }^{\circ} 33$. Bogor, Indonesia: Secretariat of the Convention on Biological Diversity, Montreal, and Center for International Forestry Research (CIFOR).

Ortega MCR. 2014. Ecological Sustainability of Mammal Hunting in Inírida region, Colombian Amazon. Tesis de Maestría en Ciencias Biológicas. Universidad Nacional de Colombia. $49 \mathrm{p}$.

Quiceno MP, Cruz-Antia D, Moreno J y van Vliet N. 2014. Descripción de la cacería y consumo de carne de monte en el río Loretoyacu y el lago Tarapoto, Puerto Narińo - Amazonas, Colombia. En Trujillo F y Duque S, eds. Los humedales de Tarapoto: Aportes al conocimiento sobre su biodiversidad y uso. Bogotá D. C., Colombia: Fundación Omacha. 294-321.

Quiceno-Mesa MP, Cruz-Antia D, van Vliet N, Neves LJ de A y Schor T. 2014. La invisibilidad de las cadenas comerciales de carne de monte en la triple frontera amazónica entre Colombia, Perú y Brasil. Revista Colombia Amazónica № 7 de 2014.

Rodríguez-Mahecha JV, Alberico M, Trujillo F y Jorgenson J, eds. 2006. Libro rojo de mamiferos de Colombia. Libros Rojos de Especies Amenazadas de Colombia. Bogotá 
D. C., Colombia: Conservación Internacional Colombia y Ministerio del Medio Ambiente, Vivienda y Desarrollo Territorial. 433 p.

Salazar-Holguín F. 2013. Zonificación hidrográfica preliminar de Colombia. [IDEAM] Instituto de Hidrología, Meteorología y Estudios Ambientales, SiGaia S. A. S. [online]. http://www.arcgis.com/home/item. html?id=103b63dcc9f448acbd63f22b728b1a02

van Vliet N, Nebesse C, Gambalemoke S, Akaibe D y Nasi R. 2012. The Bushmeat Market in Kisangani, Democratic Republic of Congo: Implications for Conservation and Food Security. Oryx 46(2):196. http://dx.doi. org/10.1017/S0030605311000202

van Vliet N, Quiceno-Mesa MP, Cruz-Antia D, Morsello C, Adams C, Mori F, Yagüe B, Hernández S, Bonilla T, Tellez L, Neves de Aquino L, Moreno J, Schor T, De Oliveira Princi M, Haiden E, Trujillo F, Nasi R.
2014. Bushmeat in the tri-frontier region of Brazil, Peru and Colombia: Demise or persistence? Occasional Paper 118. CIFOR. [online]. http://www.cifor.org/library/5363/ bushmeat-in-the-tri-frontier-region-ofbrazil-peru-and-colombia-demise-orpersistencel

van Vliet N, Cruz-Antia D, Quiceno-Mesa MP, Neves de Aquino L, Moreno J, Rairon R y Fa J. 2015. Ride, Shoot, and Call: Wildlife Use among Contemporary Urban Hunters in Três Fronteiras, Brazilian Amazon. Ecology and Society 20(3):8.

Vargas-Tovar N. 2014. 203 - Consumo de carne de monte en Colombia. En Bello JC, Báez M, Gómez MF, Orrego O y Nägele L, eds. Biodiversidad 2014. Estado y tendencias de la biodiversidad continental de Colombia. Bogotá D. C., Colombia: Instituto Alexander von Humboldt. 


\section{Anexos}

Anexo 1. Total de sitios visitados por región.

\begin{tabular}{|c|c|c|c|c|c|c|c|c|c|}
\hline Región geográfica & Municipio & $\begin{array}{l}\text { Plazas de } \\
\text { mercado }\end{array}$ & $\begin{array}{l}\text { Restaurantes/ } \\
\text { asaderos }\end{array}$ & Carnicerías & Pescaderías & $\begin{array}{l}\text { Puestos } \\
\text { en la calle }\end{array}$ & $\begin{array}{l}\text { Puestos de } \\
\text { comida }\end{array}$ & $\begin{array}{l}\text { Tiendas } \\
\text { de barrio }\end{array}$ & $\begin{array}{l}\text { Comunidades/ } \\
\text { caseríos }\end{array}$ \\
\hline \multirow[t]{3}{*}{ Amazónica } & Leticia & 1 & 16 & 0 & 0 & 0 & 14 & 0 & 0 \\
\hline & Inírida & 1 & 12 & 9 & 0 & 0 & 14 & 1 & 0 \\
\hline & Puerto Nariño & 1 & 9 & 0 & 0 & 0 & 12 & 0 & 0 \\
\hline \multirow[t]{5}{*}{ Andina } & Bogotá & 13 & 2 & 0 & 0 & 6 & 0 & 0 & 0 \\
\hline & Calarcá & 1 & 8 & 1 & 1 & 0 & 0 & 0 & 0 \\
\hline & Montenegro & 1 & 3 & 4 & 0 & 0 & 0 & 0 & 0 \\
\hline & Circasia & 1 & 6 & 18 & 1 & 0 & 0 & 0 & 0 \\
\hline & Salento & 0 & 7 & 0 & 0 & 0 & 0 & 0 & 0 \\
\hline \multirow[t]{8}{*}{ Orinoquia } & Yopal & 1 & 75 & 1 & 0 & 0 & 0 & 1 & 0 \\
\hline & Aguazul & 1 & 16 & 0 & 0 & 0 & 0 & 1 & 0 \\
\hline & Paz de Ariporo & 1 & 35 & 0 & 0 & 0 & 0 & 0 & 0 \\
\hline & Villanueva & 1 & 15 & 1 & 0 & 0 & 0 & 0 & 0 \\
\hline & Tauramena & 0 & 10 & 2 & 0 & 0 & 0 & 0 & 0 \\
\hline & Monterrey & 1 & 15 & 1 & 0 & 0 & 0 & 0 & 0 \\
\hline & Hato Corozal & 0 & 6 & 0 & 0 & 0 & 0 & 0 & 0 \\
\hline & Pore & 1 & 11 & 0 & 0 & 0 & 0 & 1 & 0 \\
\hline \multirow[t]{7}{*}{ Caribe } & Santa Marta & 1 & 0 & 0 & 0 & 0 & 12 & 0 & 0 \\
\hline & Ciénaga & 1 & 2 & 0 & 0 & 0 & 0 & 1 & 0 \\
\hline & Zona Bananera & 0 & 7 & 0 & 0 & 0 & 0 & 2 & 0 \\
\hline & Fundación & 2 & 7 & 8 & 0 & 0 & 15 & 4 & 2 \\
\hline & Aracataca & 1 & 0 & 0 & 0 & 0 & 0 & 0 & 1 \\
\hline & Algarrobo & 0 & 3 & 0 & 0 & 0 & 0 & 0 & 0 \\
\hline & El Copey & 1 & 8 & 0 & 0 & 0 & 0 & 0 & 0 \\
\hline Pacífica & Quibdó & 3 & 22 & 19 & 0 & 40 & 2 & 0 & 11 \\
\hline Total & & 34 & 295 & 64 & 2 & 46 & 69 & 11 & 14 \\
\hline
\end{tabular}


Anexo 2. Precios máximos y mínimos de compra de carne (de monte y otras) en los diferentes eslabones de la cadena de mercado.

\begin{tabular}{|c|c|c|c|c|c|c|c|c|c|c|c|c|c|}
\hline \multirow{3}{*}{ 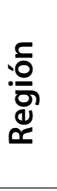 } & & \multirow[t]{3}{*}{ Tipo de carne } & \multicolumn{7}{|c|}{ COMPRA (kg, vivos, entera) (COP) } & \multicolumn{4}{|c|}{ VENTA (platos) (COP) } \\
\hline & & & \multirow[t]{2}{*}{ Presentación } & \multicolumn{2}{|c|}{ Cazadores } & \multicolumn{2}{|c|}{ Otros* } & \multicolumn{2}{|c|}{ Plaza de mercado } & \multicolumn{2}{|c|}{ Puesto de comida } & \multicolumn{2}{|c|}{ Restaurantes } \\
\hline & & & & $\begin{array}{c}\text { Precio } \\
\text { mínimo }\end{array}$ & $\begin{array}{c}\text { Precio } \\
\text { máximo }\end{array}$ & $\begin{array}{l}\text { Precio } \\
\text { mínimo }\end{array}$ & $\begin{array}{l}\text { Precio } \\
\text { máximo }\end{array}$ & $\begin{array}{c}\text { Precio } \\
\text { mínimo }\end{array}$ & $\begin{array}{c}\text { Precio } \\
\text { máximo }\end{array}$ & $\begin{array}{c}\text { Precio } \\
\text { mínimo }\end{array}$ & $\begin{array}{c}\text { Precio } \\
\text { máximo }\end{array}$ & $\begin{array}{c}\text { Precio } \\
\text { mínimo }\end{array}$ & $\begin{array}{l}\text { Precio } \\
\text { máximo }\end{array}$ \\
\hline \multirow{16}{*}{ 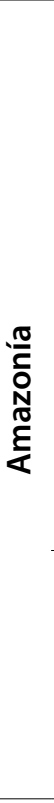 } & \multirow{16}{*}{ 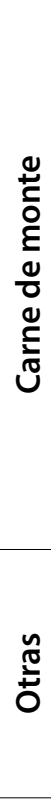 } & Carne de monte & & 5.000 & 10.000 & & & & & & & & \\
\hline & & Armadillo, cachicamo & Fresca/kg & 4.000 & 12.000 & & & & & 8.000 & 10.000 & 13.000 & \\
\hline & & Chigüiro & & & & & & & & & & 10.000 & 12.000 \\
\hline & & Churuco & Fresca/kg & 4.000 & 12.000 & & & & & & & & \\
\hline & & Cajuche & Fresca/kg & 6.000 & 10.000 & & & & & & & 13.000 & \\
\hline & & Danta & Fresca/kg & 4.000 & 12.000 & & & & & 8.000 & 10.000 & 13.000 & \\
\hline & & Lapa & Fresca/kg & 4.000 & 12.000 & & & & & 8.000 & 10.000 & 10.000 & 16.000 \\
\hline & & Mico & Fresca/kg & 4.000 & 12.000 & & & & & & & & \\
\hline & & Terecay & Fresca/kg & 4.000 & 12.000 & & & & & & & & \\
\hline & & Tortuga & Fresca/kg & 3.000 & 3.000 & & & & & & & & \\
\hline & & Venado & Fresca/kg & 4.000 & 12.000 & & & & & 8.000 & 10.000 & 13.000 & \\
\hline & & Pescado & & & & & & & & 5.000 & 8.000 & 10.000 & 30.000 \\
\hline & & Pescado palometa & & & & & & & & & & 3.000 & 5.000 \\
\hline & & Pescado cachama & & & & & & & & & & 25.000 & \\
\hline & & Carne (res y cerdo) & Fresca/kg & & & 12.000 & & & & 8.000 & & 8.000 & 20.000 \\
\hline & & Pollo & Fresca/kg & & & 6.500 & & & & 8.000 & & 8.000 & 15.000 \\
\hline \multirow{10}{*}{$\begin{array}{l}\stackrel{0}{\frac{5}{0}} \\
\stackrel{\frac{C}{\alpha}}{<}\end{array}$} & \multirow{10}{*}{ 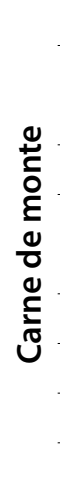 } & Carne de monte & & & & & & & & & & & \\
\hline & & Chigüiro, lancho & Fresca/kg & & & 7.400 & 11.000 & 22.000 & & & & & \\
\hline & & & Vivos/unidad & & & & & 100.000 & 300.000 & & & & \\
\hline & & Cangrejo & Vivos/unidad & & & & & 1.000 & & & & & \\
\hline & & Lapa/guagua & Fresca/kg & & & 26.400 & & & & & & & \\
\hline & & & Vivos/unidad & & & & & 350.000 & & & & & \\
\hline & & Pato moñudo & Vivos/unidad & & & & & 100.000 & & & & & \\
\hline & & Tortuga morrocoy & Vivos/unidad & & & & & 300.000 & & & & & \\
\hline & & Tortugas pequeñas & Vivos/unidad & & & & & 30.000 & & & & & \\
\hline & & Pato & Vivos/unidad & & & & & 20.000 & 50.000 & & & & \\
\hline
\end{tabular}


Anexo 2. Continuado

\begin{tabular}{|c|c|c|c|c|c|c|c|c|c|c|c|c|c|}
\hline \multirow{3}{*}{ :웡 } & & \multirow[t]{3}{*}{ Tipo de carne } & \multicolumn{7}{|c|}{ COMPRA (kg, vivos, entera) (COP) } & \multicolumn{4}{|c|}{ VENTA (platos) (COP) } \\
\hline & & & \multirow[t]{2}{*}{ Presentación } & \multicolumn{2}{|c|}{ Cazadores } & \multicolumn{2}{|c|}{ Otros * } & \multicolumn{2}{|c|}{ Plaza de mercado } & \multicolumn{2}{|c|}{ Puesto de comida } & \multicolumn{2}{|c|}{ Restaurantes } \\
\hline & & & & $\begin{array}{c}\text { Precio } \\
\text { mínimo }\end{array}$ & $\begin{array}{c}\text { Precio } \\
\text { máximo }\end{array}$ & $\begin{array}{l}\text { Precio } \\
\text { mínimo }\end{array}$ & $\begin{array}{c}\text { Precio } \\
\text { máximo }\end{array}$ & $\begin{array}{c}\text { Precio } \\
\text { mínimo }\end{array}$ & $\begin{array}{c}\text { Precio } \\
\text { máximo }\end{array}$ & $\begin{array}{l}\text { Precio } \\
\text { mínimo }\end{array}$ & $\begin{array}{c}\text { Precio } \\
\text { máximo }\end{array}$ & $\begin{array}{c}\text { Precio } \\
\text { mínimo }\end{array}$ & $\begin{array}{c}\text { Precio } \\
\text { máximo }\end{array}$ \\
\hline & \multirow{15}{*}{ 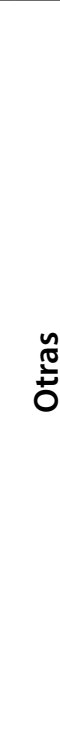 } & Pescado & Fresca/kg & & & 8.800 & & & & & & 16.000 & \\
\hline & & Trucha quindiana & Fresca/kg & & & 13.200 & & & & 10.000 & 15.000 & 10.000 & 16.000 \\
\hline & & Carne (res y cerdo) & Fresca/kg & & & 14.000 & & 5.000 & 13.000 & 5.000 & 25.000 & 10.000 & 16.000 \\
\hline & & Pollo & Fresca/kg & & & & & 6.400 & 7.700 & 5.000 & 7.000 & 16.000 & \\
\hline & & Pollo criollo & Fresca/kg & & & 5.500 & & & & & & & \\
\hline & & Gallina criolla & Fresca/unidad & & & 7.500 & 27.000 & & & & & & \\
\hline & & & Vivos/unidad & & & & & 22.000 & 50.000 & & & & \\
\hline & & Pavo real & Vivos/unidad & & & & & 500.000 & & & & & \\
\hline & & Pisco & Vivos/unidad & & & & & 100.000 & & & & & \\
\hline & & Palomas & Vivos/unidad & & & & & 5.000 & & & & & \\
\hline & & Codorniz & Vivos/unidad & & & & & 2.500 & & & & & \\
\hline & & Curíes & Vivos/unidad & & & & & 5.000 & & & & & \\
\hline & & Faisán & Vivos/unidad & & & & & 350.000 & & & & & \\
\hline & & Gansos & Vivos/unidad & & & & & 250.000 & & & & & \\
\hline & & Embutidos & & & & & & 3.600 & & & & 6.000 & \\
\hline \multirow{9}{*}{ 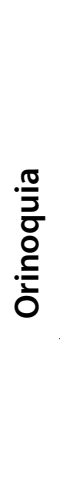 } & \multirow{6}{*}{ 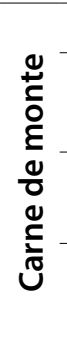 } & Carne de monte & & & & & & & & & & & \\
\hline & & Armadillo/cachicamo & Fresca/congelada/kg & & & 10.000 & 15.000 & & & & & 22.000 & 33.000 \\
\hline & & & Entera/kg & & & 170.000 & & & & & & & \\
\hline & & Chigüiro/capibara & $\begin{array}{c}\text { Fresca/congelada/ } \\
\text { salada/seca/kg }\end{array}$ & 6.000 & 8.000 & 6.600 & 13.200 & 6.000 & 17.600 & & & 18.000 & 33.000 \\
\hline & & Lapa & Congelada & & & 12.000 & & & & & & 15.000 & 33.000 \\
\hline & & & Fresca/Entera & & & 300.000 & & & & & & & \\
\hline & \multirow{3}{*}{$\stackrel{n}{\tilde{t}}$} & Pescado & Fresca/kg & & & 13.200 & 17.600 & 12.100 & 17.600 & & & 15.000 & 20.000 \\
\hline & & Carne (res y cerdo) & Fresca/kg & & & 9.900 & & 4.000 & 15.400 & & & 5.000 & 30.000 \\
\hline & & Pollo & Fresca/kg & & & 8.800 & & 8.800 & 15.400 & & & c 6.000 & 8.000 \\
\hline
\end{tabular}


Anexo 2. Continuado

\begin{tabular}{|c|c|c|c|c|c|c|c|c|c|c|c|c|}
\hline \multirow{2}{*}{ : } & \multirow[t]{2}{*}{ Tipo de carne } & \multicolumn{7}{|c|}{ COMPRA (kg, vivos, entera) (COP) } & \multicolumn{4}{|c|}{ VENTA (platos) (COP) } \\
\hline & & Presentación & \multicolumn{2}{|c|}{ Cazadores } & \multicolumn{2}{|c|}{ Otros* } & \multicolumn{2}{|c|}{ Plaza de mercado } & \multicolumn{2}{|c|}{ Puesto de comida } & \multicolumn{2}{|c|}{ Restaurantes } \\
\hline \multirow{21}{*}{ 总 } & Armadillo & Fresca/ahumada/kg & 8.000 & 8.000 & 10.000 & & 10.000 & 18.000 & 8.000 & & 15.000 & 25.000 \\
\hline & Ponche/cacó & Fresca/kg & & & 18.000 & & 18.000 & 20.000 & & & 7000 & 20.000 \\
\hline & & Ahumada/kg & & & 10.000 & & 10.000 & 20.000 & & & & \\
\hline & Ñeque/picure/guatín & Fresca/kg & 20.000 & 20.000 & 10.000 & 18.000 & 10.000 & 18.000 & 8.000 & & 10.000 & 25.000 \\
\hline & & Ahumada/kg & 8.000 & 8.000 & & & 12.000 & & & & & \\
\hline & Pato pisingo & & & & & & & & & & 20.000 & 25.000 \\
\hline & Tortuga morrocoy/morrocoya & & & & & & & & & & 20.000 & 25.000 \\
\hline & Trotuga icotea & & & & & & & & & & 20.000 & 25.000 \\
\hline & Tortuga marina & Fresca/kg & & & & & 14.000 & 16.000 & & & & \\
\hline & & Fresca/sarta & & & & & 3.000 & 4.000 & & & & \\
\hline & Pescado de estanque & Fresca/kg & & & & & 6.000 & & & & & \\
\hline & Tilapia & Fresca/kg & & & & & 12.000 & & & & & \\
\hline & Pescado marino & Fresca/kg & & & & & 4.000 & 15.000 & & & & \\
\hline & Pescado de río & Fresca $/ \mathrm{kg}$ & & & & & 10.000 & & & & & \\
\hline & Lisa & Salada/kg & & & & & 2.000 & 4.000 & & & & \\
\hline & Cordero & Fresca/kg & & & 8.000 & 12.000 & 8.000 & 12.000 & & & & \\
\hline & Carne (res y cerdo) & Fresca/kg & & & 7.000 & 12.000 & 7.000 & 15.000 & 5.000 & 7.000 & 9.000 & 12.000 \\
\hline & Pollo & Fresca/kg & & & 4.500 & & 4.500 & & & & 9.000 & 12.000 \\
\hline & Gallina criolla & & & & & & & & 5.000 & 7.000 & & \\
\hline & Embutidos & Fresca/sarta & & & 3.000 & 4.000 & 3.000 & 4.000 & & & & \\
\hline & Salchichón de carne & Fresca/sarta & & & 18.000 & & & & & & & \\
\hline
\end{tabular}


Anexo 2. Continuado

\begin{tabular}{|c|c|c|c|c|c|c|c|c|c|c|c|c|c|}
\hline \multirow{3}{*}{ 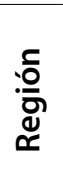 } & & \multirow[t]{3}{*}{ Tipo de carne } & \multicolumn{7}{|c|}{ COMPRA (kg, vivos, entera) (COP) } & \multicolumn{4}{|c|}{ VENTA (platos) (COP) } \\
\hline & & & \multirow[t]{2}{*}{ Presentación } & \multicolumn{2}{|c|}{ Cazadores } & \multicolumn{2}{|c|}{ Otros * } & \multicolumn{2}{|c|}{ Plaza de mercado } & \multicolumn{2}{|c|}{ Puesto de comida } & \multicolumn{2}{|c|}{ Restaurantes } \\
\hline & & & & $\begin{array}{c}\text { Precio } \\
\text { mínimo }\end{array}$ & $\begin{array}{l}\text { Precio } \\
\text { máximo }\end{array}$ & $\begin{array}{l}\text { Precio } \\
\text { mínimo }\end{array}$ & $\begin{array}{c}\text { Precio } \\
\text { máximo }\end{array}$ & $\begin{array}{l}\text { Precio } \\
\text { mínimo }\end{array}$ & $\begin{array}{c}\text { Precio } \\
\text { máximo }\end{array}$ & $\begin{array}{l}\text { Precio } \\
\text { mínimo }\end{array}$ & $\begin{array}{l}\text { Precio } \\
\text { máximo }\end{array}$ & $\begin{array}{l}\text { Precio } \\
\text { mínimo }\end{array}$ & $\begin{array}{c}\text { Precio } \\
\text { máximo }\end{array}$ \\
\hline \multirow{22}{*}{ 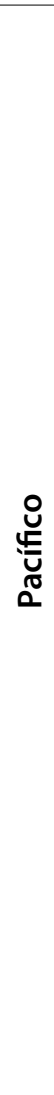 } & \multirow{22}{*}{ نَ } & \multirow{2}{*}{$\begin{array}{l}\text { Armadillo/currunde/ } \\
\text { colaetrapo/colapelua }\end{array}$} & Fresca/kg & 11.000 & 44.000 & & & 6.000 & 6.000 & & & 10.000 & 12.000 \\
\hline & & & Entero & 70.000 & & & & & & & & & \\
\hline & & Babilla & Fresca/kg & 2.200 & & & & 4.800 & 11.000 & 5.000 & 6.000 & & \\
\hline & & Chigüiro/capibara & & 3.300 & & & & & & & & & \\
\hline & & Guagua & Fresca/kg & 11.000 & 35.200 & & & 26.000 & 35.200 & 10.000 & 13.000 & 7.000 & 45.000 \\
\hline & & Pava & Fresca/kg & 7.700 & & & & & & & & & \\
\hline & & Pava pescuezo rojo & Entera & 60.000 & 100.000 & & & & & & & & \\
\hline & & Perdiz & Entera & 20.000 & & & & & & & & & \\
\hline & & Picure/guatín/ñeque & Fresca/kg & 15.400 & 30.800 & & & & & & & & \\
\hline & & Tatabro & Fresca/kg & 8.800 & 22.000 & & & & & & & 10.000 & 12.000 \\
\hline & & & Piel/entera & 50.000 & & & & & & & & & \\
\hline & & Tortuga icotea & Fresca/kg & & & & & 5.000 & & & & & \\
\hline & & Tortuga & Entera & 5.000 & & & & & & & & & \\
\hline & & Venado sabanero & Fresca/kg & 5.500 & 7.000 & & & & & & & & \\
\hline & & Venado colorado & Fresca/kg & 13.200 & & & & & & & & & \\
\hline & & Zaino/tratabro & Fresca/kg & 17.600 & 35.200 & & & & & & & & \\
\hline & & Pescado & & & & & & & & & & 6.000 & 40.000 \\
\hline & & Tilapia & & & & & & & & & & 20.000 & \\
\hline & & Bacalao & & & & & & & & & & 20.000 & \\
\hline & & Salmón & & & & & & & & & & 30.000 & \\
\hline & & Carne (res y cerdo) & Fresca/kg & & & & & 12.000 & & 6.000 & 7.000 & 6.000 & 30.000 \\
\hline & & Pollo & Fresca/kg & & & & & 6.600 & & 6.000 & 7.000 & 6.000 & 7.000 \\
\hline
\end{tabular}


Anexo 3. Listado de especies con mayor reporte de comercio en las cinco regiones y su estado de conservación.

\begin{tabular}{|c|c|c|c|c|c|}
\hline Nombre común & Región & Posibles especies & $\begin{array}{l}\text { Libros rojos de Colombia (Castaño-Mora } \\
2002 \text { y Rodríguez-Mahecha et al. 2006) }\end{array}$ & $\begin{array}{l}\text { Estado de conservación } \\
\text { (IAvH 2015) }\end{array}$ & $\begin{array}{l}\text { Estado de conservación } \\
\text { (IUCN 2015) }\end{array}$ \\
\hline Boruga & $\begin{array}{l}\text { Caribe, } \\
\text { Orinoquia, } \\
\text { Pacífica y } \\
\text { Amazónica }\end{array}$ & Cuniculus paca & Sin amenaza & Precaución menor & Preocupación menor \\
\hline Armadillo & $\begin{array}{l}\text { Caribe, } \\
\text { Orinoquia, } \\
\text { Pacífica y } \\
\text { Andina }\end{array}$ & $\begin{array}{l}\text { Dasypus kappleri } \\
\text { Dasypus novemcinctus } \\
\text { Dasypus sabanicola } \\
\text { Cabassous centralis } \\
\text { Cabassous unicinctus } \\
\text { Priodontes maximus }\end{array}$ & $\begin{array}{l}\text { Sin amenaza } \\
\text { Sin amenaza } \\
\text { Sin amenaza } \\
\text { Casi amenazada } \\
\text { Sin amenaza } \\
\text { En peligro }\end{array}$ & $\begin{array}{l}\text { No disponible } \\
\text { Sin definir } \\
\text { Sin definir } \\
\text { Casi amenazada } \\
\text { Sin definir } \\
\text { En peligro }\end{array}$ & $\begin{array}{l}\text { No evaluado } \\
\text { Preocupación menor } \\
\text { Casi amenazada } \\
\text { Datos insuficientes } \\
\text { Preocupación menor } \\
\text { Vulnerable A2cd }\end{array}$ \\
\hline Ñeque & $\begin{array}{l}\text { Pacífica, } \\
\text { Caribe y } \\
\text { Andina }\end{array}$ & $\begin{array}{l}\text { Dasyprocta punctata } \\
\text { Dasyprocta fuliginosa }\end{array}$ & $\begin{array}{l}\text { Sin amenaza } \\
\text { Sin amenaza }\end{array}$ & $\begin{array}{l}\text { Sin definir } \\
\text { Sin definir }\end{array}$ & $\begin{array}{l}\text { Preocupación menor } \\
\text { Preocupación menor }\end{array}$ \\
\hline Venado & $\begin{array}{l}\text { Caribe, } \\
\text { Amazónica y } \\
\text { Pacífica }\end{array}$ & $\begin{array}{l}\text { Mazama americana } \\
\text { Mazama gouazoubira } \\
\text { Odocoileus virginianus }\end{array}$ & $\begin{array}{l}\text { Sin amenaza } \\
\text { Sin amenaza } \\
\text { En peligro crítico }\end{array}$ & $\begin{array}{l}\text { Preocupación menor } \\
\text { Sin reporte } \\
\text { En peligro }\end{array}$ & $\begin{array}{l}\text { Datos insuficientes } \\
\text { Preocupación menor } \\
\text { Preocupación menor }\end{array}$ \\
\hline Chigüiro & $\begin{array}{l}\text { Orinoquia y } \\
\text { Andina }\end{array}$ & Hydrochoerus hydrochaeris & Sin amenaza & Sin definir & Preocupación menor \\
\hline Babilla & Pacífica & Caiman crocodilus & Preocupación menor & Preocupación menor & $\begin{array}{l}\text { Riesgo menor / } \\
\text { preocupación menor }\end{array}$ \\
\hline Danta & Amazónica & Tapirus terrestris & En peligro crítico & En peligro & Vulnerable $A 2 c d e+3 c d e$ \\
\hline $\begin{array}{l}\text { Marrano de } \\
\text { monte sin collar }\end{array}$ & Amazónica & Tayassu pecari & Sin amenaza & Vulnerable & Vulnerable A2bcde+3bcde \\
\hline Guagua loba & Andina & Dinomys branickii & Vulnerable & Vulnerable & Vulnerable A2cd \\
\hline
\end{tabular}



Los Documentos ocasionales de CIFOR presentan resultados de investigación relevantes para el manejo forestal. Su contenido es revisado por pares interna y externamente.

La mayor parte de la literatura disponible sobre el comercio de carne silvestre en América del Sur se centra en la Amazonia, probablemente debido a que el comercio de carne de monte en otros ecosistemas (bosques tropicales, bosques montañosos, sabanas, etc.) se considera insignificante y a que el potencial comercio está ausente por la disponibilidad de otras alternativas de proteínas (carne de res, pollo, pescado). Algunos estudios dispersos e informes de decomisos proporcionan evidencia del comercio de carne de monte en diferentes regiones de Colombia, pero no hay información sobre la existencia o no de cadenas de comercialización que operen clandestinamente en las distintas regiones del país, en especial en áreas urbanas. Una mejor comprensión de las cadenas de mercado de la carne de monte, de los actores involucrados, de las principales rutas comerciales y de las especies comercializadas puede brindar información clave sobre amenazas a la biodiversidad y para tomar mejores decisiones de gestión asociadas a la educación, el control y las iniciativas de uso sostenible. El presente estudio se enfocó en proporcionar un vistazo al comercio de carne de monte a nivel urbano, lo que da evidencia de su existencia en todas las ecorregiones del país. Este estudio preliminar resalta la necesidad de cuantificar y realizar seguimiento a los volúmenes de comercio de carne de monte, comprender sus motivaciones y de explorar posibles medidas para reducir las amenazas, así como ayudar a los interesados a participar en un uso legal y sostenible de la carne de monte.

\begin{tabular}{|c|c|c|}
\hline CGIAR & $\begin{array}{l}\text { PROGRAMA DE } \\
\text { INVESTIGACIÓN SOBRE } \\
\text { Bosques, Árboles y } \\
\text { Agroforestería }\end{array}$ & $\begin{array}{l}\text { Esta investigación fue realizada por CIFOR como parte del Programa de Investigación de CGIAR sobre } \\
\text { Bosques, Árboles y Agroforestería (CRP-FTA). El objetivo del programa es mejorar el manejo y uso de los } \\
\text { bosques, la agroforestería y los recursos genéticos de los árboles a lo largo del paisaje, desde bosques } \\
\text { hasta plantaciones. CIFOR dirige el programa CRP-FTA en asociación con Bioversity International, CATIE, } \\
\text { CIRAD, el Centro Internacional de Agricultura Tropical y el Centro Mundial de Agroforestería. }\end{array}$ \\
\hline
\end{tabular}

cifor.org

blog.cifor.org
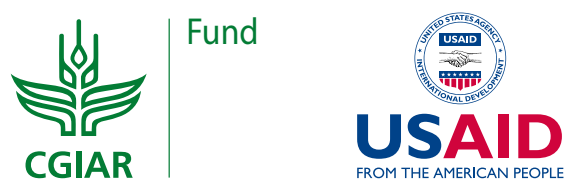

Centro para la Investigación Forestal Internacional (CIFOR)

CIFOR impulsa el bienestar humano, la conservación ambiental y la equidad mediante investigación orientada a ayudar en el diseño de políticas y prácticas que afectan a los bosques de los países en vías de desarrollo. CIFOR es un miembro del Consorcio CGIAR. Nuestra sede central se encuentra en Bogor, Indonesia, y contamos con oficinas en Asia, África y América Latina. 